\title{
Geology for a Changing World 2010-2020: Implementing the U.S. Geological Survey Science Strategy
}

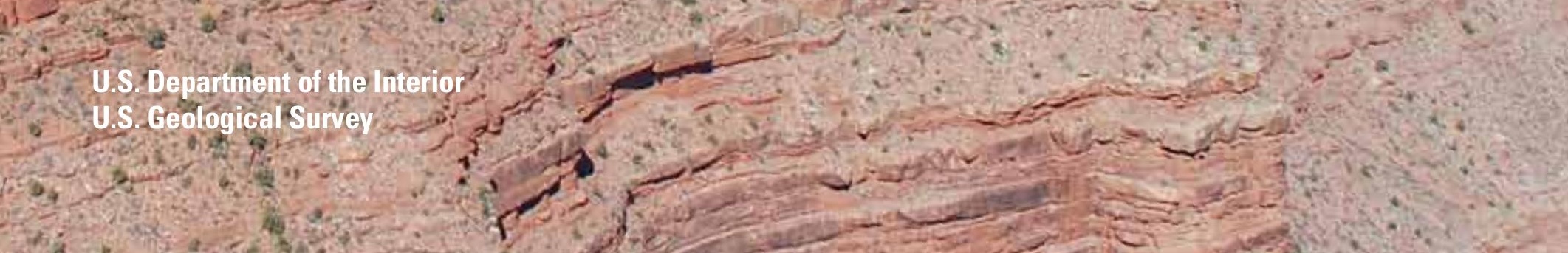


Cover: View of the Grand Canyon. Photograph by Linda C.S. Gundersen, U.S. Geological Survey. More than 1.5 billion years of strata are exposed in the Grand Canyon, providing a magnificent glimpse into the rich and varied geologic history of North America. For further information, see http://pubs.usgs.gov/imap/i-2688/ (Billingsley, G.H., 2000, Geologic map of the Grand Canyon 30' × 60' quadrangle, Coconino and Mohave Counties, northwestern Arizona). 


\section{Geology for a Changing World 2010-2020: Implementing the U.S. Geological Survey Science Strategy}

By Linda C.S. Gundersen, Jayne Belnap, Martin Goldhaber, Arthur Goldstein, Peter J. Haeussler, S.E. Ingebritsen, John W. Jones, Geoffrey S. Plumlee, E. Robert Thieler, Robert S. Thompson, and Judith M. Back

Circular 1369 


\section{U.S. Department of the Interior \\ KEN SALAZAR, Secretary \\ U.S. Geological Survey \\ Marcia K. McNutt, Director}

\section{U.S. Geological Survey, Reston, Virginia: 2011}

For more information on the USGS - the Federal source for science about the Earth, its natural and living resources, natural hazards, and the environment—visit http://www.usgs.gov or call 1-888-ASK-USGS

For an overview of USGS information products, including maps, imagery, and publications, visit http://www.usgs.gov/pubprod

To order this and other USGS information products, visit http://store.usgs.gov

Any use of trade, product, or firm names is for descriptive purposes only and does not imply endorsement by the U.S. Government.

Although this report is in the public domain, permission must be secured from the individual copyright owners to reproduce any copyrighted materials contained within this report.

Suggested citation:

Gundersen, L.C.S., Belnap, Jayne, Goldhaber, Martin, Goldstein, Arthur, Haeussler, P.J., Ingebritsen, S.E., Jones, J.W., Plumlee, G.S., Thieler, E.R., Thompson, R.S., and Back, J.M., 2011, Geology for a changing world 2010-2020Implementing the U.S. Geological Survey science strategy: U.S. Geological Survey Circular 1369, 68 p. (Also available online.)

ISBN 978-1-4113-3105-1 


\section{Contents}

Preface

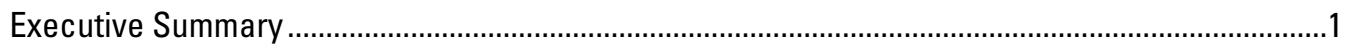

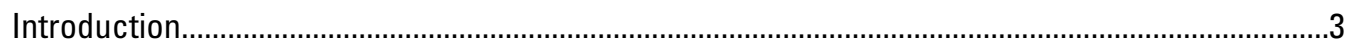

Goal 1. Characterize and Interpret the Geologic Framework of the Earth Through Time ..............5

Goal 2. Understand Earth Surface and Climatic Processes and Anticipate Their Effects on Ecosystem Health and Change ......................................................................................13

Goal 3. Understand and Quantify the Availability of Earth's Natural Resources in a Global

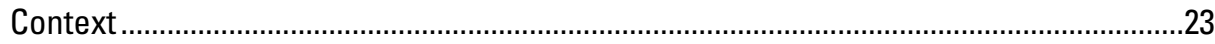

Goal 4. Increase the Resilience of Communities to Geologic and Environmental Hazards..........33

Goal 5. Apply the Most Advanced Technologies and Best Practices To Effectively Acquire, Analyze, and Communicate Our Data and Knowledge ..................................................43

Goal 6. Develop a Flexible and Diverse Workforce for the Future ................................................51

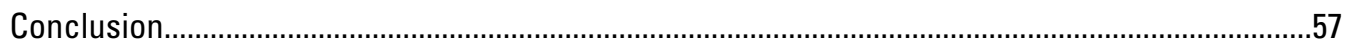

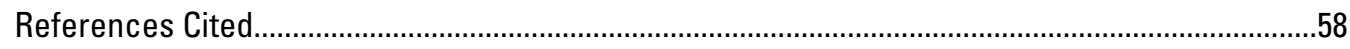

Appendix A. Documents Reviewed by the Geology Science Strategy Team..............................61

Appendix B. Selected Accomplishments of the Geology Science Strategy for 2000-2010.........63

Appendix C. Divisions of Geologic Time ……………............................................................68

\section{Highlights}

1. The USGS Science Strategy ...........................................................................................iv

2. Great Southern California ShakeOut-The USGS Works with Partners and Communities To Save Lives and Dollars ...........................................................................vi

3. Three-Dimensional Geologic Maps of the Earth Beneath California.................................6

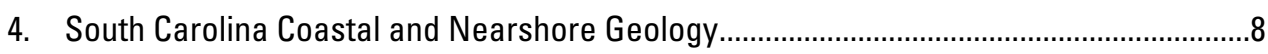

5. Edwards and Trinity Aquifer Study in Texas ................................................................

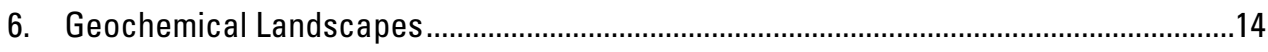

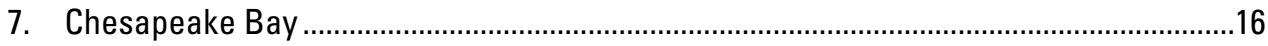

8. The Problem With Dust..................................................................................................20

9. Mineral Resource Assessments ....................................................................................24

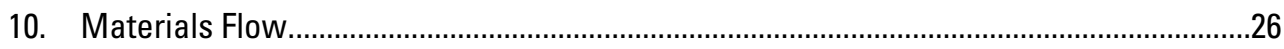

11. USGS Science and Information for Conventional Energy and Alternative

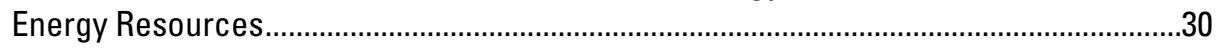

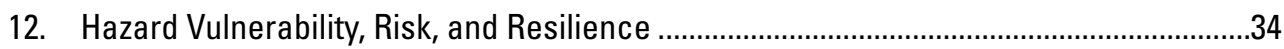

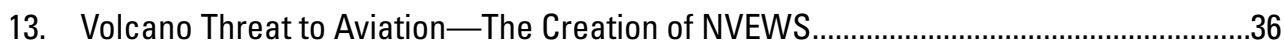

14. Understanding and Forecasting Coastal Change From Extreme Storms ..........................40

15. New Efforts in Data and Technology_-The USGS Integrated Data Environment ...........44

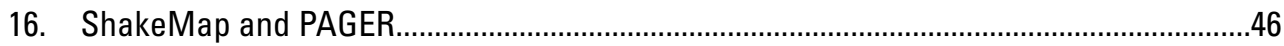

17. Preserving our Nation's Geological and Geophysical Data and Materials .....................48

18. The Changing Demographics of Geologists Inside and Outside the USGS ......................52

19. EDMAP - Training the Next Generation of Geoscientists .............................................54

B1. Selected Accomplishments of the Geology Science Strategy for 2000-2010.................64 


\section{The USGS Science Strategy}

In 2007, the U.S. Geological Survey (USGS) developed a science strategy outlining the major natural science issues facing the Nation in the next decade. The strategy consists of six science directions that focus on areas where natural science can make a substantial contribution to the

\section{Understanding Ecosystems and Predicting Ecosystem Change: Ensuring the Nation's Economic and Environmental Future}

Advance the understanding of ecosystem structure, function, patterns, and processes and develop new products, including standardized national maps of ecosystems. Provide regularly updated reports on the status of ecosystems and assessment of trends to help communities and managers make informed decisions.

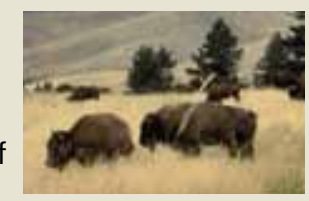

\section{Climate Variability and Change: Clarifying the Record and Assessing Consequences}

Expand research and monitoring initiatives in the science of carbon, nitrogen, and water cycles, hydroclimatic and ecosystem effects of climate change, and land-cover and land-use change. Continue studies of paleoclimate and past interactions of climate

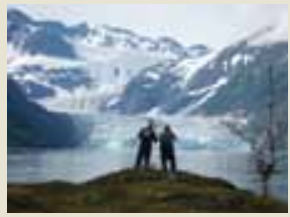
with landscapes and ecosystems, and apply that knowledge to understanding potential future states and processes. Provide robust predictive and empirical tools for managers to test adaptive strategies, reduce risk, and increase the potential for hydrologic and ecological systems to be self-sustaining, resilient, or adaptable to climate change and related disturbances.

\section{Energy and Minerals for America's Future: Providing a Scientific Foundation for Resource Security, Environmental Health, Economic Vitality, and Land Management}

Contribute comprehensively to discourse and decisions about future natural resource security, environmental effects of resource use, the economic vitality of the Nation, and management of natural resources on Federal and other lands. Use a multidisciplinary approach to understand and evaluate how the complex life cycle of occurrence, formation processes,

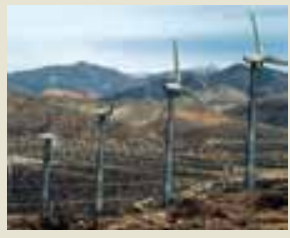
extraction methods, use, and waste products of energy and mineral resources influence, or are influenced by, landscape, hydrology, climate, ecosystems, and human health. Improve the reliability and accuracy of assessments and information products. well-being of the Nation and the world and two directions related to data and technology, which are essential for the success of the science strategy. The eight directions were described in USGS Circular 1309 (USGS, 2007) and are summarized below.

\section{A National Hazards, Risk, and Resilience Assessment Program: Ensuring the Long-Term Health and Wealth of the Nation}

Continue to collect accurate and timely information from modern earth observation networks, assess areas at risk from natural hazards, and conduct research to improve hazard predictions. Work with the Nation's communities to assess the vulnerability of cities and ecosystems and to

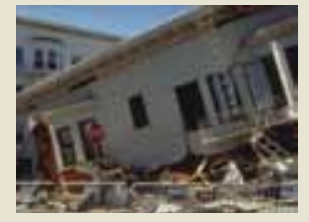
ensure that decisionmakers have the science needed to reduce losses. Develop a national risk-monitoring program, built on a robust underpinning of hazard assessment and research, to visualize and provide perspectives at multiple scales of vulnerability and resilience to adverse land change and hazards.

\section{The Role of Environment and Wildlife in Human Health: A System that Identifies Environmental Risk to Public Health in America}

Continue to identify wild animal disease reservoirs and maintain critical knowledge about wild animal disease transmission to humans, drinking-water contaminants, air-dust-soil-sediment-rock contaminants, pathogens in recreational water, and the use of wild animals as sentinels of human health. Fully integrate data holdings and environmen-

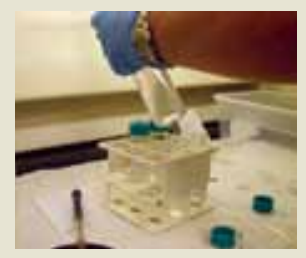
tal science expertise to produce a national database and atlas of geology and ecology-sourced diseases and toxicants. Partner with allied health science agencies to support spatially related health research.

\section{A Water Census of the United States: Quantifying, Forecasting, and Securing Freshwater for America's Future}

Develop a Water Census of the United States to inform the public and decisionmakers about (1) the status of its freshwater resources and how they are changing; (2) a more precise determination of water use for meeting future human, environmental, and wildlife needs; (3) how freshwater availability is related to natural

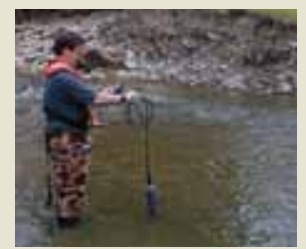
storage and movement of water, as well as engineered systems, water use, and related transfers; (4) how to identify nontraditional sources (not commonly thought to be resources) that might provide freshwater for human and environmental needs; and (5) forecasts of likely outcomes for water availability, water quality, and aquatic ecosystem health caused by changes in land use and land cover, natural and engineered infrastructure, water use, and climate.

\section{Data Integration}

Create a more integrated and accessible environment for vast resources of past and future data. Invest in cyberinfrastructure, nurture and cultivate programs in natural-science informatics, and participate in efforts to build a global integrated science and computing platform.

\section{Leveraging Evolving Technologies}

Foster a culture and resource base that encourage innovation, thereby advancing scientific discovery through the development and application of state-of-the-art technologies. 


\section{Preface}

In February 2007, the U.S. Geological Survey (USGS) released a new science strategy, USGS Circular 1309, "Facing Tomorrow's Challenges-U.S. Geological Survey Science in the Decade 2007-2017." This comprehensive and forward-looking document sets forth six strategic directions representing the major natural science challenges facing society today: ecosystem change, climate variability, energy and mineral resources for the future, natural hazard risk and resilience, wildlife and human health, and water availability (see highlight 1). In response to the new USGS science strategy, the Associate Director for Geology charged an interdisciplinary team of scientists to create an implementation strategy that would encompass all geologic activities across the USGS. The charge to the team was twofold: (1) describe the fundamental research in the geological sciences needed in the next decade and (2) define a path to integrate the geological sciences with the other natural sciences to more fully understand the Earth's complex systems. Thus, this report identifies the geology activities, interdisciplinary activities, strategic actions, critical partnerships, and new products needed to meet the ambitious directions of the USGS science strategy.

Achieving much of the work proposed here will require changes in the way the USGS conducts and funds science. Stronger collaboration across the scientific disciplines is necessary, both within the USGS and with academic, public, and private partners to accomplish the goals of this document. Flexibility in the USGS workforce and new expertise are crucial to improving our ability to respond rapidly to changing demands and to bring the best science to bear on high-priority issues. Development and adoption of new technologies and information science will be essential to improving the quality, accessibility, and use of our science.

This geology science strategy is especially timely given the significant changes that are affecting the surface of our planet and the fundamental role that geologic processes play in mitigating or exacerbating these changes. The research strategy presented here will help us understand the key geologic processes involved in change and how human activity alters the rates and outcomes of these processes. Such an understanding will aid the United States in more effective, ecosystem-based land-management practices, in creating communities that are healthier and more resilient to hazards and change, and in the wise use of increasingly scarce resources.

We wish to thank all who participated in the creation of this strategy. This report benefited greatly from the input and review of hundreds of scientists, managers, and policymakers from within and outside the USGS. We want to especially thank Elizabeth Good, for her extraordinary efforts and meticulous editing, Anna Glover, for the design and production of the layout and her tireless efforts with the illustrations and photographs used in this document, and Bruce Geyman, for the conceptual design of this report. Their efforts were instrumental to the completion of this report.

An extensive body of literature was also used to inform the writing team as we developed the ideas in this science strategy and is provided at the end of this report (appendix A). Finally, this report builds on the strong foundation provided by the previous geology science strategy described in USGS Circular 1172, "Geology for a Changing World: A Science Strategy for the Geologic Division of the U.S. Geological Survey, 2000-2010.”

\footnotetext{
Facing page:

Top left. Bison grazing in a Montana ecosystem. Photograph from U.S. Fish and Wildlife Service.

Center left. Glacier in Prince William Sound, Alaska. Photograph by Don Becker (USGS), August 22, 2008.

Bottom left. Wind turbines on BLM public land, California. Photograph from U.S. Bureau of Land Management. Top right. Building affected by liquefaction in the 1989 Loma Prieta earthquake, California. USGS photograph.

Center right. Sample of a chemical that may enter groundwater. Photograph by Joseph Ayotte (USGS).

Bottom right. A USGS scientist measuring water quality in Holes Creek, Kettering, Ohio. USGS photograph.

Bottom center (between shaded boxes). Five data layers for the map of the conterminous United States from the National Atlas of the United States ${ }^{\circledR}$ : climate, vegetation growth, streams and waterbodies, geology, and roads.
} 


\section{₹ Great Southern California Shake0ut-The USGS Works with Partners and Communities To Save Lives and Dollars}

At 10 a.m. on November 13, 2008, millions of people participated in the Great Southern California Shake0ut Drill, which at the time was the largest earthquake preparedness activity in U.S. history. The USGS developed the ShakeOut science scenario depicting a magnitude 7.8 earthquake striking the southern San Andreas fault, starting at the Salton Sea

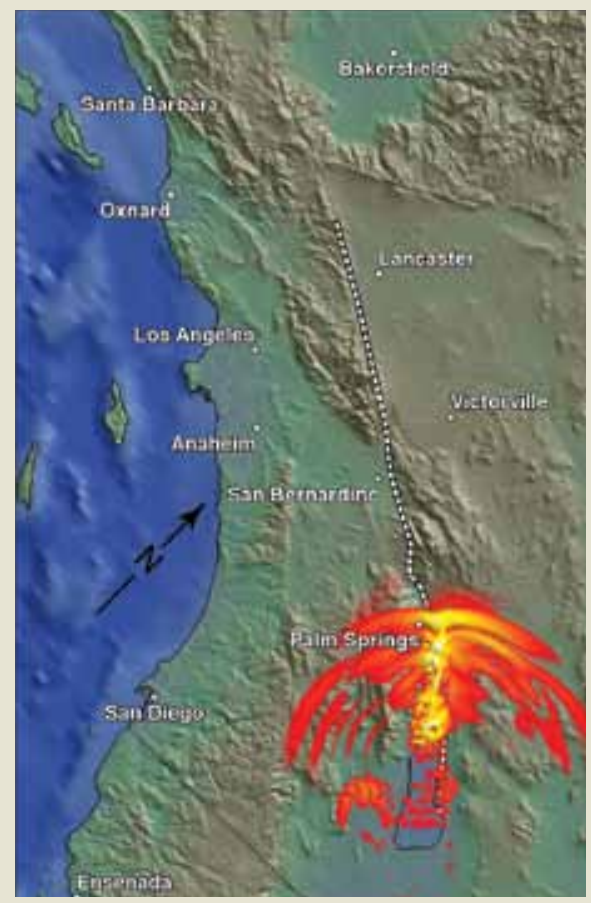

and rupturing northward 200 miles (Jones and others, 2008). In the scenario, the earthquake would kill 1,800 people, injure 53,000 , cause $\$ 213$ billion in damage, and have long-lasting social and economic consequences. The USGS worked with many partners and communities to plan the drill so that people could learn how to reduce their risk. The ShakeOut

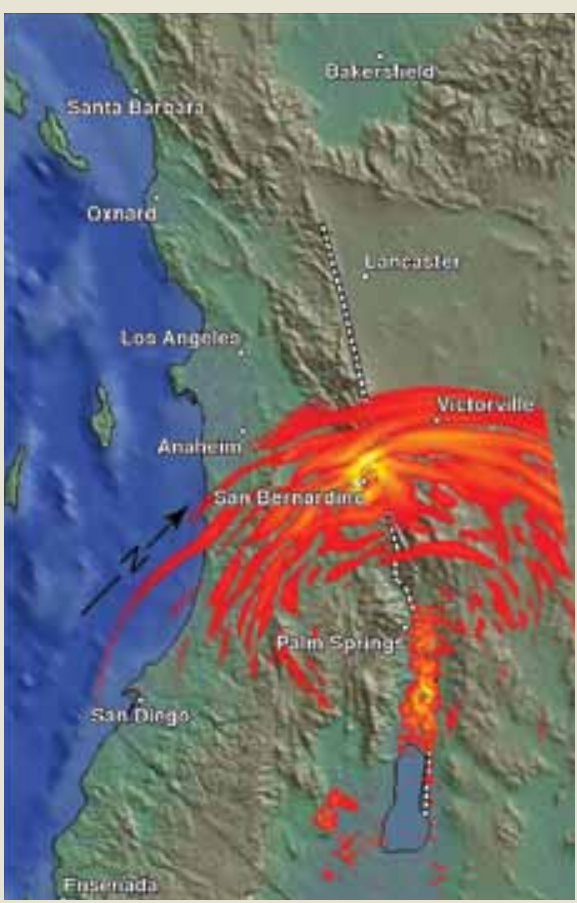

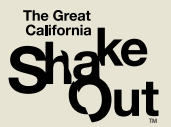

exercise was so successful that it has become an annual State-wide exercise in California. Other earthquake-prone areas have conducted or are planning similar exercises (http://www.shakeout.org/): New Zealand's west coast (2009); Nevada and Guam (2010); and Oregon, British Columbia, and the central United States (2011).

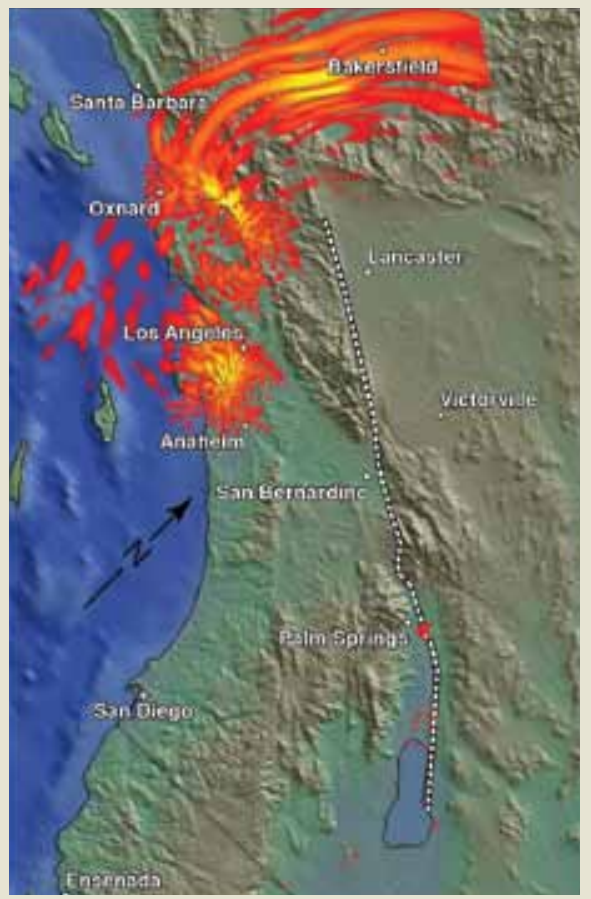

Computer-generated snapshots showing ground motions for the 2008 ShakeOut Scenario earthquake at three points in time-30 (left), 60 (center), and 120 (right) seconds after the southern San Andreas fault (dashed line) first begins rupturing at Bombay Beach, on the eastern shore of the Salton Sea.
From Perry and others (2008); simulation by Rob Graves of URS Corporation for the Southern California Earthquake Center on high-performance computers at the University of Southern California; images courtesy of Geoff Ely, University of California San Diego/San Diego Supercomputer Center.

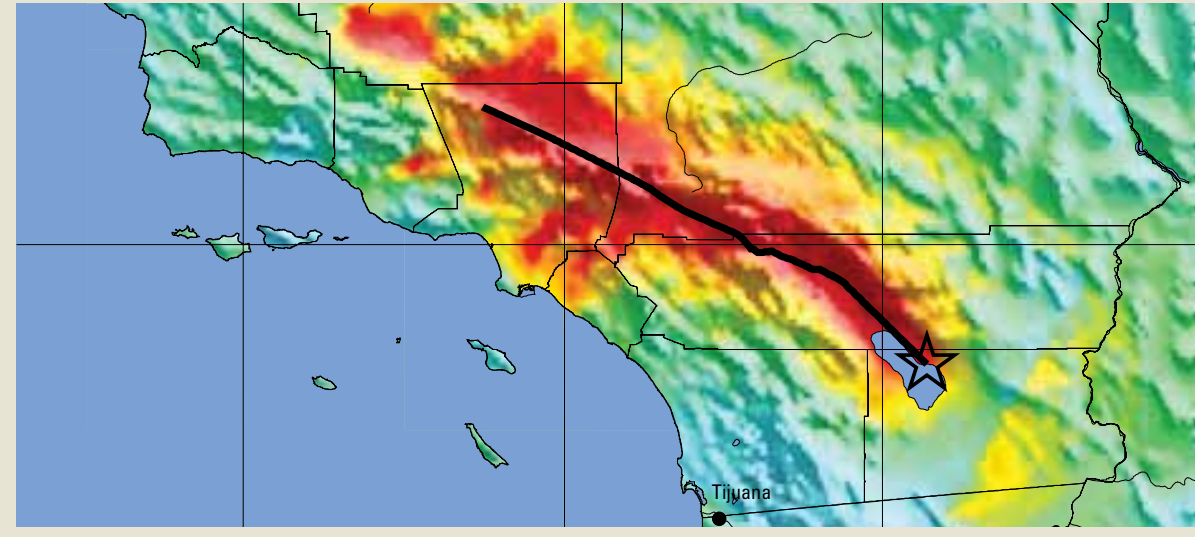

USGS ShakeMap of a portion of the San Andreas fault (black line) showing topographic relief overlain by instrumental intensities for the simulated magnitude 7.8 ShakeOut Scenario earthquake. Lowest shaking intensities are in blue, and highest intensities are in red. From Perry and others (2008).

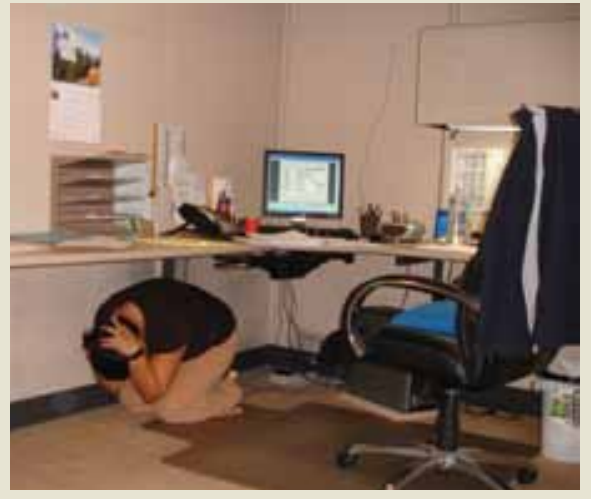

Prime Tech Cabinets Inc. worker participating in the 2008 Great Southern California ShakeOut. Photograph by Felipe J. Guerena, Prime Tech Cabinets Inc. 


\title{
Geology for a Changing World 2010-2020: Implementing the U.S. Geological Survey Science Strategy
}

\author{
By Linda C.S. Gundersen, ${ }^{1}$ Jayne Belnap, ${ }^{2}$ Martin Goldhaber, ${ }^{3}$ Arthur Goldstein, ${ }^{4}$ Peter J. Haeussler, ${ }^{5}$ \\ S.E. Ingebritsen, ${ }^{6}$ John W. Jones, ${ }^{1}$ Geoffrey S. Plumlee, ${ }^{3}$ E. Robert Thieler, ${ }^{7}$ Robert S. Thompson, ${ }^{3}$ and \\ Judith M. Back'
}

\section{Executive Summary}

This report describes a science strategy for the geologic activities of the U.S. Geological Survey (USGS) for the years 2010-2020. It presents six goals with accompanying strategic actions and products that implement the science directions of USGS Circular 1309, "Facing Tomorrow's Challenges-U.S. Geological Survey Science in the Decade 2007-2017." These six goals focus on providing the geologic underpinning needed to wisely use our natural resources, understand and mitigate hazards (highlight 2) and environmental change, and understand the relationship between humans and the environment. The goals emphasize the critical role of the USGS in providing long-term research, monitoring, and assessments for the Nation and the world. Further, they describe measures that must be undertaken to ensure geologic expertise and knowledge for the future.

The natural science issues facing today's world are complex and cut across many scientific disciplines. The Earth is a system in which atmosphere, oceans, land, and life are all connected. Rocks and soils contain the answers to important questions about the origin of energy and mineral resources, the evolution of life, climate change, natural hazards, ecosystem structures and functions, and the movements of nutrients and toxicants. The science of geology has the power to help us understand the processes that link the physical and biological world so that we can model and forecast changes in the system.

Ensuring the success of this strategy will require integration of geological knowledge with the other natural sciences and extensive collaboration across USGS science centers and with partners in Federal, State, and local agencies,

\footnotetext{
${ }^{1}$ U.S. Geological Survey, Reston, Va.

${ }^{2}$ U.S. Geological Survey, Moab, Utah.

${ }^{3}$ U.S. Geological Survey, Denver, Colo.

${ }^{4}$ National Science Foundation, Arlington, Va.

${ }^{5}$ U.S. Geological Survey, Anchorage, Alaska.

${ }^{6}$ U.S. Geological Survey, Menlo Park, Calif.

${ }^{7}$ U.S. Geological Survey, Woods Hole, Mass.
}

academia, industry, nongovernmental organizations and, most importantly, the American public. The first four goals of this report describe the scientific issues facing society in the next 10 years and the actions and products needed to respond to these issues. The final two goals focus on the expertise and infrastructure needed to ensure the long-term sustainability of the geological sciences in the USGS.

The ultimate goal of USGS science and of the strategy laid out in this document is to contribute to the development of a sustainable society that operates in harmony with the Earth systems that society depends upon. As we begin the second decade of the 21 st century, our Nation faces growing challenges in resource availability, climate and environmental change, and natural hazards. Meeting these challenges will require strong collaboration across the natural and social sciences and extensive partnerships with both the public and private sectors. The six goals described in this document represent a mix of scientific focus areas and operational necessities that together provide a comprehensive roadmap for USGS geologic science to effectively contribute to the USGS mission, providing science for a changing world.

\section{Goal 1. Characterize and Interpret the Geologic Framework of the Earth Through Time}

The first goal of this report focuses on understanding the geology and history of the Earth through time. The emphasis is on creating an integrated, four-dimensional, digital framework for the Earth that incorporates data from the many subdisciplines of geology, such as tectonics, sedimentology, geophysics, paleontology, and geochemistry. Such a framework currently does not exist and will require new process-oriented research and mapping, interpretation and modeling, extensive collaboration with external partners, and data integration tools and technology. The knowledge provided by this framework will be essential to successful implementation of each of the strategic directions of the USGS science strategy and will form a strong foundation for future generations of scientists. 


\section{Goal 2. Understand Earth Surface and Climatic Processes and Anticipate Their Effects on Ecosystem Health and Change}

Goal 2 of this report underscores the need to apply our knowledge of geology to the processes that govern terrestrial and biological systems. Of particular importance is how the environment and humans respond to changes in Earth surface processes caused by a wide variety of drivers, from climate variability to resource development. The outcome of this goal is to understand, anticipate, model, forecast, and mitigate these changes, providing benefits to humans and ecosystems through adaptive management. This goal is most strongly focused on the need for understanding fundamental geologic processes that will support three strategic directions of the USGS science strategy: (1) understanding ecosystems and predicting ecosystem change, (2) climate variability and change, and (3) the role of environment and wildlife in human health.

\section{Goal 3. Understand and Quantify the Availability of Earth's Natural Resources in a Global Context}

Providing the science needed to understand, quantify, and potentially sustain our natural resources is the purpose of goal 3. As population increases on a finite Earth, competition for resources becomes a global issue. Decisions made about using energy, minerals, and water and managing the environment have far-reaching impacts, both in space and time. Knowing the quality and location of the Earth's resources, anticipating resource needs, understanding the cascading effect of resource development on ecosystem services, and assessing our ability to sequester carbon will allow long-term sustainable development of resources and healthy communities. This goal provides the underpinning research, methodology, and assessments needed to implement the "energy and minerals for America's future" strategic direction of the USGS science strategy and supports two other strategic directions: (1) the role of environment and wildlife in human health and (2) climate variability and change.

\section{Goal 4. Increase the Resilience of Communities to Geologic and Environmental Hazards}

Earthquakes, landslides, volcanic eruptions, fire, extreme storms, coastal inundation, and related events are serious economic, public safety, environmental, and national security challenges. Goal 4 emphasizes the need for providing realtime, integrated national monitoring and warning systems, conducting research to better understand risk, and planning effective communication products and partnerships to build resilient communities across the globe. The expansion of population and infrastructure in hazard-prone areas has dramatically increased vulnerability to damage, injury, and loss that can change a natural hazard into a disaster. Improved collaboration with communities, engineers, emergency responders, and policymakers will result in more effective planning, thus reducing the monetary and human costs of natural hazards and increasing our overall resilience to disasters. This goal supports the geologic hazard science and monitoring needed for the "national hazards, risk, and resilience assessment program" strategic direction of the USGS science strategy.

\section{Goal 5. Apply the Most Advanced Technologies and Best Practices To Effectively Acquire, Analyze, and Communicate Our Data and Knowledge}

Our fast-paced world demands that we provide timely data and analyses for a myriad of issues that inform decisions at the local to global scale. Goal 5 outlines how to meet this demand through use of the best technology and instrumentation, national monitoring networks, and an information infrastructure to preserve, access, and integrate the scientific data we produce. Careful investment and leveraging of resources, providing tools and training, and partnering across programs internally and externally will be needed to maintain and improve our scientific infrastructure. Improved computational capability is required to develop innovative analysis, complex modeling, and visualization applications. This goal supports two cross-cutting science directions of the USGS science strategy: (1) data integration and (2) leveraging evolving technologies.

\section{Goal 6. Develop a Flexible and Diverse Workforce for the Future}

In order to continue the critical long-term science that the USGS provides, we will need to hire a diverse staff with new skills and knowledge while maintaining continuity and fundamental expertise in the geological sciences. Goal 6 places an emphasis on the people who work at the USGSour greatest asset in providing science for a changing world. Earth scientists are in high demand, and so training, mentoring, internships, and recruitment programs for secondary, undergraduate, and graduate students will need to be expanded. We will also explore innovative approaches to hiring, developing, and rewarding employees. This goal supports all of the strategic directions of the USGS science strategy. 


\section{Introduction}

Globalization, the integration of the Earth's economic and social systems, has brought unprecedented access to knowledge and resources. At the same time, many parts of the world are experiencing rapid growth in population and an increasing need for natural resources, placing unprecedented stress on the environment. The global transportation network has created new pathways for disease, invasive species, and toxins. Further, in the coming decades, the world will face extremes in weather and a general rise in global temperature and sea level as our climate changes. With increasing population, especially along coasts, rivers, wilderness areas, and mountain ranges, the exposure and susceptibility to risks from volcanoes, earthquakes, landslides, tsunamis, wildland fires, and floods will also grow. Global competition for natural resources has the potential to affect our ability to sustain the Nation's economy, security, quality of life, and natural environment. How can we sustain growth while providing the energy, materials, water, food, healthy environment, security, and safety that the Nation and the world require?

The U.S. Geological Survey (USGS) has the capability today to help our Nation and the world benefit from globalization while avoiding and mitigating possible consequences in the future. Because the Earth behaves as a system in which atmosphere, oceans, land, and living organisms are all interconnected, the USGS needs to increase its global role and collaborate with governments and communities throughout the world. USGS science can be used to enhance quality of life and sustainable use of natural resources. The Bureau provides the advanced and integrated natural science information needed to adaptively manage critical wildlife, land, water, forests, and soils.

The goals described in this report focus on understanding and anticipating changes in the natural environment. They emphasize the unique role of the USGS in providing research, long-term monitoring, and assessments for the Nation and the world. Each goal includes the highest priority strategic actions that must be undertaken and the proposed products and outcomes needed.

For the past decade, the geological sciences in the USGS have been guided by "Geology for a Changing World: A Science Strategy for the Geologic Division of the U.S. Geological Survey, 2000-2010" (USGS Circular 1172 by Bohlen and others, 1998). Successes achieved by implementing the strategy defined in Circular 1172 are highlighted in appendix B of this report. As a result of that strategy, we created a strong foundation in timely hazard warning and mitigation; strengthened our monitoring systems; fostered local, regional, and international partnerships; and developed innovative hazard science, communication, and visualization. Under that plan, scientific integration with other disciplines became a hallmark of the geologic mapping, coastal and marine geology, and Earth surface dynamics programs. USGS energy and mineral resource assessments of undiscovered deposits expanded across the globe and included new resources and economic factors. Adopting a life-cycle view of resources and commodities and examining their production, use, and disposal led to an improved understanding of the flow of materials. Significant advancements were made into new areas of earth science research that link geologic processes to ecosystem and human health.

The strategy proposed here builds on the success of "Geology for a Changing World" and takes it a step further by emphasizing even more integration across the natural sciences and with the economic and social sciences as well. This plan also focuses on the need for integrating digital data, advanced modeling and monitoring of geological, hydrological, and biological systems, and providing tools for managers to respond rapidly and wisely to change. 


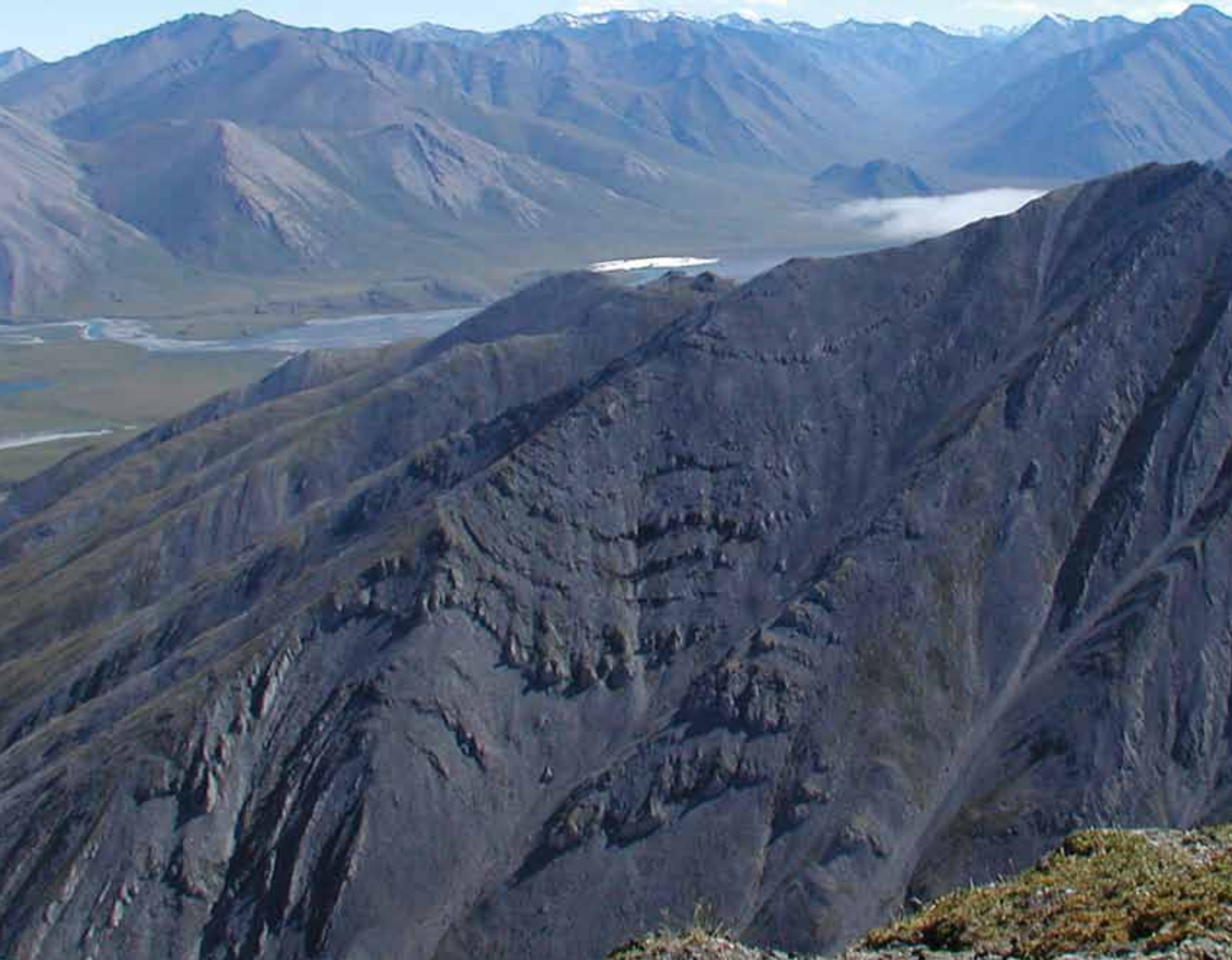

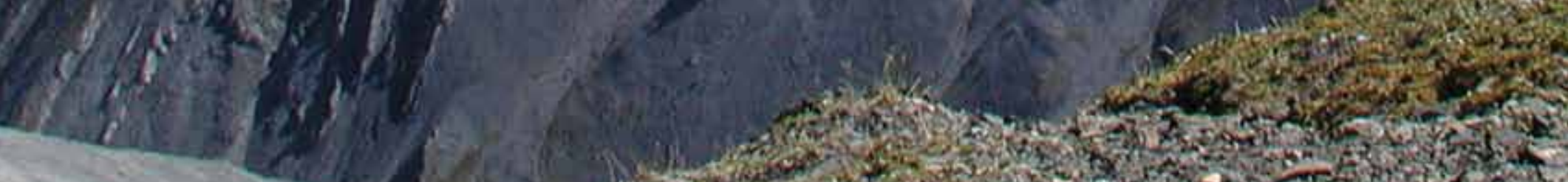
is 


\section{Goal 1. Characterize and Interpret the Geologic Framework of the Earth Through Time}

The Earth's crust hosts most of the life on the planet, as well as the water, energy, and mineral resources that sustain society. The crust contains the answers to questions about the location and origins of these resources, the evolution of life, climate change, natural hazards, and the movements of nutrients and toxicants. A comprehensive understanding of the Earth's geologic framework is needed to inform the critical decisions the Nation and the world will make about resource utilization, environmental quality, and hazard mitigation.

Facing page. Detachment folds in upper Paleozoic strata of the Brooks Range, Alaska. The Canning River can be seen in the distance. Divisions of geologic time are summarized in appendix C. Photograph by Randall Orndorff, USGS. 


\section{Three-Dimensional Geologic Maps of the Earth Beneath California}

USGS researchers are constructing three- and four-dimensional (3D and 4D) geologic maps as a means of better understanding structural anatomy and evolution of the California crust. These state-of-the-art maps also support many other applications such as their use as a basis to model the ground motion that resulted from the 1906 San Francisco earthquake (http://earthquake.usgs.gov/ regional/nca/1906/simulations/) and to predict strong ground motions expected from future earthquakes on the Hayward fault (Aagaard and others, 2010).

A new 3D geologic map of the central California Coast Ranges (Monterey-Santa
Barbara) will provide the foundation for a detailed computer simulation of seismic wave propagation and ground shaking for the 2003 San Simeon earthquake similar to that produced for the 1906 San Francisco earthquake. The Coast Ranges map (some information from which is shown below) is being used to support the following studies:

- A 4D analysis of the evolution in space and time of the San Andreas fault. The analysis explicitly addresses the evolution of along fault, cross fault, and vertical deformation in the rocks in the vicinity of the fault.
- Groundwater issues and the structure of Coast Range basins

- A new probabilistic seismic hazard assessment of the central Coast Ranges

- The tectonic evolution of the Coast Ranges between the San Andreas and Hosgri faults and north of the Western Transverse Ranges

- Work under the Cooperative Research and Development Agreement (CRADA) between the USGS and the Pacific Gas and Electric Company (PG\&E)

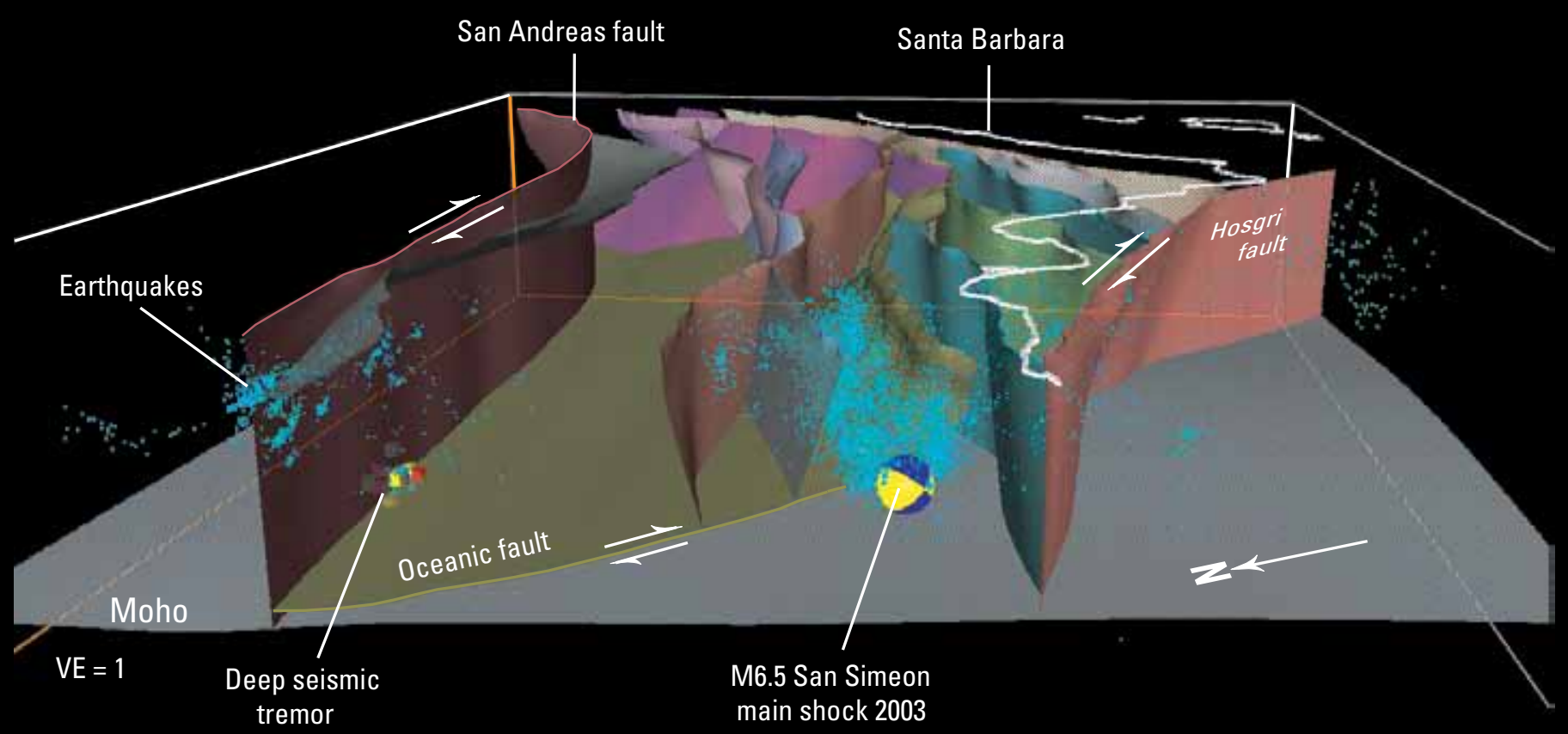

View to the southeast along the 3D geologic map of the central California Coast Ranges; this illustration shows the fault architecture and fault activity hierarchy of the 3D map and represents only part of the information contained in the full map. Hypocenters of earthquakes that occurred in the past 20 years are shown in blue. The main shock of the San Simeon earthquake occurred on December 22, 2003, and had a magnitude of 6.5. Of particular interest are (1) the locations of the San Simeon hypocenter on the Oceanic fault and its aftershocks in the hanging wall of that fault and (2) the locations of the deep tremor events on the San Andreas fault where it truncates the Oceanic fault. The Oceanic fault surface in this interpretation was constrained by its mapped trace, by the San Simeon main shock and its aftershocks, by other historic microseismicity, and by deep seismicreflection data. It was not constrained by the locations of the deep tremor events. "Beachball" is located at the hypocenter of this earthquake and shows its focal mechanism. Moho, the boundary between the Earth's crust (above) and mantle (below) where seismic waves change velocity; VE, vertical exaggeration. Image from Robert Jachens, Victoria Langenheim, Carl Wentworth, Robert Simpson, and Russell Graymer, all USGS.
Map showing location of 3D model.

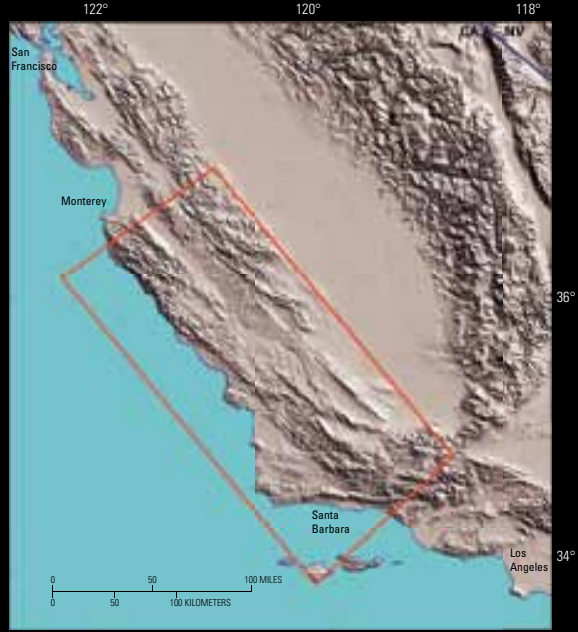




\section{Societal Needs and Benefits}

Studies of the Earth's crust, which forms our continents and underlies our oceans, provide the foundation for understanding most geological processes of societal significance. Life occurs upon or within the Earth and is sustained by its interactions with water, the atmosphere, and sunlight. Moreover, the nature of available geological materials has been a primary influence on the rise and fall of past civilizations. Soils that are derived from the weathering and erosion of surficial geologic materials are the foundation of agriculture. The crust of the continents hosts substantial energy, mineral, and groundwater resources. New sources of energy and minerals vital for our Nation's future are being discovered in continental margins and ocean basins. Continental and marine sedimentary basins record the Earth's changing climate. These basins are a principal target for geologic carbon sequestration, a potential means of reducing the release of this greenhouse gas into the atmosphere. Nearly all damaging earthquakes and volcanic eruptions occur within the continental crust or at the boundaries between continental and oceanic crust. Thus, a geological understanding of how the Earth works is vital to improving our understanding of energy, mineral, soil, and water resources, how our climate is changing, where and when hazards will occur, and the sustainability of life itself. This geologic framework is essential to accomplish the strategic directions of the USGS science strategy.

For more than 130 years, the USGS and its partners in State geological surveys have been the leaders in understanding the geologic framework of the United States. Geologic mapping has been a core activity for the entire history of the USGS because it provides the basic foundation for all geologic studies and the physical science framework for understanding environmental processes. In essence, geologic mapping is analogous to deciphering the genetic code of our physical Earth. There is a large and increasing demand for USGS geologic mapping products at the regional and national scale by many Federal, State, and local agencies, private industry, nongovernmental organizations, universities, and the public. Meeting those needs over the next decade is one of the most significant challenges we face.
The USGS will use new technology and knowledge coupled with the syntheses of current geologic mapping, geochemical and geophysical surveys, geochronology, paleontology, structural geology, and sedimentology to create dynamic and accessible geologic maps and four-dimensional models of the United States, its coasts, and continental shelf (highlights 3 and 4). Geologic mapping has traditionally been conducted by field geologists traversing and describing rock outcrops, surveying the ocean floor, or examining drill core. Today, geologists working on both land and sea have access to a broad variety of technologies that provide information in the third dimension (depth) and fourth dimension (time). Techniques such as sidescan sonar, multibeam bathymetry, and seismic-reflection profiling are used to define surface and subsurface layers and structures in oceans and lakes. Measurements of gravity, magnetic, and electrical fields are used to decipher shallow and deep crustal structures. Light Detection and Ranging (lidar) is providing detailed topographic profiles at resolutions that allow us to measure changes in sedimentation, erosion, and subsidence, as well as detect faults and deformation.

New technologies in dating rocks, sediments, and surfaces are improving our understanding of the timing and duration of geologic events and processes. As a result, earth scientists can understand the path that rocks took through temperature, depth, and time as they were formed, buried, exhumed, and eroded. This history informs us about the genesis of energy and mineral resources, the evolution of landscapes, soil development, and climate change. Although advances in technology greatly enhance geologic interpretation, the work cannot be done without hands-on fieldwork by geologists and geophysicists. Moreover, the effectiveness of a field geologist is heightened by experience and knowledge of a region. The USGS and its partners have benefited tremendously by having regional geologic expertise that allows quick response to societal issues as they arise. Among our highest priorities are the training and hiring of the next generation of field geologists.

Civilization exists by geological consent, subject to change without notice.

Will Durant 


\section{South Carolina Coastal and Nearshore Geology}

Natural coastal systems are increasingly being disturbed by human activity and climate change. Although representing only about 17 percent of the conterminous United States, coastal counties were home to about 53 percent of our population in 2003 (Crossett and others, 2004). In northeastern South Carolina, large infusions of new sediment are required to maintain landwardmigrating beaches that threaten static infrastructure. The USGS and the South
Carolina Sea Grant Consortium conducted a 7-year, multidisciplinary study to better understand the processes that control sediment movement along the coast (Barnhardt, 2009). Geologic mapping of onshore and offshore areas has improved our understanding of the rates and processes of coastal change at different time scales (storm event, decadal, and millennial) and has accurately determined the location and quantity of offshore sand resources. Mapping products and data generated by the project have challenged long-held assumptions about how beaches evolve, especially how they respond to storms and rising sea level. Municipalities and government agencies have used the results of the study to more effectively stabilize beaches and protect public safety.

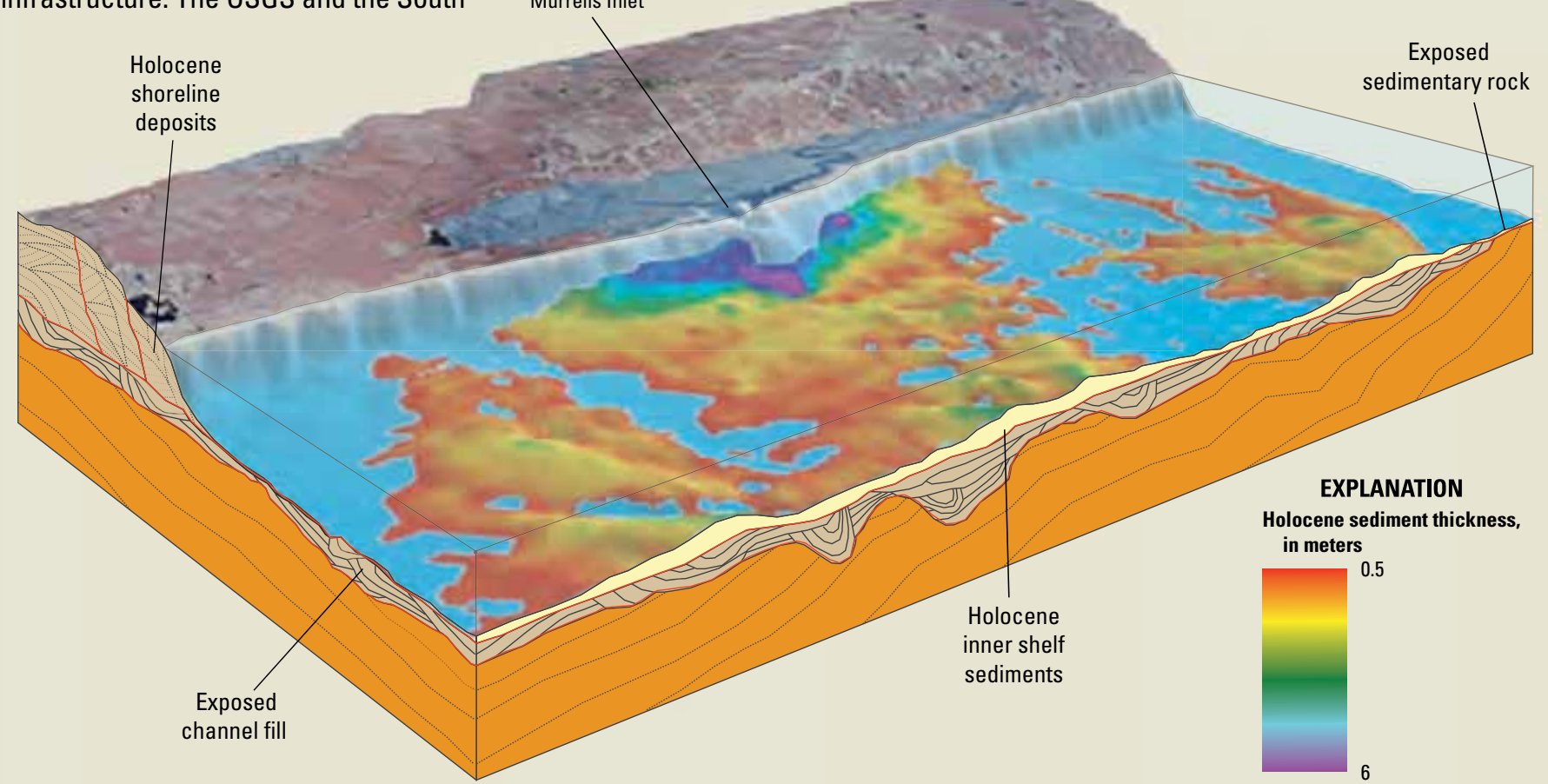

Block diagram of the Murrells Inlet area, South Carolina, showing the shallowest and youngest components of the Grand Strand geologic framework. Holocene shoreline and inner shelf sediments overlie the regionally extensive erosional unconformity and have been deposited in the last 7,000 years. Wedge-shaped shoreline deposits lie above and adjacent to the eroded remains of older Pleistocene shoreline deposits and thin considerably across the shoreface onto the inner shelf. Rocks and channel fills are exposed at the sea floor over extensive areas lacking Holocene sediment cover. Deposits up to 6 meters ( 20 feet) thick are primarily associated with tidal inlets. Red lines indicate erosional unconformities. The onshore land image was compiled from 1999 digital-orthophoto quarter quadrangles provided by the South Carolina Department of Natural Resources. From Barnhardt (2009, fig. 3.1C).

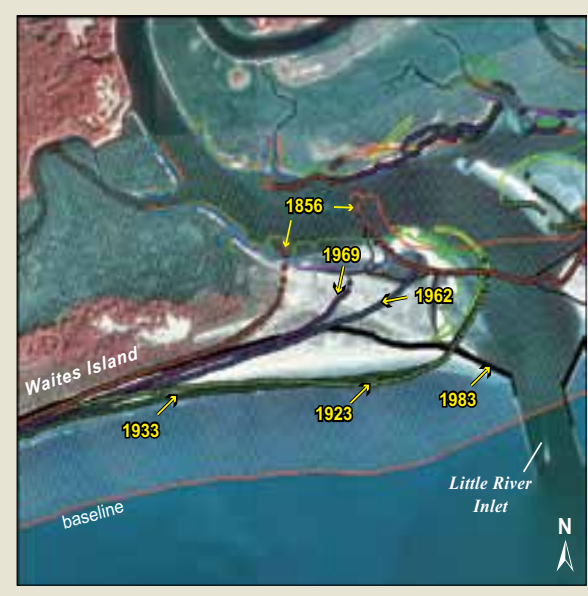

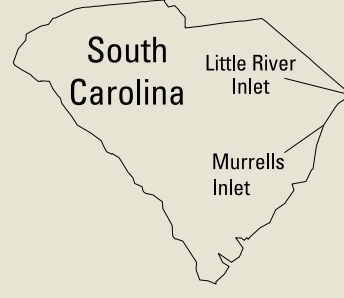

ing at a baseline 500 meters $(\mathrm{m})$ offshore (red line) and extending inland for 2,000 $\mathrm{m}$, were drawn every $25 \mathrm{~m}$ along the coast. Where a transect intersected a former shoreline position (colored dots), the distance from the baseline was used to calculate the average rate of shoreline change over that time period. From Barnhardt (2009, fig. 4.1).

Aerial photograph showing historical shorelines from 1856 to 1983 around Waites Island and Little River Inlet. Shorenormal transects normal transects (gray lines), start-

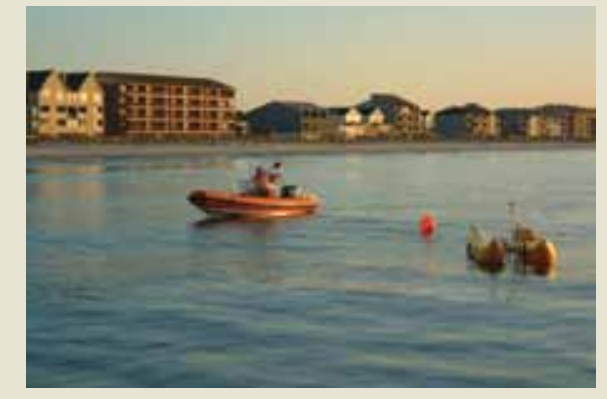

Geologists towing a subbottom profiler (yellow pontoons) in shallow water near the beach. The profiler used sound waves to provide images of the internal structure of the sea floor. From Barnhardt (2009, cover). 


\section{Strategic Actions}

1. Understand and predict geologic processes and rates of change related to water, hazards, energy, minerals, ecosystems, and climate change

New field technologies and a strong geologic mapping workforce will be used to gather and integrate data in highpriority geographic areas. Emphasis will be on geologic mapping needed to understand important problems related to resources, hazards, ecosystems, climate change, and U.S. Department of the Interior (DOI) land-management needs. High priority will be given to continental and coastal studies that respond to the USGS science strategy with emphasis on partnerships with governments and communities. This priority work will provide focus areas for development of the geologic framework datasets, encourage interdisciplinary collaboration on process studies, and demonstrate the scientific utility of USGS geologic data. Accelerating global change will require an increased emphasis on understanding and modeling the processes that link geology, ecology, and climate throughout Earth's history in order to understand potential future scenarios. Understanding and quantifying the specific role of tectonic processes in resource formation and landscape dynamics will also be a critical area of research. We will continue to expand studies of sediment transport and related processes and their relation to river, bay, and estuarine health, sea-level change, subsidence, and coastal vulnerability. Understanding and mapping the sea floor will be critical to support marine spatial planning and ecosystem-based resource management.

\section{Develop and adopt new capabilities for understanding} the evolution of the Earth

The USGS will develop and adopt new technologies and methods to support research on the geologic framework of the Earth. Advances in field, laboratory, and remotely sensed technology and simulation methods will lead to efficiencies and generate the high-resolution, high-quality data needed to support three- and four-dimensional models of crustal characteristics and processes. Specific emphasis will be given to (1) advanced field mapping techniques using hand-held global positioning and digital data recording devices; (2) adoption and development of laser-based instrumentation and new sensors that allow more precise dating and characterization of geologic materials; and (3) new instrumentation and processing methods for remote sensing of surface and subsurface characteristics. Success in these areas will require collaborative relationships with other science agencies and universities across the globe, technology training programs, and new hires with skills and knowledge of evolving and emerging technologies.

3. Develop the interpretations, protocols, and standards needed to provide seamless geologic maps

Creation of seamless geologic maps that can be produced on demand will require adoption of a common geologic map data model, expansion of the use of geoinformatics, and establishment of publishing standards so that users can specify the area, size, and type of map needed, without regard to the boundaries of previously published geologic maps. Although informatics and geographic information system (GIS) technology will help us achieve this goal, there remain numerous issues related to merging maps, correlating rock units, and properly conveying the level of knowledge and spatial resolution that will require new analysis and interpretation. Additionally, issues related to proper citation and credit to original authors and institutions will need to be resolved. 


\section{Edwards and Trinity Aquifer Study in Texas}

Geologic mapping, geophysical surveys, geochronology, 3D subsurface modeling, and noble gas geochemical studies were integrated to better understand the resources of two of the most important aquifers in the United States. The Edwards aquifer, which has been designated a sole source aquifer by the U.S. Environmental Protection Agency, is one of the most productive carbonate aquifers in the United States. The
Edwards aquifer serves the domestic, industrial, and agricultural needs of approximately 2 million people and is the primary source of water for San Antonio, Tex. The Trinity aquifer forms the catchment area for the Edwards recharge aquifer, and it intercepts some surface flow above the Edwards recharge zone. Waters sustain critical habitat for federally listed endangered species and support a vigorous tourism economy. Increased knowledge about the complex hydrologic processes that control water availability in the Edwards aquifer is imperative for effective resource management. Optimizing the use of the aquifer while ensuring that present and future needs are satisfied is the ultimate goal for the region. Figures below are from Blome and others (2007).
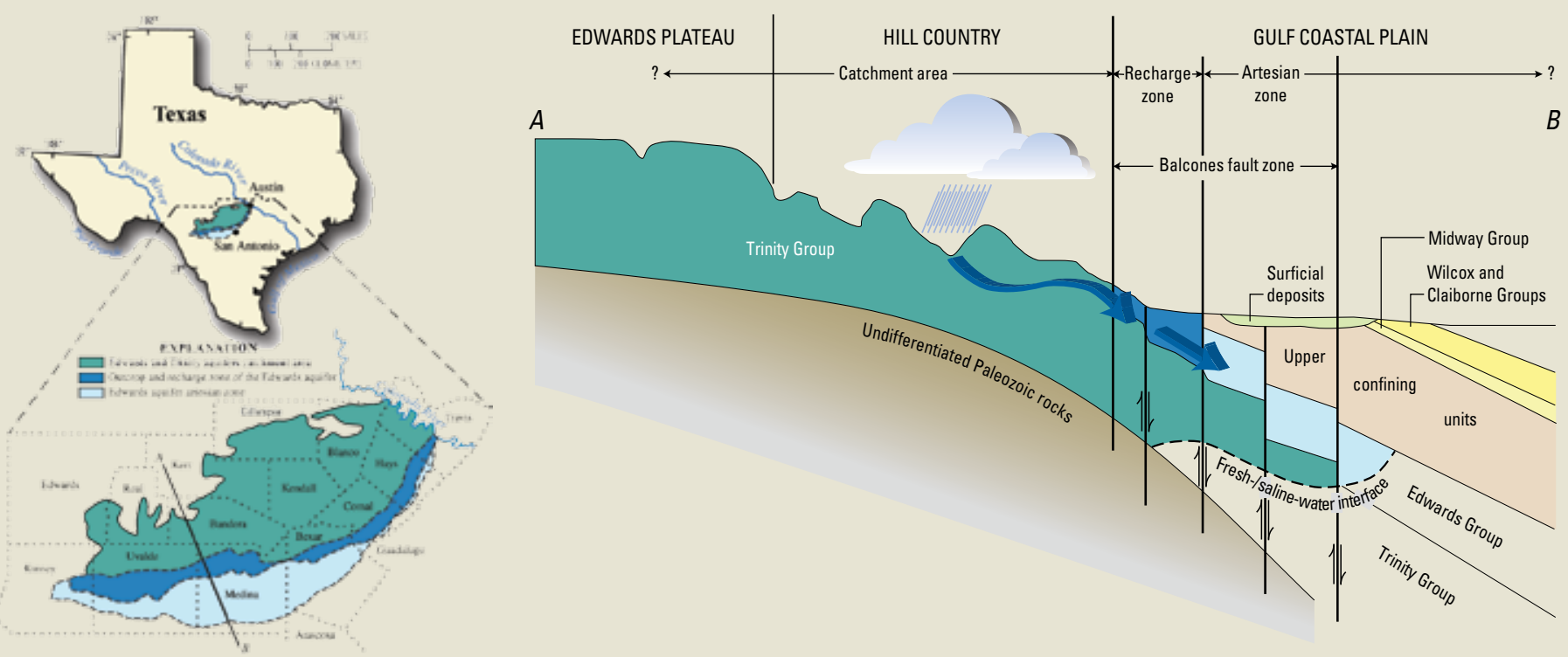

Distribution of the Edwards and Trinity aquifers. Structural schematic cross section of the Edwards aquifer and catchment area (Trinity aquifer).
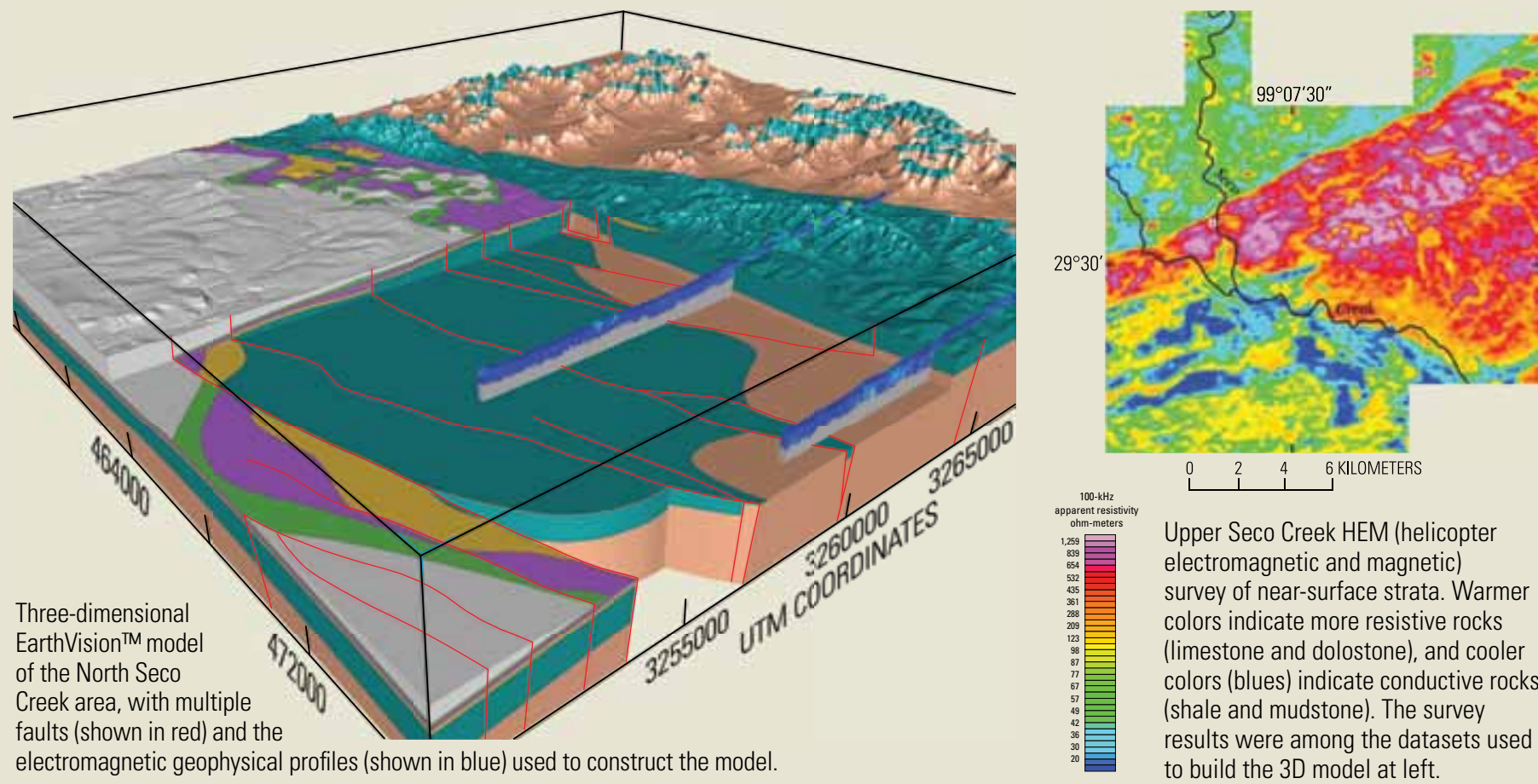

Upper Seco Creek HEM (helicopter electromagnetic and magnetic) survey of near-surface strata. Warmer colors indicate more resistive rocks (limestone and dolostone), and cooler colors (blues) indicate conductive rocks (shale and mudstone). The survey results were among the datasets used to build the 3D model at left. 


\section{Products and Outcomes}

1. Three-dimensional geologic maps and interpretations of the continental and offshore areas of the United States and its territories

Geologic and geophysical maps and associated datasets will remain core products of the USGS and its geologic mapping partners. Although two-dimensional geologic maps will still be needed, geologic maps that better incorporate 3D information will become the standard. As we move toward better integration and innovative analyses of geologic data, geophysical data, and remote sensing imagery, we need to collect additional information on physical and geochemical properties to better characterize mapped units and more accurately create models of the third dimension. Increased use of high-resolution digital elevation models and lidar data to refine geologic and geophysical maps and understand processes is needed. Emphasis will be on areas with risks from multiple hazards, critical groundwater aquifers (highlight 5), new energy and mineral deposits, and the coastal zone and continental shelf.

\section{Geologic maps and models of the Earth through time}

The USGS will facilitate geologic mapping in four dimensions through the use of comprehensive approaches that integrate geophysical and drill-hole data with improved dating and paleoecology methods. Maps made by utilizing advances in database modeling and visualization will allow analysis of geologic changes through time and across various scales. Dynamic and digital, these maps will link to related data and interpretive products and readily incorporate new geological, geochemical, geophysical, paleoecological, and geochronological data as they become available. Working with partners such as State governments, the National Oceanic and Atmospheric Administration (NOAA), the U.S. Army Corps of Engineers (USACE), and the Bureau of Ocean Energy Management (BOEM, formerly part of the Minerals Management Service, MMS), the USGS will use this integrated approach to mapping to connect onshore and offshore geologic information, including data for the U.S. coastal zone, continental margin, and extended Exclusive Economic Zone.

\section{Derivative maps, syntheses, and interpretations needed to make decisions}

Derivative geologic maps and reports are needed to more effectively communicate geologic knowledge to specific audiences. Derivative products that emphasize the physical properties of rocks and soils, such as the grain size, chemistry, porosity, and physics of earth materials, have a broad spectrum of applications in engineering, hydrology, ecology, and agriculture. Depending on the intended audience, these derivative products will be thematic maps, technical articles, or educational materials that are digitally linked to the original geologic framework data. With input from stakeholders, derivative products can be critical to the development of timely and effective science, policy, and decisionmaking. Geologic maps provide a physical representation of the Earth, but they have not traditionally conveyed dynamic and predictive knowledge. The USGS will improve its ability to produce digital products that include geologic scenarios, simulations, and predictive models relevant to climate change, ecosystem change and health, groundwater flow, resource assessment, carbon sequestration, and potential hazards.

\section{High-resolution stratigraphy, geochemistry, and geochronology}

Technological advances now allow more precise dating and characterization of geologic units. Such high-resolution measurements have a multitude of applications, including improving the quality of information on geologic maps and allowing for modeling in the third and fourth dimensions. The use of laser-based instrumentation and new sensors to derive knowledge from geologic materials will be enhanced. 


\section{Goal 2. Understand Earth Surface and Climatic Processes and Anticipate Their Effects on Ecosystem Health and Change}

Ecosystems arise from the intricate interactions of life and the chemical and physical processes that occur at or near the Earth's surface. Geology, climate, and land-use history determine where various kinds of ecosystems develop. These factors also influence the nature and rates of physical, chemical, hydrological, and biological processes that occur within an ecosystem. Ecosystems are increasingly modified by natural and human-induced stresses, such as climate change, sea-level rise, desertification, and extinction of species. These and other alterations pose a challenge for the sustained well-being and security of the Nation. The USGS will continue to develop and expand the geologic knowledge needed to help the Nation monitor, anticipate, and adapt in order to maintain ecosystem sustainability in this changing world. 


\section{$\stackrel{\bullet}{*}$ Geochemical Landscapes}

The geochemical patterns exhibited by Earth surface materials result from the complex interactions of geologic, hydrologic, geomorphic, atmospheric, biologic, and anthropogenic processes operating over a range of temporal and spatial scales. The USGS is characterizing these patterns and processes for several regions of the United States. These detailed studies can be used to understand geochemical processes operating in the environment that may affect human and environmental health. In this example, there is a clear differentiation of soil geochemistry across the Sacramento valley of northern California. The separation between the two sides of the valley is maintained by a levee built up along the Sacramento River. The chemical differential across the valley reflects contrasting soil source materials in the Coast Ranges to the west and the Sierra Nevada Mountains to the east.

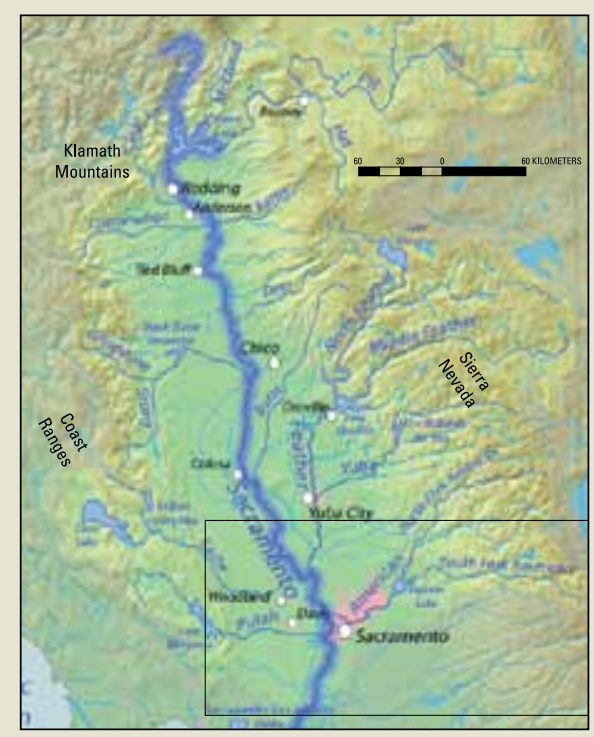

Vicinity map showing location of chemical plots (rectangle) in relation to the Sierra Nevada and Klamath Mountains and Coast Ranges, Calif. Map from http://en.wikipedia.org/wiki/ File:Sacramentorivermap.jpg.
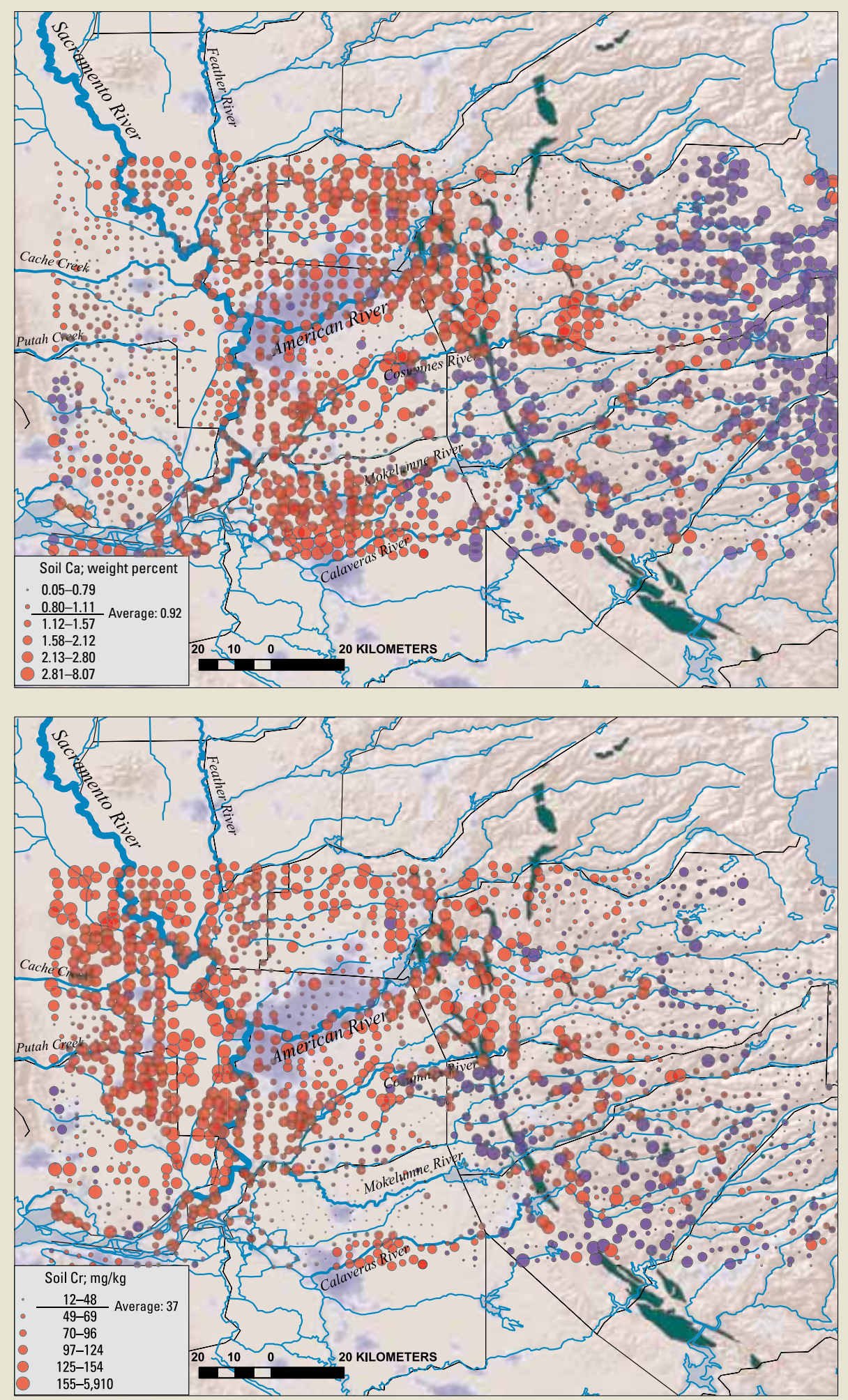

Calcium (Ca, upper map) and chromium ( $\mathrm{Cr}$, lower map) in surface soil of northern California, shown as proportional symbols; the larger the circle, the higher the content. The geometric mean for soil of the continental United States is 0.92 weight percent for calcium and 37 milligrams of chromium per kilogram of soil (Helmke, 2000). The red points are surface soil (upper 20 centimeters) and the purple points are stream sediment. Urban areas are shaded. Calcium map modified from Goldhaber and others (2009); chromium map from Morrison and others (2009). 


\section{Societal Needs and Benefits}

Soils are the thin film over the Earth's surface in which geological, biological, and human processes intersect. Geology and ecosystems are intimately coupled. Ecosystems occur over a range of scales from the microscopic to the planetary. Regardless of scale, the processes that support ecosystems and human society are rooted in geology and localized within the rocks, soils, and waters of the outermost layer of the Earth. The crustal environment supports terrestrial, freshwater, and marine resources. Weathering converts rocks into nutrientbearing soil (highlight 6 ). Because soils provide the basis for terrestrial life, they literally and figuratively provide the foundation of civilization. The continental crust also hosts our precious freshwater resources. Shallow marine and coastal ecosystems are a critical interface between the continents and the oceans.

Humans have become a dominant agent of change on our planet. The rapid growth and spread of the human population and accompanying widespread land-use impacts, coupled with climatic changes related to the release of greenhouse gases into the atmosphere, are altering the Earth's surface and its ecosystems (highlight 7). Of special concern are changes to soils and the water, carbon, and nutrient cycles that are having increasingly negative consequences for all terrestrial and marine ecosystems and, ultimately, for human society and health. Of increasing concern is the continuing decrease in the ocean's $\mathrm{pH}$, known as ocean acidification, that is caused by the dissolution of $\mathrm{CO}_{2}$ in seawater.

There are many examples of past civilizations that have declined as a result of failing to conserve natural resources or to adapt to climate and other changing conditions (Diamond, 2005). Our Nation and the world are facing similar risks.

Environmental degradation, loss of water or soil resources and food supply, and other environmental issues have destabilized governments and caused armed conflict among nations; hence, environmental security has emerged in the last decade as an important concern for the United States and all other nations.

The USGS science strategy identifies research on interactions among ecosystems, Earth surface geologic processes, and climatic regimes as a core future activity for the USGS. Characterization of the Nation's surficial geology, and the processes affecting it, has long been a strength of the USGS. This goal builds on this existing strength and expands its application to understanding ecosystem dynamics. Because these topics cross disciplinary boundaries, we will need to link geologic mapping expertise with such subdisciplines as geomorphology, geochemistry, biogeochemistry, climatology, and geoecology and with expertise from other disciplines such as biology, hydrology, and geography, both within and external to the USGS. Our interdisciplinary capabilities, combined with a continuing commitment to long-term studies, place the USGS in a unique position to address change in our environment. There are several steps to achieving this goal: (1) characterizing the components and processes present in ecosystems today, (2) monitoring ongoing changes, (3) examining past factors that resulted in the present-day conditions, (4) modeling past and future environmental changes, and (5) understanding links to human health. Collectively, this information will provide the foundation for predicting the range of possible future conditions and their likely consequences for ecosystems and human society. It will be critical to use the latest available technologies and to develop new approaches in monitoring, assessment, and research. 


\section{E Chesapeake Bay}

Chesapeake Bay, the Nation's largest estuary, has been negatively affected by human activities as the population in the watershed has doubled since 1950, resulting in degraded water quality, loss of habitat, and declines in populations of biological communities. Extensive agriculture and urbanization in the watershed have put major stresses (nutrients, sediments, contaminants) on water quality in rivers, tributaries, and the bay itself. Since the mid-1980s, the USGS has worked with partners in the Chesapeake Bay Program to study ways to restore the bay ecosystem. The paleoclimate of the watershed provides insight for ecosystem management. USGS scientists have used marine, estuarine, and terrestrial proxies to examine impacts of climate change on the watershed in both its natural and anthropogenically altered states. These proxies include pollen (temperature and precipitation), microfaunal assemblages (salinity, dissolved oxygen levels, temperature), phytoplankton (dissolved oxygen, salinity), and shell chemistry (temperature, salinity).

Sediment sources to the Chesapeake Bay estuary from river input, coastal erosion sediment, Atlantic sediment, and other deposits. From Cronin (2007, fig. 7.1).
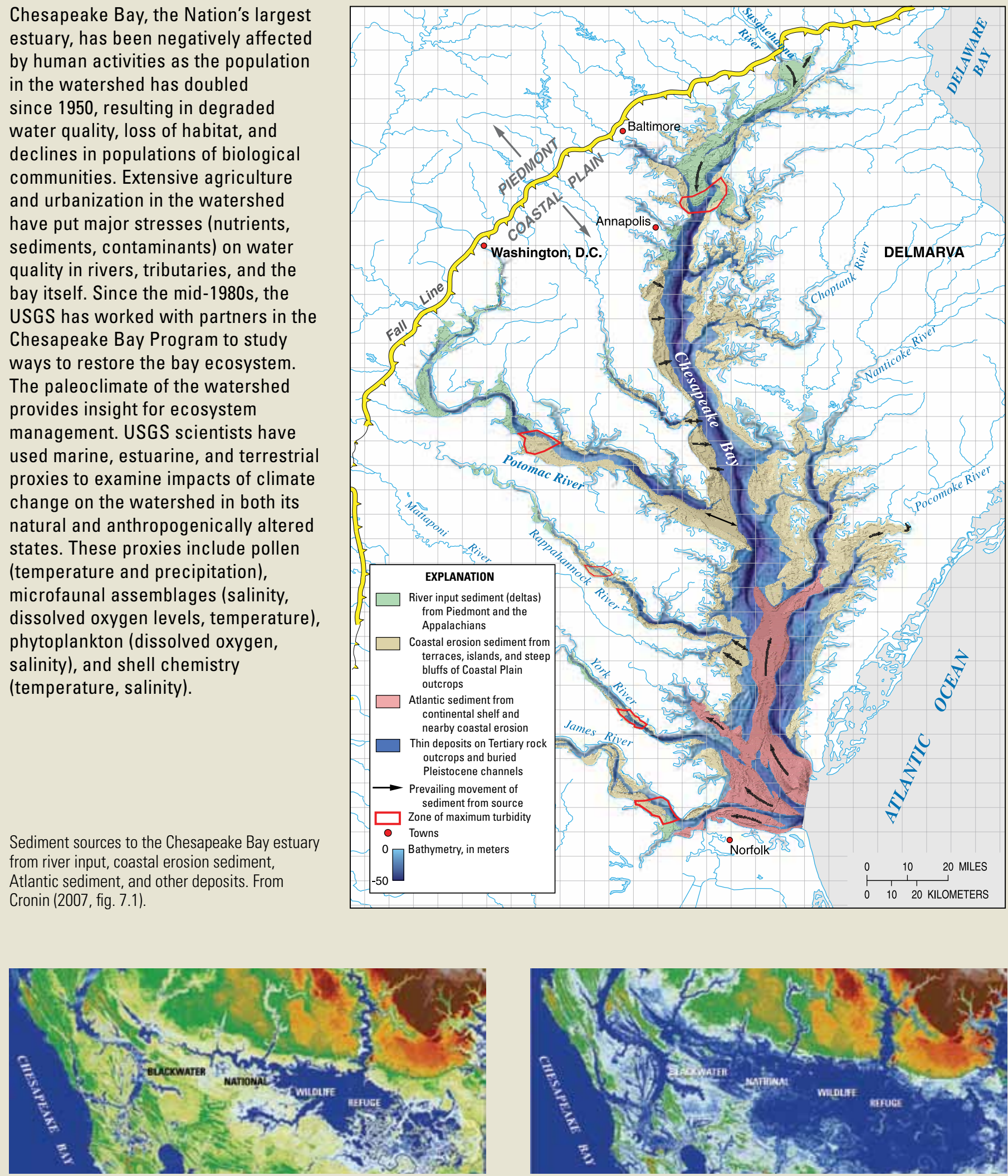

Digital elevation model forecasts of sea-level rise at Blackwater National Wildlife Refuge, Dorchester County, Md., for 2002 (left) and 2100 (right); the 2100 forecast is based on an assumed 6.2-millimeter-per-year rise in sea level. Sea-level rise during the coming century will affect tidal wetlands throughout the estuary. From Cahoon (2007, fig. 12.1). 


\section{Strategic Actions}

1. Characterize and understand the key physical, chemical, and biological components and processes that determine ecosystem structure and function

In the coming decade, the USGS will map, describe, and strive to understand the key physical, chemical, and biological characteristics and processes that affect ecosystem structure and function. We will focus on how geologic materials and processes determine the distribution, abundance, and well-being of life on Earth. Given the critical nature of soils to our environment, we will expand USGS soil science expertise and, in collaboration with other Federal agencies, emphasize the processes that control soil formation and its physical, biological, and chemical properties (see photograph of soil crusts on p. 19). We will quantify atmospheric and riverine transport of terrestrial sediments, refine the mapping of our geologic units deposited during the Quaternary Period (see appendix $\mathrm{C}$ for divisions of geologic time), and improve our understanding of geomorphic change. We will continue to build our database of inorganic soil geochemical analyses, augment this with organic and geomicrobiological information, and integrate these data into national hydrologic and ecosystem studies. We will improve understanding of how geological, biological, and chemical cycles interact to support life and health. A special emphasis will be placed on human interaction with and effects on carbon, nitrogen, and water cycles at local to global scales.

\section{Monitor processes and changes at the Earth's surface to understand variation and disturbances in natural cycles}

Monitoring at relevant scales provides the baseline and time series data needed to quantify rates and scales of natural processes. Current monitoring of carbon, water, and nutrient cycles, permafrost distribution, soil movement via wind and water, vegetation changes as controlled by geology and climate, and coastal change will be expanded through increased spatial coverage and finer temporal resolution. More effective and complementary use of in situ and remote observations is critical in this regard. New interdisciplinary efforts will mine extensive geophysical and remotely sensed datasets and monitor interactions among physical, chemical, and biotic parameters. Emphasis will be on geological controls of the interaction among vegetation, topography, climate, water, and coastal change and on addressing both basic science and resource management issues. We will engage external partners and monitoring efforts such as DOI's Landscape Conservation Cooperatives (http://www.fws.gov/science/SHC/lcc. $\mathrm{html}$ ), the National Science Foundation's (NSF's) Long Term Ecological Research sites (http://www.lternet.edu/), the National Ecological Observatory Network (http://www.neoninc.org/), the Organization of Biological
Field Stations (http://www.obfs.org/), and the multiagency National Phenology Network (http://www.usanpn.org/). The knowledge and data created through our monitoring programs will be key resources for global change assessments and supporting resource management planning.

\section{Understand past changes in the Earth's climate and ecosystems}

It is critical to understand how ecosystems have responded to long-term climatic changes under a wide range of past climatic states from deep time to the present, and how human actions have modified ecosystem processes, to better understand likely future scenarios. USGS studies will include site-specific reconstructions of change, analyses of local to global patterns of climate and ecosystem change through time, and investigations focused on past functioning of key biogeochemical processes. These studies will reveal the rates, amplitudes, and geographic patterns of past climatic and environmental changes, information that is critical for assessing the importance of current changes. Emphasis will include changes in geochemical cycles, erosion rates, and chemical fluxes and the ecological effects of variations in atmospheric chemistry. Paleoenvironmental reconstructions will provide the basis for assessing how well models of climatic and environmental change simulate conditions different from those of today. USGS paleoenvironmental research will include close collaborations with the university community; NSF, NOAA, and other Federal agencies; and international consortia of paleoclimate researchers.

\section{Model and forecast potential future changes in the Earth's climate and ecosystems}

Anticipating how global change will affect our environment requires understanding the complex interactions among climate, life, and geology. The USGS will address this challenge by modeling Earth surface and ecosystem responses to a range of past and future climate states and land-use scenarios. Understanding how climate change is linked to disturbance regimes such as fire, insect outbreaks, and species invasions is important for adaptive management on our public lands. Likely future scenarios will be created to assess the sensitivity of key lands and resources under a range of future global change conditions, with the objective of informing decisions by policymakers and land and resource managers. Specifically, the USGS will model biological, geological, and chemical cycles; sediment erosion and deposition; and ecosystem responses to climatic changes and to perturbations to natural disturbance regimes. This work will be cross disciplinary within the USGS and will involve extensive collaborations with external modeling groups. 
5. Interpret the links among geology, the environment, and human health

We will expand our interdisciplinary environmental research and increase collaboration with health scientists to address environmental and health issues. We will use geologic expertise from a wide range of subdisciplines to help health scientists understand toxicologically important characteristics of earth materials. Collaborations with health scientists will leverage our earth science databases and expertise to provide insights into disease epidemiology, geological and geochemical controls on pathogen ecology, and zoonotic (animal-borne) diseases. Studies examining the effects of climate and Earth surface change on ecosystem health will also consider potential effects on human health. We will address emerging issues such as potential environmental and health effects of materials used in or generated by advanced technology such as nanotechnology and genetic engineering.

\section{Expand USGS activities that enhance environmental security}

The USGS is in a unique position within the Federal Government to provide information on processes controlling a wide range of environmental and health issues that may affect the security of the United States and other governments. Working in cooperation with partners such as the State Department, United Nations Environment Program, and our sister agencies in other countries, the USGS can take a variety of actions to enhance this role. These include helping to track and understand geology-related or geology-influenced environmental and health issues in a global context, enhancing research on these issues that cross international borders and affect the United States, and providing expertise to other countries on their own pressing issues in environmental health.

\section{Understand the regional environmental effects of agricultural practices}

Agriculture directly affects more than 50 percent of the land use in the conterminous 48 States and indirectly affects an even larger proportion of the Nation's terrestrial, aquatic, and marine resources. Changes in farming practices over the last 200 years have shifted the character of the landscape through increasing cultivation, draining of wetlands, intensification of agricultural production, and application of fertilizers, pesticides, and antibiotics. The eroded materials may play a significant role in the net gain or loss of carbon from the Nation's surface environment and in the distribution of anthropogenic constituents. The fate of these eroded sediments is not well characterized. In cooperation with other Federal, State, and nongovernmental organizations, the USGS can bring an interdisciplinary approach to this topic by integrating the overall geologic and hydrologic context of agricultural lands with long-term research and ecosystem monitoring to assess the effects of agriculture on the broader landscape. Issues the USGS will consider include changes in soil composition and erosion by cultivation, carbon storage, generation of dust, effects of agricultural practices on soil and water quality, and implications of global climate change for agriculture. Through development of integrated mapping products with a goal of improving resource protection, the USGS will provide critical information for agricultural land management and conservation decisions.

Facing page. Pinnacled biological soil crusts, Arches National Park, Utah. Biological soil crusts are formed by living organisms (primarily cyanobacteria) and their byproducts. They occur in arid to semiarid regions and play an important role in ecosystem health by contributing to soil stability, water retention, and soil fertility. They are very fragile and can be easily damaged by human activity. Photograph by Linda C.S. Gundersen, USGS. 


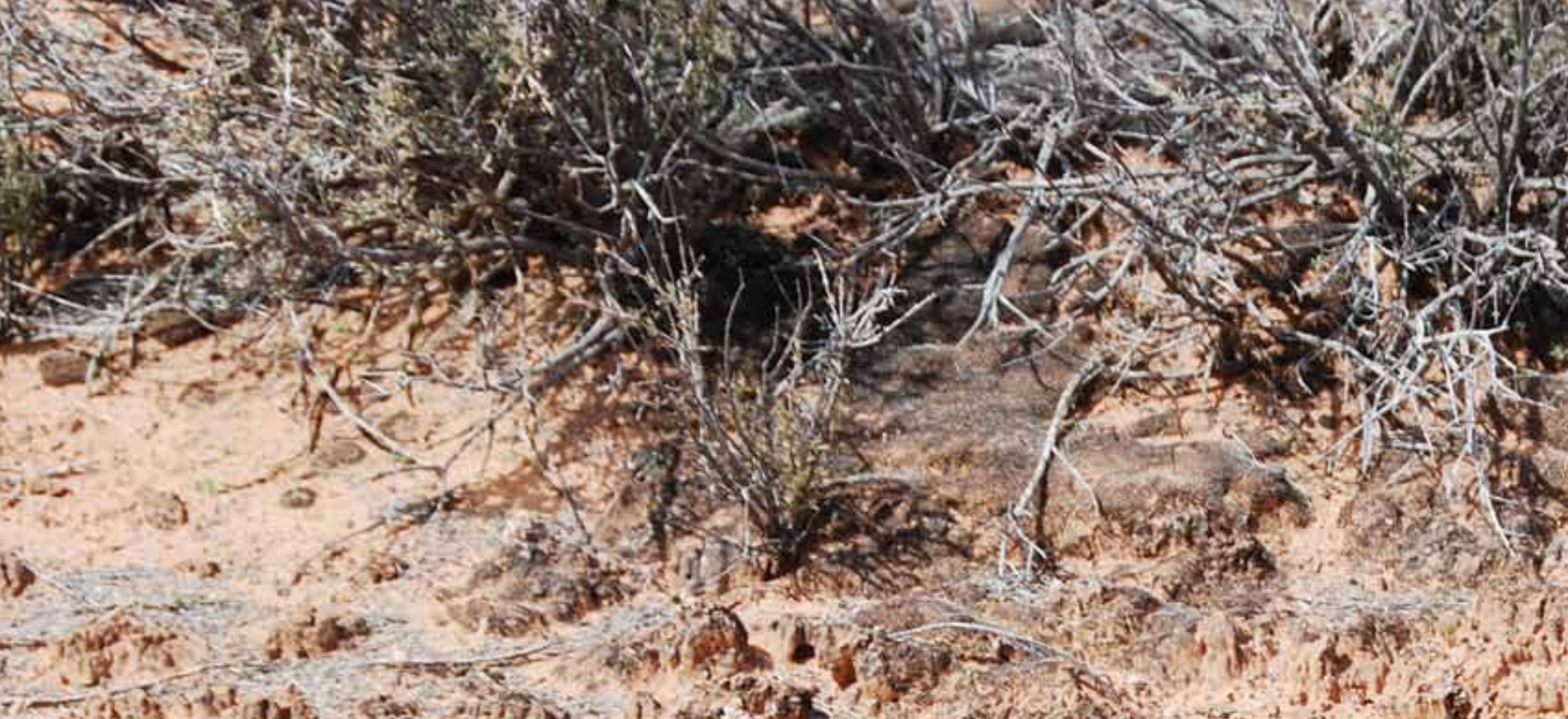

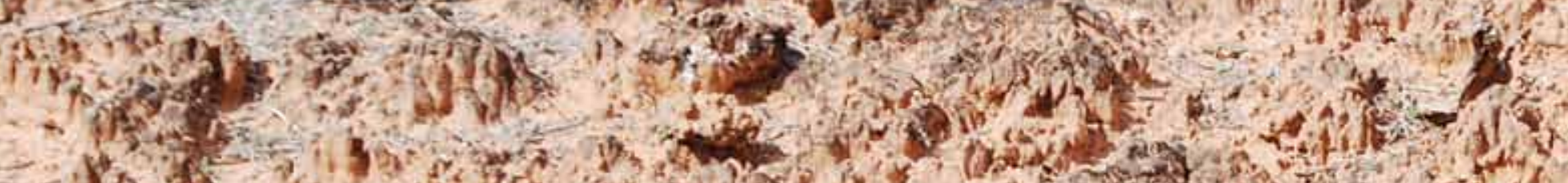

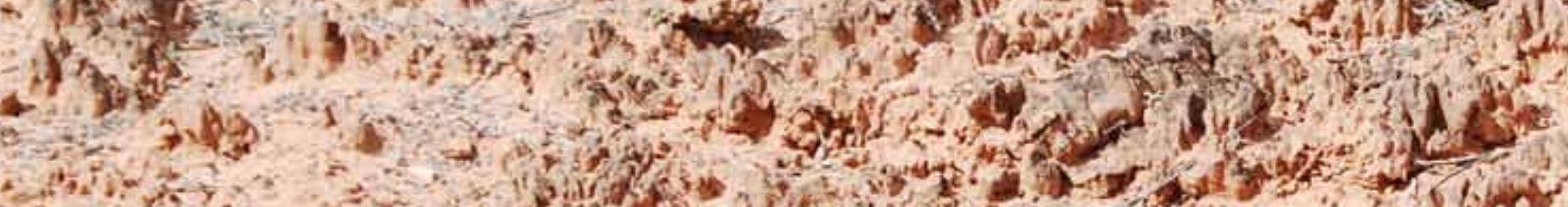

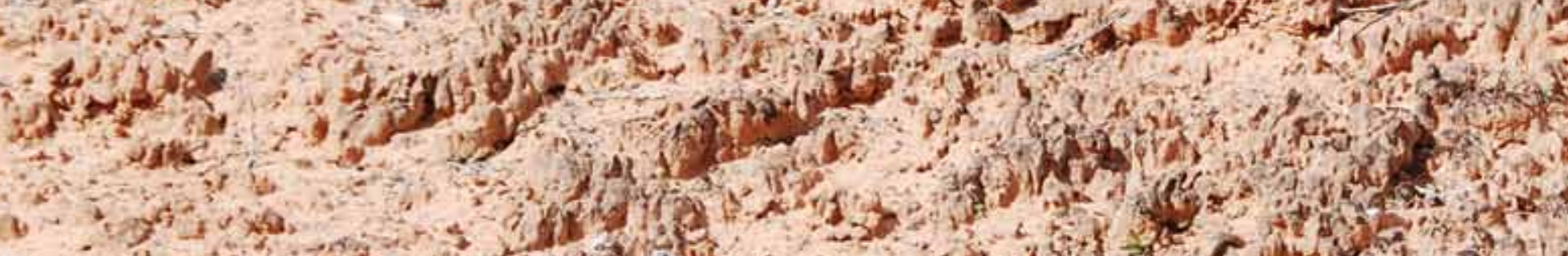

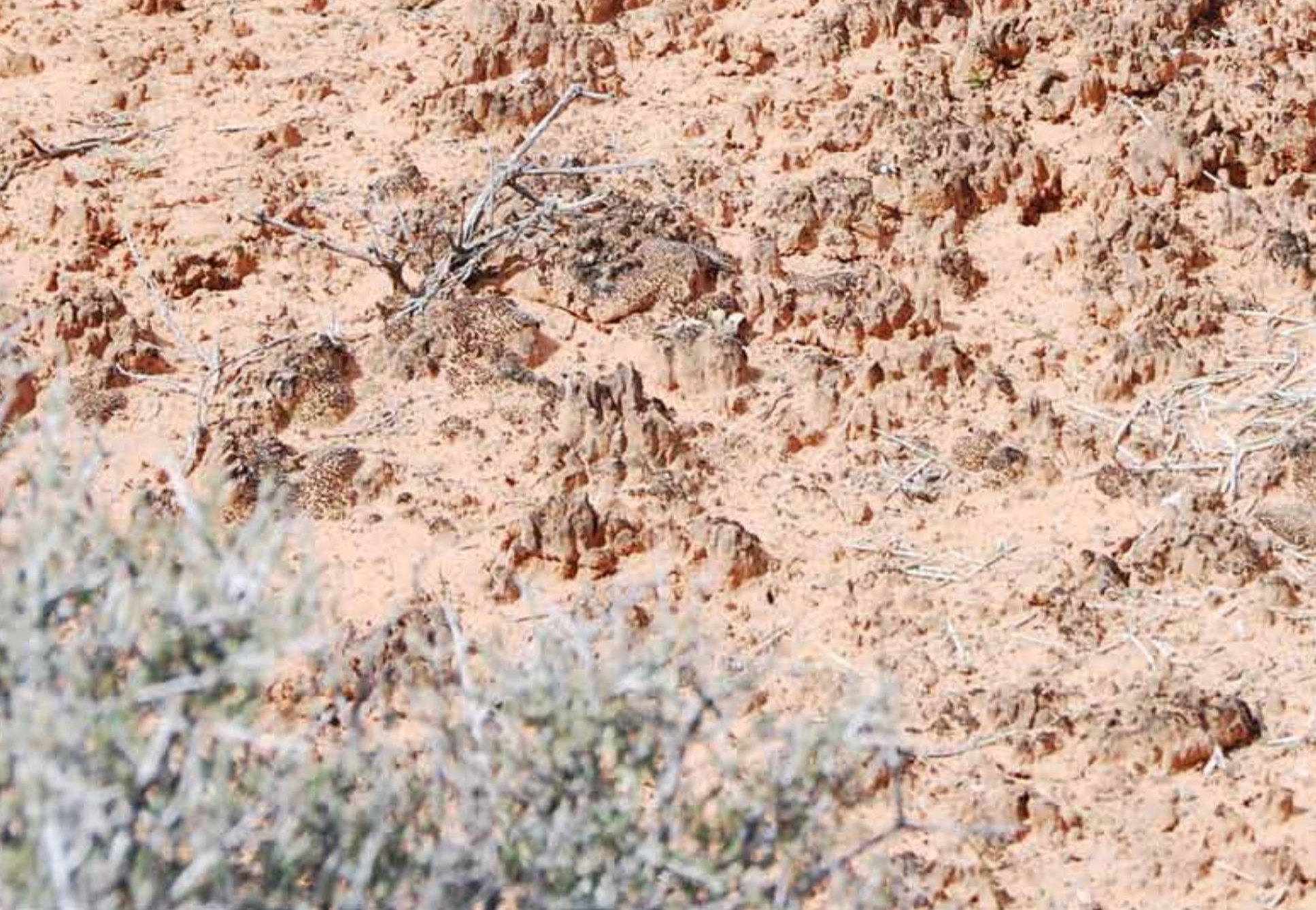




\section{The Problem With Dust}

Most desert soil surfaces are stable until disturbed (Field and others, 2009). When disturbed, loss of soil via wind erosion reduces soil fertility at the source, as dust loss exceeds input. Dust in transit reduces air quality, causes traffic accidents, and can compromise human health. Dust deposition onto the snowpack increases melt rates by darkening the snow surface and increasing the absorption of solar radiation (the dominant melting force). As most dust is deposited in April and May, it coincides with high solar irradiance. High melt rates are sustained because snow melts from under the dust, consolidating individual dust layers and further darkening the surface.

Dust deposition in the southern Rockies increased fivefold during the past 150 years from the average rate for the past 5,000 years and may be related to disturbance of fragile desert soil surfaces by large livestock herds and agriculture (Neff and others, 2008). Current activities (for example, recreation, energy development, agriculture) maintain high dust levels. During 2005 and 2006, dust deposition in

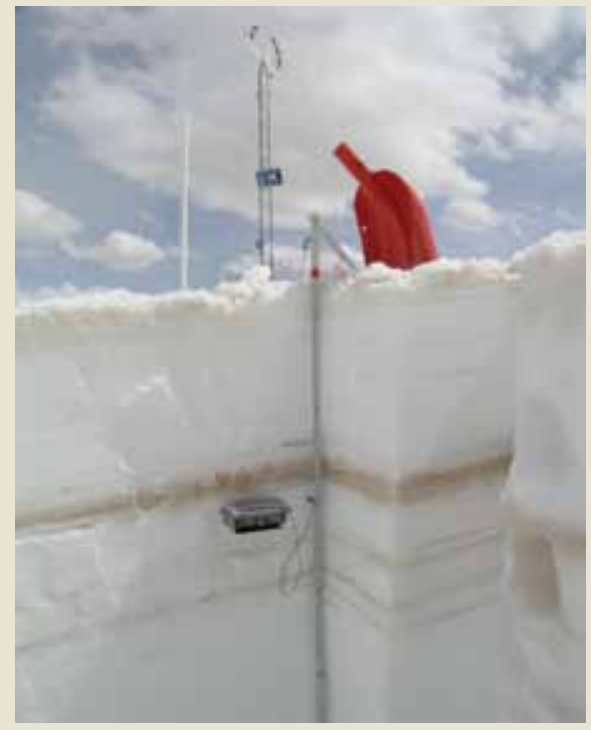

Dust layers in a snowpit at the Center for Snow and Avalanche Studies' Senator Beck Basin study area near Red Mountain Pass, Colo. Photograph by Chris Landry, used courtesy of Center for Snow and Avalanche Studies, Silverton, Colo. the southern Rockies shortened snow cover by 18 to 35 days (Painter and others, 2007), whereas events in 2009 resulted in 48 fewer days of snow cover (T.L. Painter, NASA, written commun., 2010). Earlier snowmelt results in earlier

runoff, less late season water, and increased evaporative loss of water from exposed soils, reducing total runoff. Dust production can be mitigated by altering the timing, type, and intensity of soil disturbance in low-elevation lands.

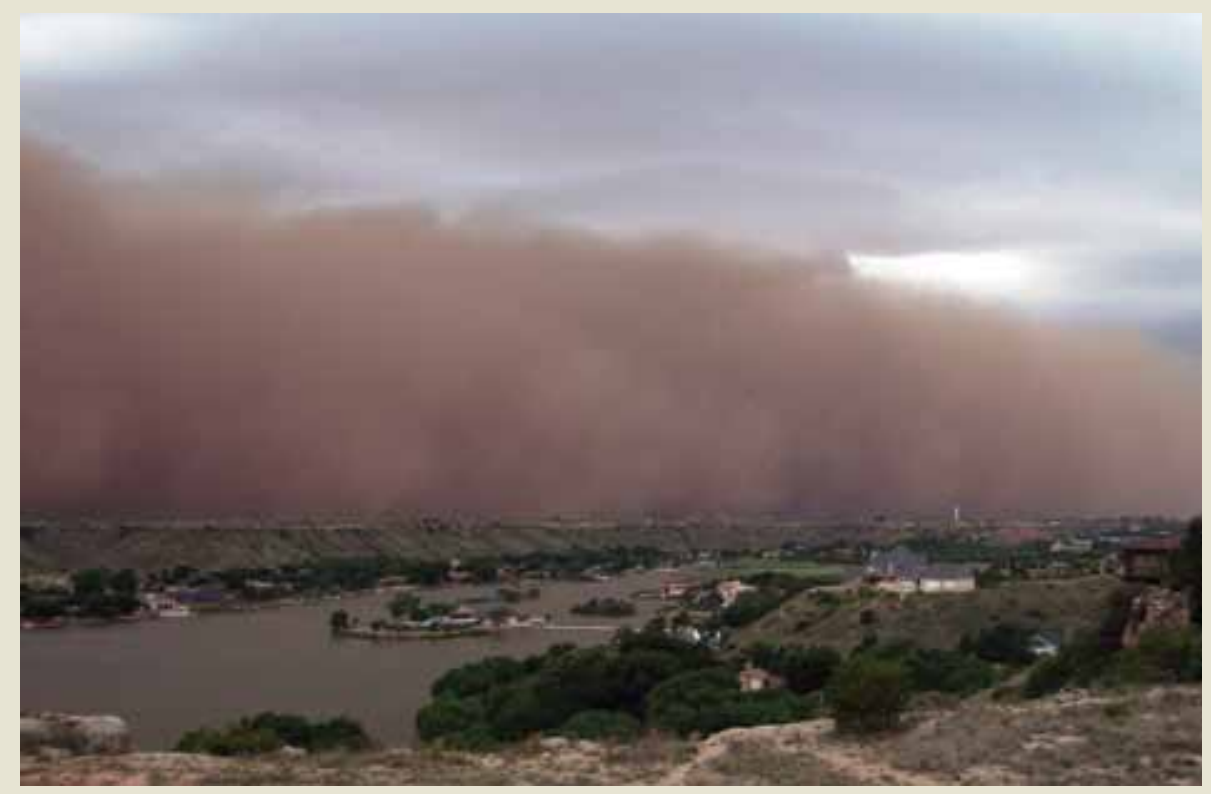

Gust-front dust cloud moving across the Llano Estacado toward Yellow House Canyon near the residential community of Ransom Canyon, Tex. Photograph by Leaflet (http://en.wikipedia.org/wiki/ File:Haboob_Ransom_Canyon_Texas_2009.jpg.)

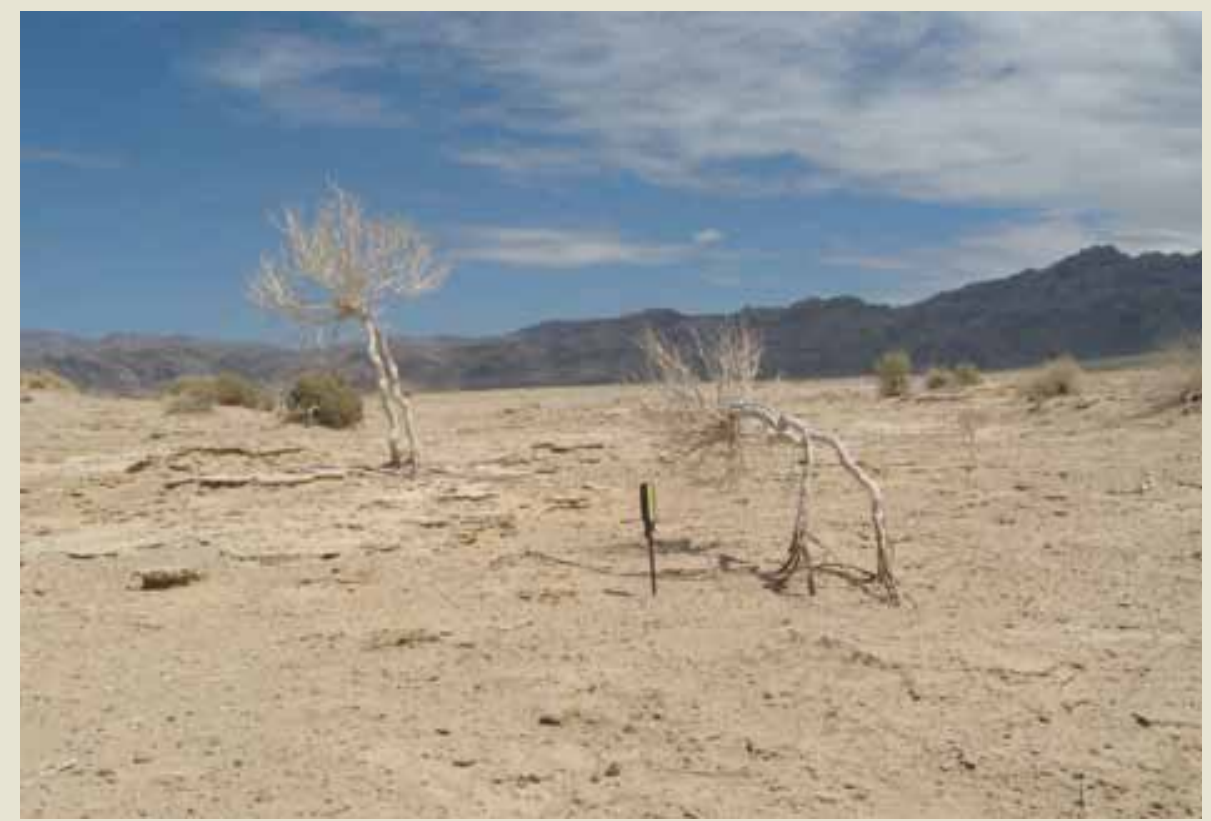

Many factors, including drought and surface disturbances from human activities, can promote wind erosion. Emission of dust from wind-eroded landscapes causes the loss of soil and the resources that it provides. Here soil levels are 30 to 35 centimeters below what they were when these shrubs were alive about 10 years ago. Photograph by Richard Reynolds, USGS. 


\section{Products and Outcomes}

\section{Digital maps of geologic and soil properties that influence ecosystems}

The geologic and soil characteristics of a site (surficial and bedrock geology, geomorphology, and geochemistry) strongly influence the plants and animals present at that site, the resistance and resilience of ecosystems to land-use and climate change, and the resulting ecosystem services. The USGS will expand production of ecologically relevant maps and will relate those maps, at appropriate scales, to ongoing and future ecological studies. These maps will specifically target relevant physical attributes such as rock type, texture, and chemistry, as well as soil properties that affect organism and ecosystem health.

\section{Quantitative assessments and digital maps of fundamental fluxes}

Human activities have greatly accelerated the transport of many materials, such as waterborne sediments and atmospherically deposited constituents such as dust (highlight 8), carbon, and nitrogen compounds and elements of environmental concern, including mercury and lead. This movement can dramatically affect ecosystems, both where the materials originate and where they are deposited. For instance, abandoned farmlands and other disturbed soil surfaces are often a major source of windborne and waterborne sediments. The loss of soil reduces soil fertility and water-holding capacity. The deposition of soil can reduce water quality and aquatic biota, damage plants, and reduce snow albedo, accelerating snowpack melt rates, as well as act as a vector for transport of potentially deleterious constituents. The USGS will document the source of specific wind- and water-transported materials, as well as quantify the amount of loss, how the loss of this material affects the source ecosystem, and how deposited material affects the receiving ecosystem.

\section{Syntheses of past ecosystem and land-surface changes}

Research on past ecosystems provides evidence of the amplitudes, rates, and spatial-temporal patterns of variations that resulted from changes in the atmosphere-land surfacebiosphere system. The USGS will establish a framework for the interpretation of data on past ecosystem and landsurface change. This framework will utilize USGS strengths in paleontology, geochemistry, geochronology, and surficial geology to develop rigorous quality and dating standards; implement systematic and advanced approaches to data compilation, synthesis, and interpretation; and produce local to global interpretations of past changes. Key products will include summaries of ecosystem and landscape characteristics of past climate episodes and abrupt climate change, time series of change focused on sensitive regions or processes, and assessments of the amplitudes and rates of past changes compared to ongoing and projected changes.

\section{Digital atlas of land-use-change and climate-change vulnerability}

Landscape sensitivity to environmental change is related to substrate composition, topographic position, and hydrology, among other factors. The USGS will identify ecosystem components and processes vulnerable to changes in climate and land use. This information will be synthesized to produce a national atlas of the relative vulnerability of various environments to global change. These maps will reflect, for example, sea-level change, ground subsidence, permafrost distribution, soil and coastal modification, the influence of substrate in ecosystem dynamics, and changes in coastal environments. Products will be designed for use by land and resource managers and created through collaboration with other scientific disciplines and State and Federal land and resource managers.

\section{Digital national hydrogeochemical landscape map}

The term "landscape geochemistry" describes the linked chemical transformation of near-surface fluids and materials as they co-evolve through biotic and abiotic processes. A national-level soil geochemical dataset is currently being compiled, which, in conjunction with existing USGS sediment and water geochemical databases, can be used to construct a geochemical landscapes map. A difficult but achievable goal for the next decade is to merge such a map with data from the National Water Information System, with regional synthesis maps of water-quality data from the National Water-Quality Assessment (NAWQA) Program, with the USGS Hydrologic Landscapes map, and with other relevant datasets. This merged product will describe movement of fluids at and near the Earth's surface and will provide critical information on the underlying processes that control their chemistry as well. The resulting "hydrogeochemical landscape" maps and data will serve as a useful national baseline against which to compare future surface geochemical changes and will provide essential physical and chemical data for ecologic studies. 


\section{Geology for a Changing World 2010-2020: Implementing the U.S. Geological Survey Science Strategy}

\section{Geologic input for a USGS national environmental} health system

The USGS science strategy (USGS, 2007, p. 43) calls for the establishment and maintenance of a national-scale environmental health information system that would "serve as a clearinghouse for spatially referenced environmental information (data, research, modeling interpretations) linked to a set of Geographic Information System (GIS) decision support tools." The geologic sciences can provide fundamental components for this system such as bedrock geologic maps, national geochemical and geophysical databases, and databases describing aspects of energy and mineral resources (see map below of asbestos occurrences). These data and research will help in development of derivative products that provide insights into geology-related health issues. For example, integrating geological and epidemiological data may yield insight into where health and geological parameters are linked. To be effective, the USGS will need to work with the health community to better understand and define meaningful relationships among geologic and health data.

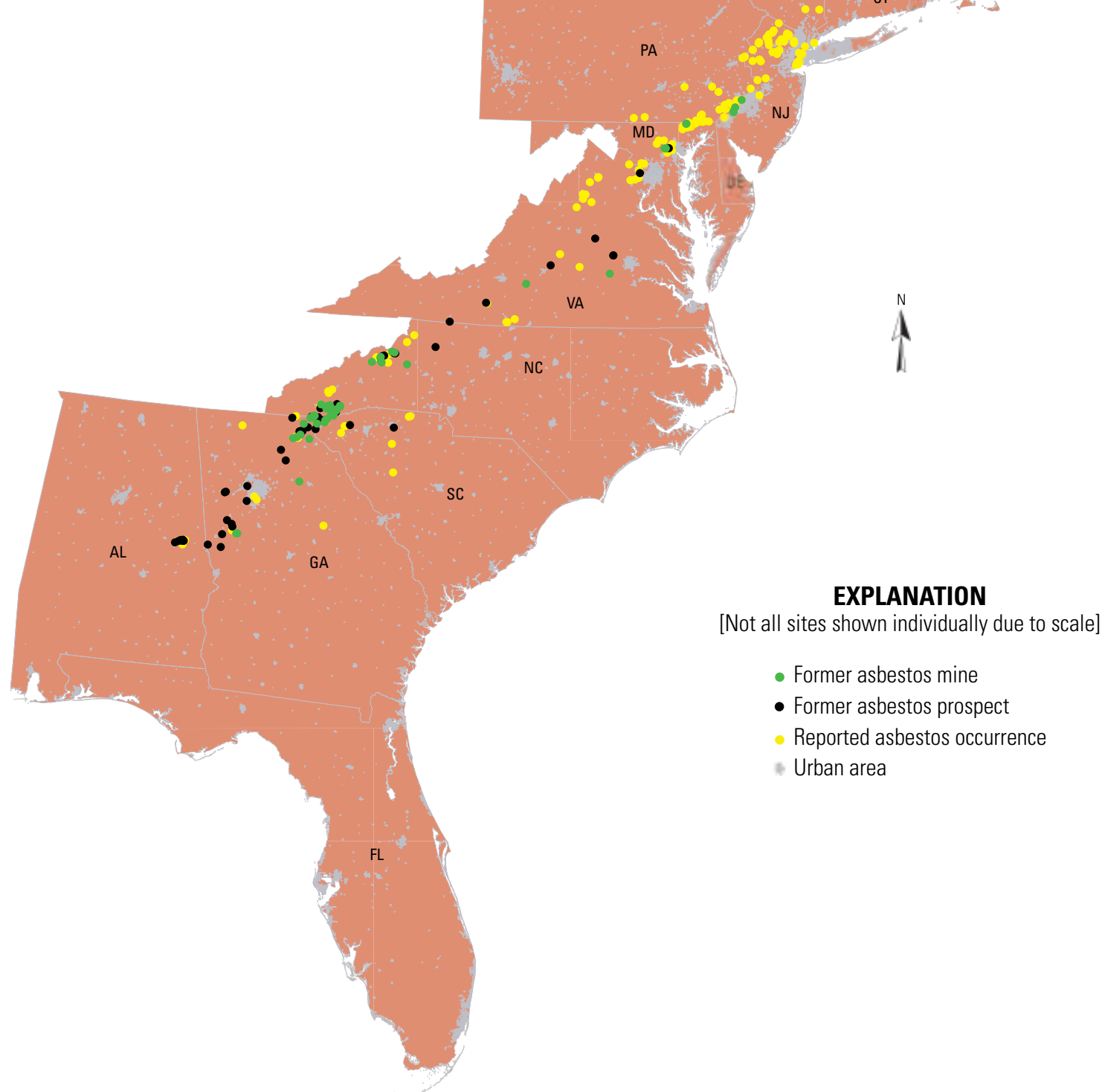

Locations of 331 natural asbestos occurrences in the Eastern United States. These occurrences range in size from small veins to large ore bodies once mined for commercial and industrial uses. Using the map and an accompanying digital database, the user can examine the characteristics and distribution of previously reported asbestos occurrences in the Eastern United States. Map and database from Van Gosen (2006). 
Goal 3. Understand and Quantify the Availability of Earth's Natural Resources in a Global Context

The Nation's security and economic health depend on ready access to natural resources that can be developed and used in a sustainable manner. Increasing global population and standards of living are placing unprecedented demands on resource markets and increasing global competition. The USGS will conduct interdisciplinary investigations into the global availability and societal use of energy, mineral, water, and soil resources and develop methodologies to assess the potential costs and benefits of developing and using these resources by integrating geologic, economic, environmental, and health information. 


\section{Mineral Resource Assessments}

The USGS responds to the Nation's need for mineral resources by providing assessments of undiscovered resources. Understanding the processes that form mineral deposits, characterizing known deposits throughout the world, and utilizing methods and techniques developed over many years are all essential for assessment of commodities crucial to the economy and security of the United States.

A new USGS quantitative assessment of previously undiscovered porphyry copper deposits in the Andes Mountains of South America identified 26 different tracts of land where the geology is permissive for these deposits within 1 kilometer of the Earth's surface (Cunningham and others, 2008). The assessment, prepared jointly with the geological surveys of Argentina, Chile, Colombia, and Peru, estimated that 750 million metric tons of undiscovered copper exists in the Andes, which means that there may be as much undiscovered copper as has already been discovered. This work was part of a large USGS study, initiated in 2002, as a cooperative international effort to create for the first time a consistent and comprehensive global assessment of undiscovered resources of copper, platinum-group elements (PGE), and potash in selected types of mineral deposits.

\section{EXPLANATION}

- Porphyry copper deposit

- Porphyry copper prospect

Tracts permissive for undiscovered porphyry copper deposits

(Mean estimated undiscovered copper, in millions of metric tons)

Greater than 50

$30-50$

$10-30$

Less than 10

Map showing locations of discovered deposits and prospects of porphyry copper and 26 tracts (colored areas) that are permissive for undiscovered porphyry copper deposits within 1 kilometer of the Earth's surface in the Andes Mountains of South America. Data from Cunningham and others (2008); map from C.L. Dicken, USGS.

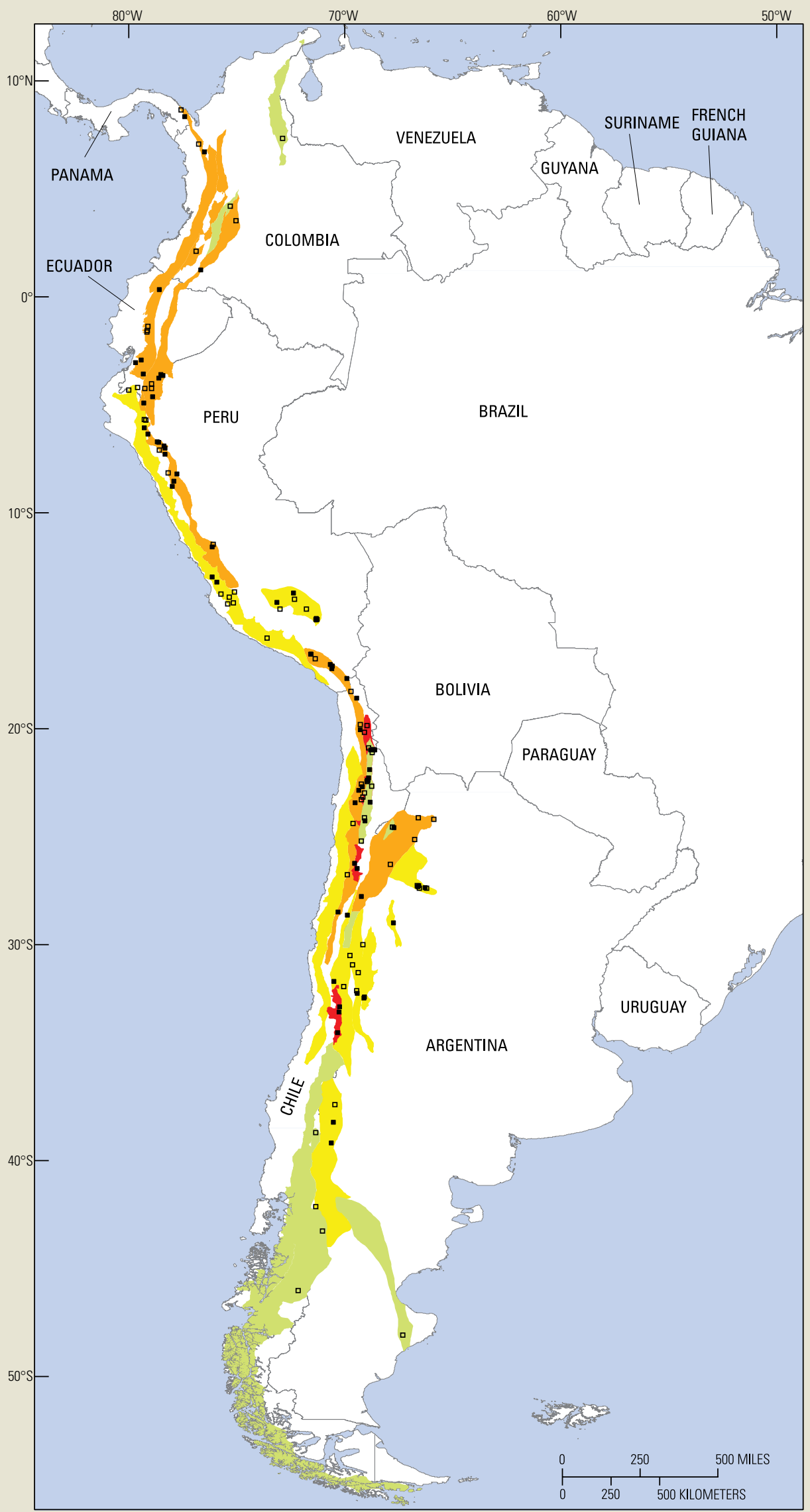




\section{Societal Needs and Benefits}

Many societies recognize the need to develop and use the Earth's natural resources in a sustainable manner to ensure long-term resource availability, promote strong economies, and protect the environment. Sustainable resource development is crucial to the overall security of the United States and other nations worldwide. However, the growing global population and rapid economic development in many countries are increasing demand and competition for natural resources, resulting in rising prices of certain commodities, diminishing availability, and increasing pressure for development. Providing the natural resources needed to sustain a robust global economy will be a major challenge in this century. For example, to bridge from our Nation's energy past to its future, we will need innovative strategies for reducing fossil energy use, capturing and storing carbon to mitigate its effect on climate change, and obtaining mineral commodities needed for the production of energy from nontraditional resources.

Water, soils, and ecosystems also provide natural resources critical to the survival and prosperity of human societies. Water resources are tied to supply, demand, quality, and economic issues, as are the development and consumption of energy and mineral resources. Soils and ecosystems are now recognized as key elements in maintaining the economic health of societies around the world, providing services critical to life and health. Sustainability will require a much better understanding of the complex linkages among these diverse resources to determine the availability of a resource for use. For example, the viability of a proposed energy or mineral resource development project may hinge on availability of an adequate water supply or may be balanced against the desire to protect the viability of an ecosystem equally dependent on the same water supply. Accounting for the inputs, outputs, and tradeoffs to develop or sustain a resource is known as life-cycle assessment. Life-cycle assessment of a resource includes understanding its formation and global occurrence; economic and social factors that influence its supply and demand; societal, economic, and environmental costs and benefits associated with its development and utilization; its flow through society; and issues of reuse or disposal.
Resources have to be viewed in a global context that includes the resources found on continental shelves and in ocean basins. The oceans are fundamentally important to global ecosystems and are crucial sources of food, recreational opportunities, transportation, and biodiversity. These demands on ocean resources will increasingly come into conflict with, and must be balanced with, the role of ocean basins as sources for conventional oil and natural gas resources and their growing role as sources for emerging alternative energy and mineral resources such as gas hydrates, wind, wave, and tidal power, sand and aggregate, and manganese and titanium.

The USGS is recognized worldwide for assessments of undiscovered energy and mineral resources and for analysis of the global trade in mineral commodities. Our assessment methodologies for oil, gas, coal, and nonfuel minerals are the accepted standards. Recent accomplishments include the release of groundbreaking assessments of global mineral resources (highlight 9), unconventional gas, and geothermal energy and a methodology for geologic carbon sequestration. To meet our future global resource challenges and changing societal needs, the USGS will expand its energy and mineral resource information, assessment, and research activities to include integrated life-cycle assessments of multiple earth resources in a global geologic, environmental, and economic context. Scarce, critical, or emerging commodities for technology and alternative energy, such as rare earth elements, gas hydrates, geothermal energy, and biofuels, may require specific additional assessments on local to national scales. As the need for more domestic resources continues, the USGS will need to be responsive to the local, regional and national needs of DOI land managers and national policy. Issues such as national security, energy security, and economic vitality will require the USGS to produce knowledge of resources on a global scale relative to our national endowment. An important component of USGS resource activities will be partnerships with government, industry, and academia to provide expertise in economics and social science and to help frame resource needs and tradeoffs. 


\section{Materials Flow}

Materials-flow analysis is a systematic way of accounting for what happens to materials from the time they are extracted, through processing and manufacturing, to ultimate disposition. The USGS studies the life cycle of mineral materials and trends in material use, as well as how materials affect the economy. The purpose of materialsflow research is to understand how we use our resources and to identify policies and practices that encourage efficient resource use. Studies have been completed for arsenic, cadmium, chromium, cobalt, lead, manganese, mercury, salt, sulfur, tungsten, vanadium, and zinc (see list of materials-flow reports at USGS, 2010a).

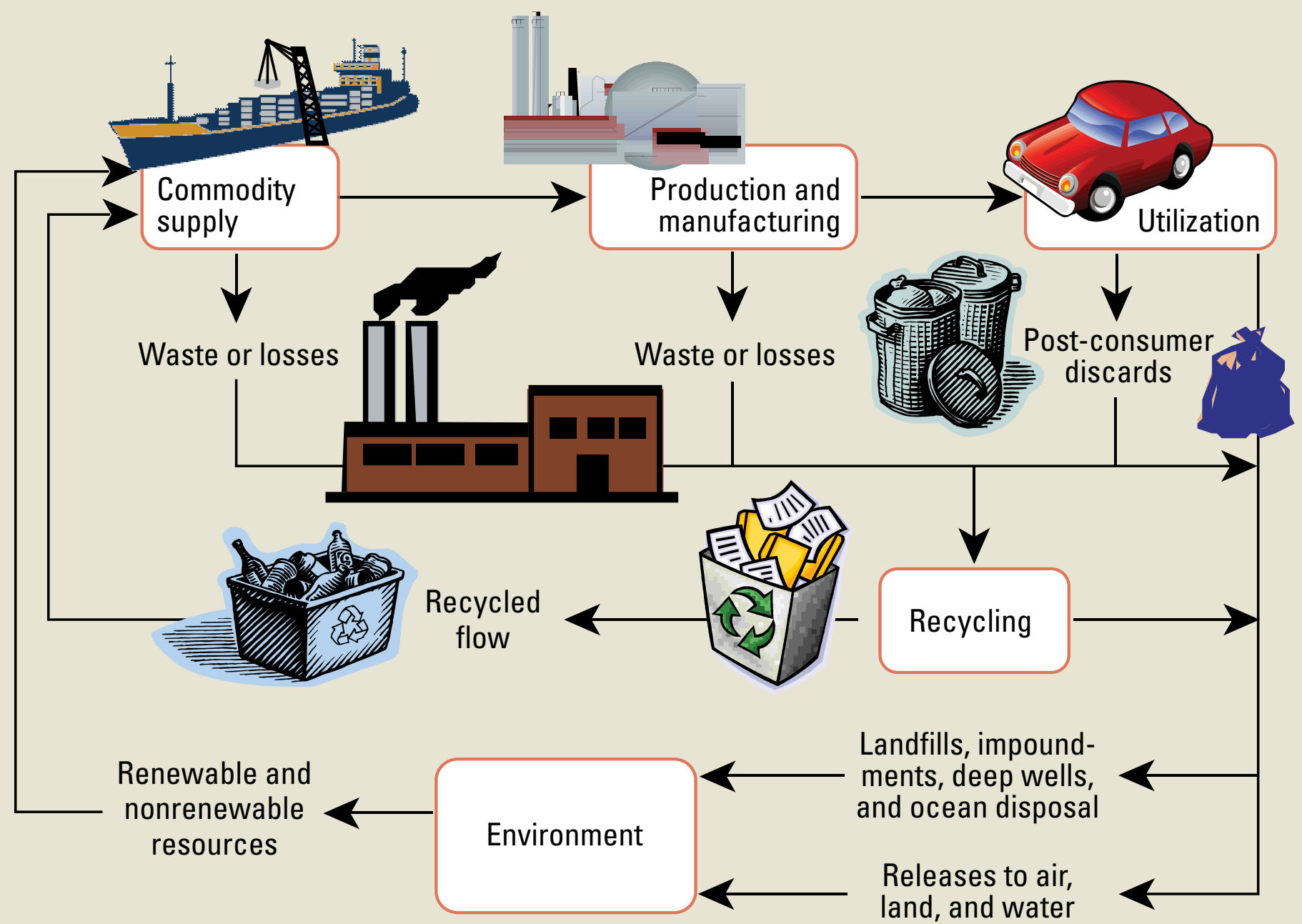

The materials-flow cycle aids in the analysis of the flow of materials through the environment and economy. The cycle is used to trace the flow of materials from extraction, through production, manufacturing, and utilization, to recycling or disposal. Throughout these processes, losses occur through discard of wastes or dissipation of materials to the environment. By use of this type of analysis, the contributions of individual processes can be identified. Modified from Wagner (2002, fig. 2). 


\section{Strategic Actions}

\section{Conduct targeted energy and mineral resources research to improve understanding and provide assessments for emerging resource needs}

Understanding the processes that form energy and mineral deposits, developing geophysical and geochemical methods for finding undiscovered resources, and understanding environmental and health implications of resource occurrence and development are essential areas of research needing continued investments by the USGS. Emphasis will also be placed on alternative and frontier energy resources, as well as the mineral resources needed for technology, agriculture, infrastructure, and alternative energy development. Environmental and health research related to energy and mineral resources will focus on understanding the sources, transport, and fate of toxicants in the environment and on working with the health community to establish clearer links between toxic elements and human and wildlife health.

\section{Establish an interdisciplinary capability for resource and commodity analysis}

Creation of an interdisciplinary capability that combines geologic expertise in resource and commodity analysis with ecologic and water resource assessment activities of the USGS has the potential to create a unique and powerful ability to understand the future of the Earth's resources. We propose a virtual center for integrated resource assessment focused on strategic resource questions and developing the tools and methodologies needed to answer them. Existing expertise will be augmented through selective hiring and partnerships with the Bureau of Land Management (BLM), the Bureau of Ocean Energy Management (BOEM), the U.S. Fish and Wildlife Service (FWS), the U.S. Department of Agriculture Forest Service, the U.S. Department of Energy (DOE) and its Energy Information Administration, and others to provide an integrated approach that considers resource economics; commodity information on mineral, energy, water, soil, and ecosystems; materials flow; future technology; social sciences; engineering; and environmental sciences. Challenges that will need to be resolved in establishing this capability include integrating diverse resource assessments, analyses, and data in a quantitative set of methodologies and understanding the associated uncertainties. The center will respond to questions of national and global importance related to the present availability and future sustainability of our critical resources.

\section{Conduct quantitative materials-flow studies of earth materials important to the Nation's economy}

The USGS will apply a materials-flow approach (highlight 10) for the study of metals and industrial minerals, traditional and emerging energy materials, water, soil nutrients, and greenhouse gases. As the United States continues to shift away from importing raw materials with which to manufacture products and toward importing finished products, we will need to understand the international flow of materials necessary for these products. The movement of material through the economy will assume increasing importance as issues related to material use, resource recovery, and disposal become prominent. This work will be critical to our ability to conduct full-cost accounting of resource usage and will augment traditional assessments of undiscovered resources.

\section{Modernize and enhance the mineral commodity information activities of the USGS}

The USGS reports on more than 100 nonfuel mineral commodities produced from domestic and international sources, and the reports are based on research and on 20,000 industry surveys. This information is a key foundation for calculating economic indices of the Federal Reserve, analyzing trade and market trends, and understanding the economic underpinnings of national security. In the next decade, the USGS will use advanced digital technologies to modernize and enhance the collection and analysis of commodity data, reducing the cost of collection and publication. These activities will provide the basis for USGS studies of the flow of materials through the international economy and the environment.

\section{Understand the linkages among energy, mineral, soil, water, and ecosystem resources}

Understanding how the occurrence, development, and use of any one resource can affect the quality and quantity of another resource will be the focus of this activity. The processes that form or sustain resources are intimately linked and include aspects of biological, hydrological, and geochemical cycles. Scientists need to understand these relationships to provide the information needed by land managers to evaluate multiple land-use options. We will need to develop new scientific methods to monitor and assess interdependencies among land, water, and ecosystem resources. These methodologies will require investigation of biogeochemical cycles in soils, the dynamics of carbon sequestration, the geologic controls on groundwater and surface-water aquifers and reservoirs, and baselines for important elements and nutrients in rocks and soils. This work will require close collaboration across many scientific disciplines and with land and resource managers. 
6. Conduct multiresource assessments in a global geologic, economic, and environmental context

Managers need robust and integrated analyses of multiple resources to evaluate the tradeoffs and effects of development on Federal lands. The USGS will work with partners to provide integrated assessments of the global geologic distribution and production of energy, mineral, water, soil, and ecological resources. These assessments will include the environmental effects of development and use of resources and will explore interdependencies among resources, such as new mineral commodity needs associated with emerging energy technology. Global energy assessments will expand from studies of petroleum, gas, and coal to include unconventional and alternative energy sources (see photograph on facing page). We will expand recent work on geothermal, oil shale, unconventional gas, and gas hydrates and will include uranium, tar sands, biofuels, and other energy sources. The focus will also be on key metals (such as copper, gold, titanium, and rare earth elements), industrial minerals (certain clays, zeolites, and mineral fertilizers), and infrastructure materials (sand, gravel, aggregate, and cement). The USGS will expand its recent development of a geologic carbon sequestration methodology to conduct assessments of carbon sequestration in geological terranes and to look beyond traditional seal-and-trap-type reservoirs to understand and discover potential new areas for geologic sequestration. Other new research directions include assessments that compare the potential energy-, mineral-, and ecological-resource value of an area and assessments of baseline environmental conditions and ecosystem services in an area proposed for development. These resource assessments will draw upon appropriate expertise from diverse disciplines. For example, information on earthquake hazards would be a logical addition to resource assessment in regions where seismic activity might affect extraction methods, economics, and the environment.

\section{Increase studies of offshore resources}

In the next decade, our society will make important decisions about coastal and ocean resource use. Issues include establishment of offshore wind farms, beach nourishment to mitigate coastal erosion, preserving and restoring essential marine, barrier island, and wetland habitats, and understanding effects of coastal groundwater withdrawals. USGS research on coastal and marine issues will require enhanced partnerships with other agencies such as BOEM, USACE, and NOAA, as well as greater involvement with coastal communities and State governments. International laws, such as the United Nations Convention on the Law of the Sea, will require an increased USGS role in mapping, defining the extent of our continental shelf, and understanding our marine resources.

Facing page. Photograph of the Twin Groves wind farm in McLean County, III., by Guenter Conzelmann, Argonne National Laboratories. USGS energy studies will expand to include assessments of unconventional and alternative energy sources, such as gas hydrates, geothermal systems, and biofuels, and analyses of the effects of developing solar and wind energy. Multidisciplinary scientific assessments will provide necessary information to help land managers make informed decisions about developing alternative energy sources on public lands. 


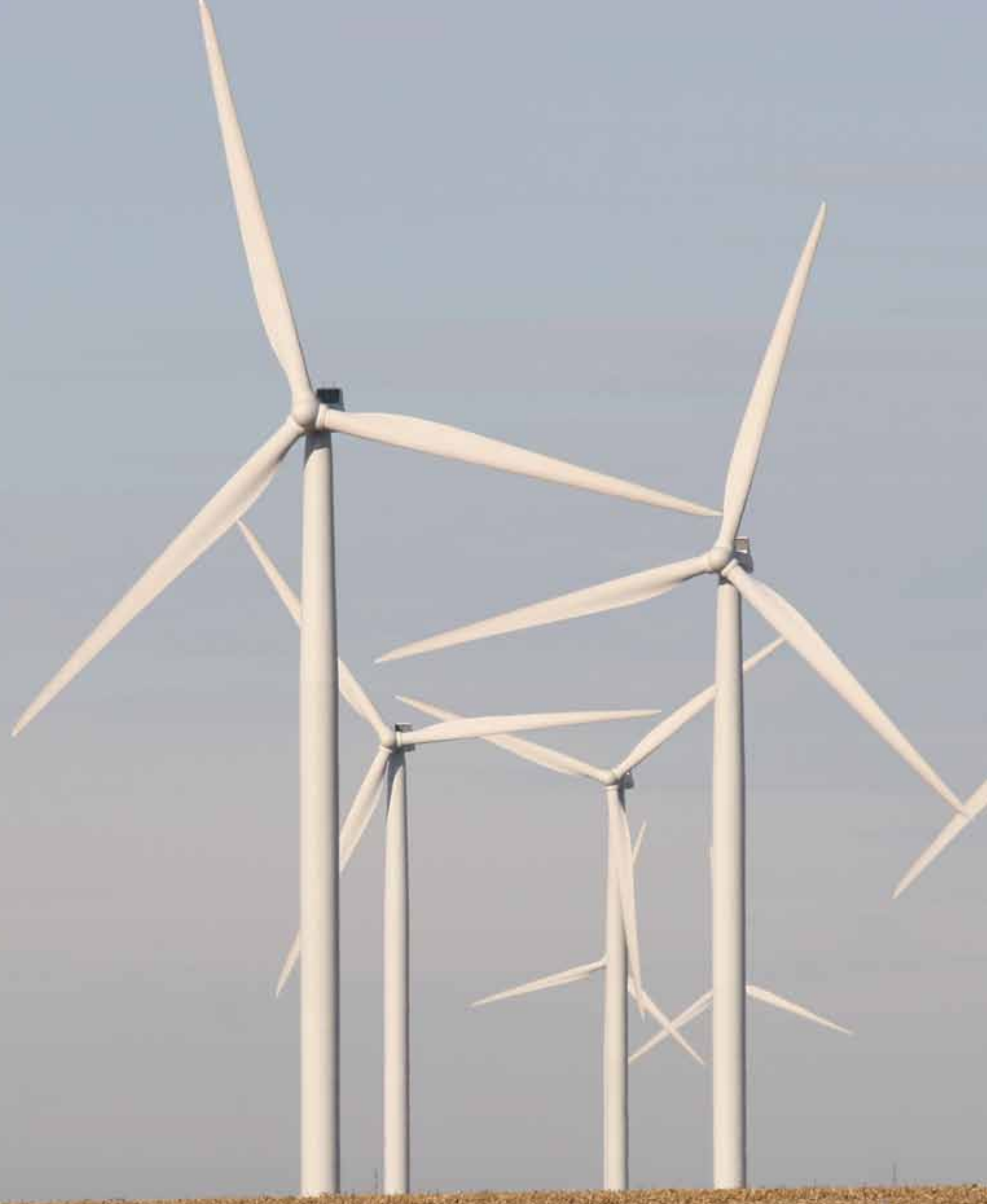

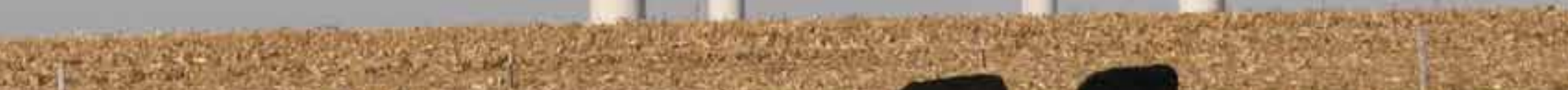

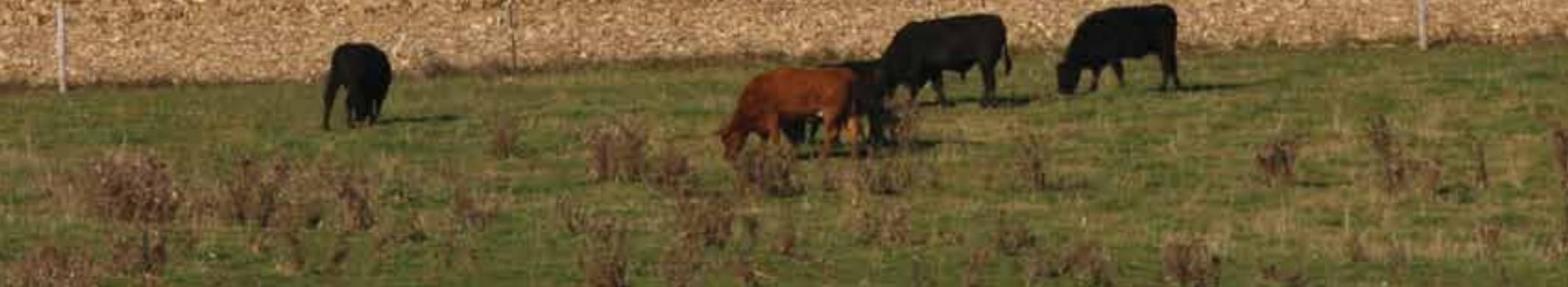




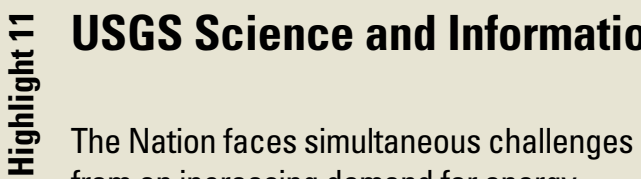 from an increasing demand for energy and a concomitant need to minimize environmental effects associated with energy resource development and utilization. The USGS addresses these challenges by supporting scientific investigations of conventional and alternative energy resources-for example, research on the geology of (1) oil, gas, and coal resources, (2) emerging resources such as gas hydrates, and (3) underutilized resources such as}

geothermal systems. The USGS also studies the effects associated with energy resource occurrence, production, and utilization. Unbiased, scientifically sound knowledge describing domestic and international energy resources is important to Federal, State, and local leaders for developing informed policies about commerce, the environment, and national security. The USGS is the sole provider of much of this information around the world. USGS study results provide impartial, robust scientific information

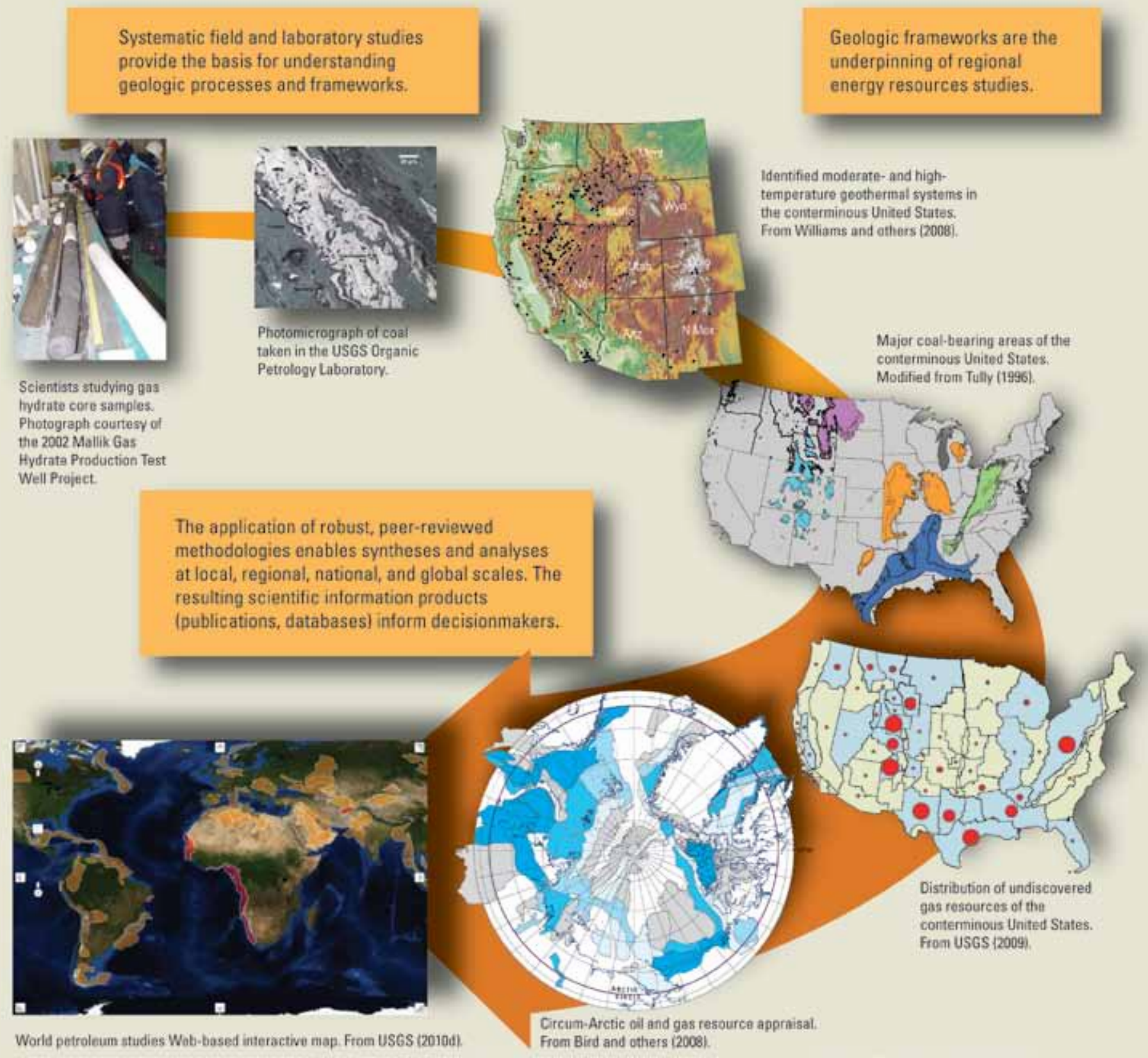




\section{Products and Outcomes}

\section{Periodic reports on the state of the Nation's earth resources}

The USGS will prepare periodic reports to summarize supply, consumption, and production trends, emerging needs, environmental or societal issues, and other key aspects of the Nation's energy, mineral, water, soil, and ecological resources. Data gathering will be coordinated across the USGS and augmented with the help of external partners where appropriate. The purpose is twofold: (1) provide decisionmakers and other customers with an integrated overview of the Nation's resource status in a global context and (2) summarize information that can be used to guide future USGS resource activities.

\section{Integrated multiresource assessments at local to global scales}

The USGS will prepare integrated assessments to provide policymakers and other users with fundamental information on key energy, mineral, water, soil, and ecological resources in a region of interest (highlight 11). Global assessments will provide context within which local- to regional-scale assessment activities can be prioritized and implemented. The assessments will require development and use of common geological, geochemical, geophysical, hydrological, and biological datasets, as well as collaboration among scientists across the USGS. These assessments will anticipate the costs and benefits associated with developing and using the resources by integrating appropriate economic, environmental, and health information. The USGS will need to partner with land managers and others in government and academia to develop the relevant cost-and-benefit methodologies.

\section{Integrated multiresource assessment of the world's ocean basins}

The USGS will provide an initial overview assessment of key energy and mineral resources in the world's oceans within the next 5 years. This assessment will include information on the geologic occurrences and spatial distribution of the resources and an overview of the potential ecological effects that could result from their extraction. Followup assessments involving more extensive collection of new data will target specific geographic areas, such as those areas with ecological sensitivity or multiuse conflicts or commodities with a high likelihood of development.

\section{Issue-driven resource assessments at local to global} scales

The USGS will maintain the staffing and funding flexibility to provide rapid resource assessments that address strategic and critical mineral resource needs at various scales. Examples include assessments of the national and (or) global occurrence of a mineral or energy resource for which demand is emerging and increasing, impartial assessments of potential environmental considerations in an area of future mineral or energy resource development, or multiple resource assessments and environmental baseline assessments of a particular Federal land unit such as a National Forest.

\section{Total resource endowment and life-cycle assessments of specific land units}

The USGS will work with land managers to develop the interdisciplinary methodologies needed to provide fullcost accounting of the total energy, mineral, water, soil, and ecological resource endowment of a particular region or Federal land unit. This assessment would provide resource managers and planners with an impartial view of the total and relative value of all resources in the area. Relative value would incorporate diverse factors such as economic costs and benefits, infrastructure development, and the costs of mitigating environmental effects of resource development. This is a particularly challenging product to create, given the difficulty in understanding the value of noncommodity resources, but the assessment methodology will be a critical tool to develop as multiuse demands on public land increase. 


\title{
Goal 4. Increase the Resilience of Communities to Geologic and Environmental Hazards
}

\author{
The expansion of population and \\ infrastructure into areas prone to geologic \\ and environmental hazards has dramatically \\ increased vulnerability to damage, injury, \\ and loss. In response, the USGS will improve \\ our monitoring networks, understanding and \\ assessment of hazards, and communication of \\ risk to the public. Increased collaboration with \\ communities, engineers, emergency responders, \\ and policymakers will support more effective \\ planning, reduce disaster cost, and increase \\ overall resilience to hazards.
}

Facing page. View of Mount Hood from Portland, Oreg. Volcanic threat is the combination of hazards (the dangerous or destructive natural phenomena produced by a volcano) and exposure (the people and property at risk from the volcanic phenomena). A recent ranking of U.S. volcanoes by threat level included Mount Hood among the 18 volcanoes at the highest threat level (Ewert and others, 2005). Photograph by Michael Wiley (http://en.wikipedia.org/wiki/ File:Bancorpmthood.jpg). 


\section{$\simeq$ Hazard Vulnerability, Risk, and Resilience}

USGS research on and monitoring of natural hazards help decrease vulnerability and risk and increase resilience when hazards occur. Although earthquakes, floods, hurricanes, landslides, tsunamis, volcanic eruptions, and other hazards occur in nature, a community's vulnerability and risk can be minimized and its resilience to natural hazards can be increased. The USGS response to the catastrophic Station fire of 2009 in the San Gabriel Mountains of southern California is an example of how USGS science has decreased vulnerability and risk. Within weeks of the fire, the USGS released a state-of-the-art hazard assessment showing which basins were most likely to produce the largest debris flows and which areas could be impacted by the flows (Cannon and others, 2009). This information was used by land managers and emergency-response agencies to prioritize mitigation approaches and plan for warnings and evacuations. Information provided by the USGS on the rainfall conditions that could lead to debris flows and floods from the burned area and data from real-time monitoring equipment installed in the most severely burned portions of the area were used by the National Weather Service (of the National Oceanic and Atmospheric Administration) to issue advisories, watches, and warnings and provided critical information to emergencyresponse personnel.

Conceptual diagram of societal risk from disasters. Modified from Wood (2007, fig. 3).

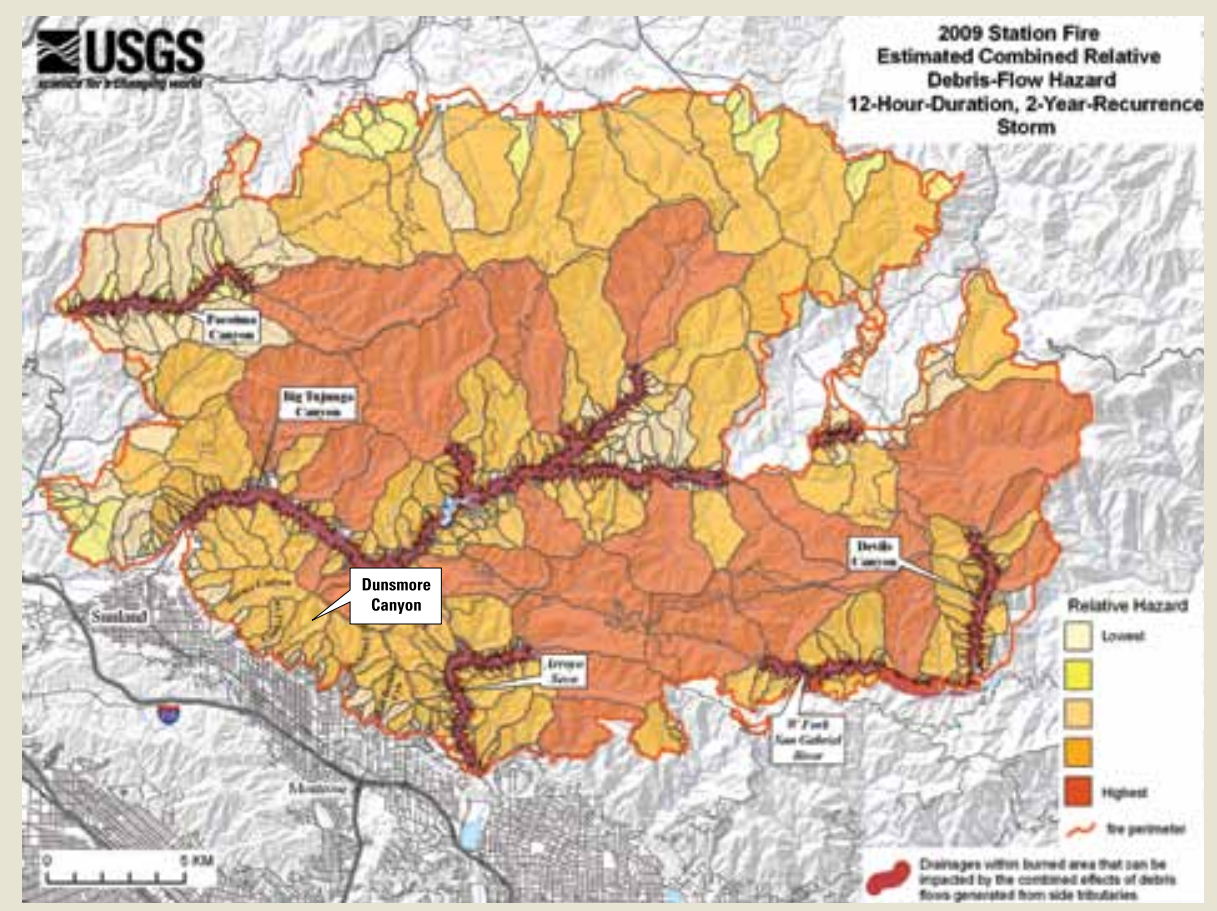

Combined relative debris-flow hazard ranking for basins burned by the Station fire in response to a hypothetical widespread, 12-hour-duration, 2-year-recurrence storm. From Cannon and others (2009, fig. 5B). Dunsmore Canyon (location of area shown below) is labeled.

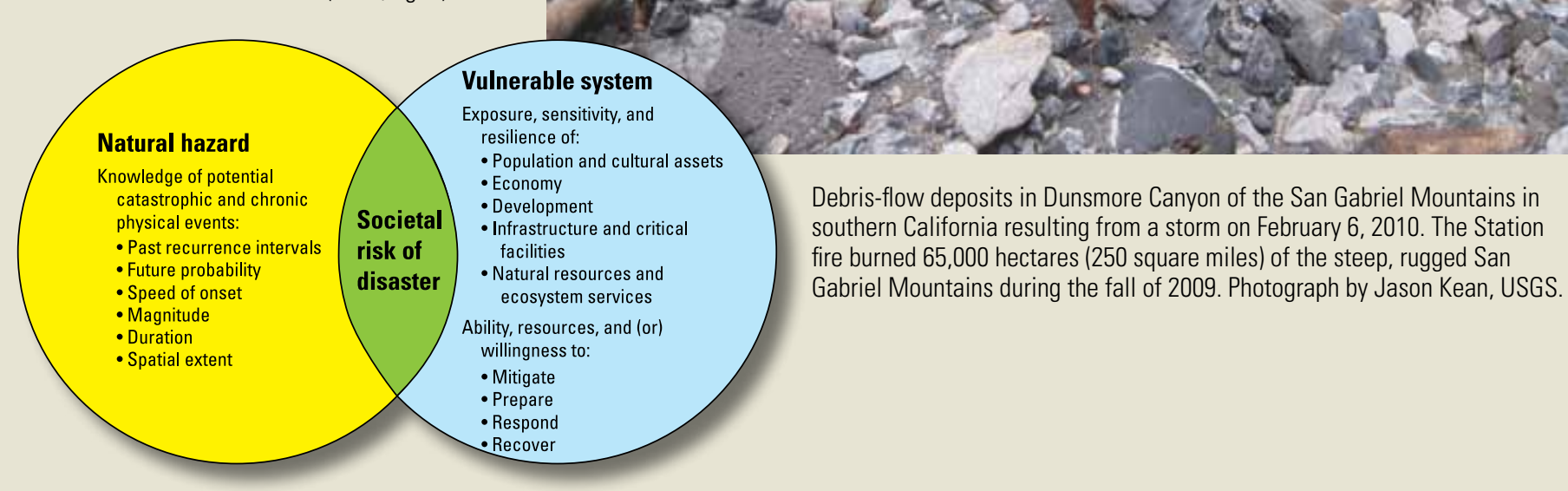




\section{Societal Needs and Benefits}

The vulnerability of the Nation to a spectrum of natural and anthropogenic hazards is increasing. Sudden events such as earthquakes, floods, hurricanes, landslides, tsunamis, volcanic eruptions, and wildfires pose immediate threats to people and the environment. They also have ripple effects that are often not anticipated, such as causing energy and food shortages. Longer term, chronic hazards such as sea-level rise, coastal erosion, and climate-related changes threaten our social structures, economy, and ecosystems. The costs of responding to disasters will continue to increase as population grows in hazard-prone areas such as coasts, flood plains, unstable terrain, and seismically active zones.

The USGS is well positioned to take on the challenges of hazards research in the next decade. The USGS has long been a national and global leader in understanding the basic processes of geologic hazards, as well as in monitoring, assessing, warning about, and responding to earthquakes, volcanic eruptions, and landslides. USGS seismic hazards maps inform the building codes adopted nationwide, and USGS alerts of volcanic activity are used by the U.S. Department of Defense, the Federal Aviation Administration (FAA), and airline pilots to keep air traffic safely flowing. The Volcano Disaster Assistance Program, a partnership between the USGS and the U.S. Agency for International Development, provides expertise, portable monitoring equipment, and crisis response for volcanic eruptions worldwide. The Global Seismographic Network, a partnership with the National Science Foundation and the Incorporated Research Institutions for Seismology, provides real-time data to the USGS National Earthquake Information Center and NOAA's tsunami warning centers, illustrating our capability in partnering and responding to global disasters. The USGS-NOAA debris flow warning system for wildfire-denuded hillslopes in southern California has been used for effective and highly targeted alerts of potential mud and debris flows, resulting in life-saving evacuations (highlight 12).

Hazard assessments are also critical for management of our public lands, and the USGS is taking the lead in providing risk-assessment information to DOI land and resource managers. USGS coastal mapping and modeling are being used to create hurricane-vulnerability maps and sea-levelrise-vulnerability indices that are used by the National Park
Service (NPS) and U.S. Fish and Wildlife Service (FWS) to develop management and response plans. The USGS has a mandated role in geologic hazards through the Disaster Relief Act of 1974 and the Earthquake Hazards Reduction Act of 1977 and subsequent reauthorizations. In addition, there is a growing role for USGS input to risk and resilience assessments associated with environmental hazards.

Certain geographic areas are vulnerable to multiple, unrelated hazards; for instance, a coastal community may be susceptible to both tsunamis and hurricanes. Other locations may be vulnerable to hazards that are linked through cause and effect, such as when vegetation removal by wildfire in the dry season may make a mountain community vulnerable to flash floods and debris flows in wetter periods. The multidisciplinary and multiprogram nature of the USGS fosters integrated scientific research that can be used to understand how multiple hazards in an area are linked and to communicate the overall risks associated with these multiple hazards. The recently established USGS Southern California Multi-Hazards Demonstration Project uses an interdisciplinary approach and strong collaborations with community partners to understand, assess, and increase resilience to the multiple natural hazards in that region.

The complexity of multiple hazards creates certain organizational challenges. USGS responses to Hurricane Katrina (2005) and the 2007 southern California wildfires characterized the inherent geological, hydrological, chemical, ecological, and health hazard challenges of such events and highlighted the power of linked geologic and environmental hazards responses to disasters. Each USGS discipline brought an extensive mix of expertise, data, and technologies to these problems that collectively made the USGS unique among all Federal agencies in the strength and breadth of its hazards capabilities. However, the Katrina and wildfire responses also illustrated the policy and funding challenges faced by the USGS in bringing expertise to bear from throughout the organization. In order to achieve the goals of the USGS science strategy, we will need to better integrate our activities, engaging and enabling scientists across the USGS to develop holistic assessments of individual and multiple hazards and place them in a timely and useful context for decisionmakers. 


\section{$\stackrel{m}{=}$ Volcano Threat to Aviation-The Creation of NVEWS}

Dangerous encounters of aircraft with volcanic ash in the 1980s caused engine failures and led to the realization that there are no "remote" volcanoes with respect to aviation. Airplanes are vulnerable to volcanic ash clouds from explosive volcanic eruptions. Approximately half of the 169 active and potentially active volcanoes in the United States are dangerous because of their proximity to communities and infrastructure. The USGS, in partnership

\section{with the Consortium of U.S. Volcano} Observatories, is creating a coordinated volcano monitoring network, called the National Volcano Early Warning System (NVEWS). The goal of NVEWS is to reduce community and air traffic vulnerability to volcanic hazards by connecting the monitoring and research efforts of USGS scientists and its partners with decisionmakers, emergency managers, the Federal Aviation Administration, and the general public.

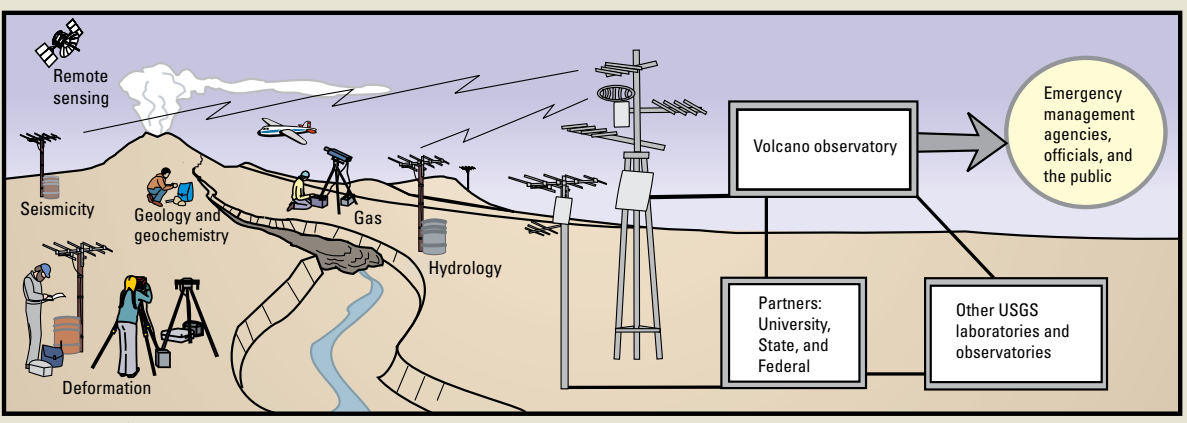

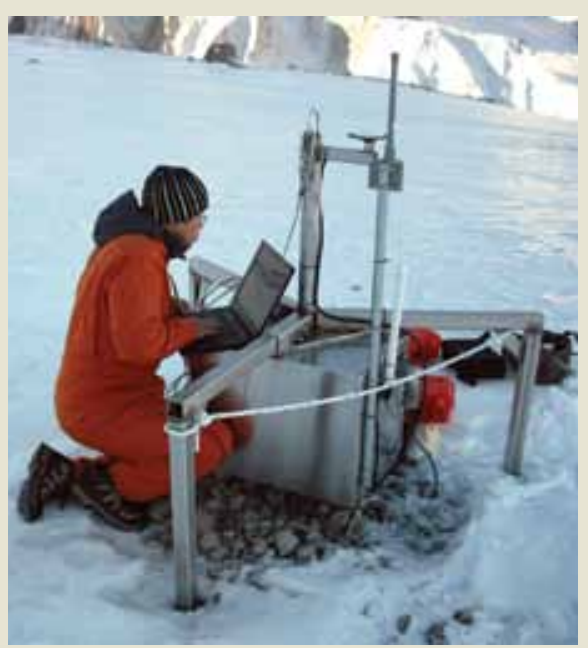

Graduate student Mingsen Xu checks on a spider (spindly frame holding an instrument) in the crater of Mount St. Helens Volcano, Wash. Photograph by Rick LaHusen, USGS, 2009.

How the National Volcano Early Warning System will work. From Ewert and others (2005, fig. 2).

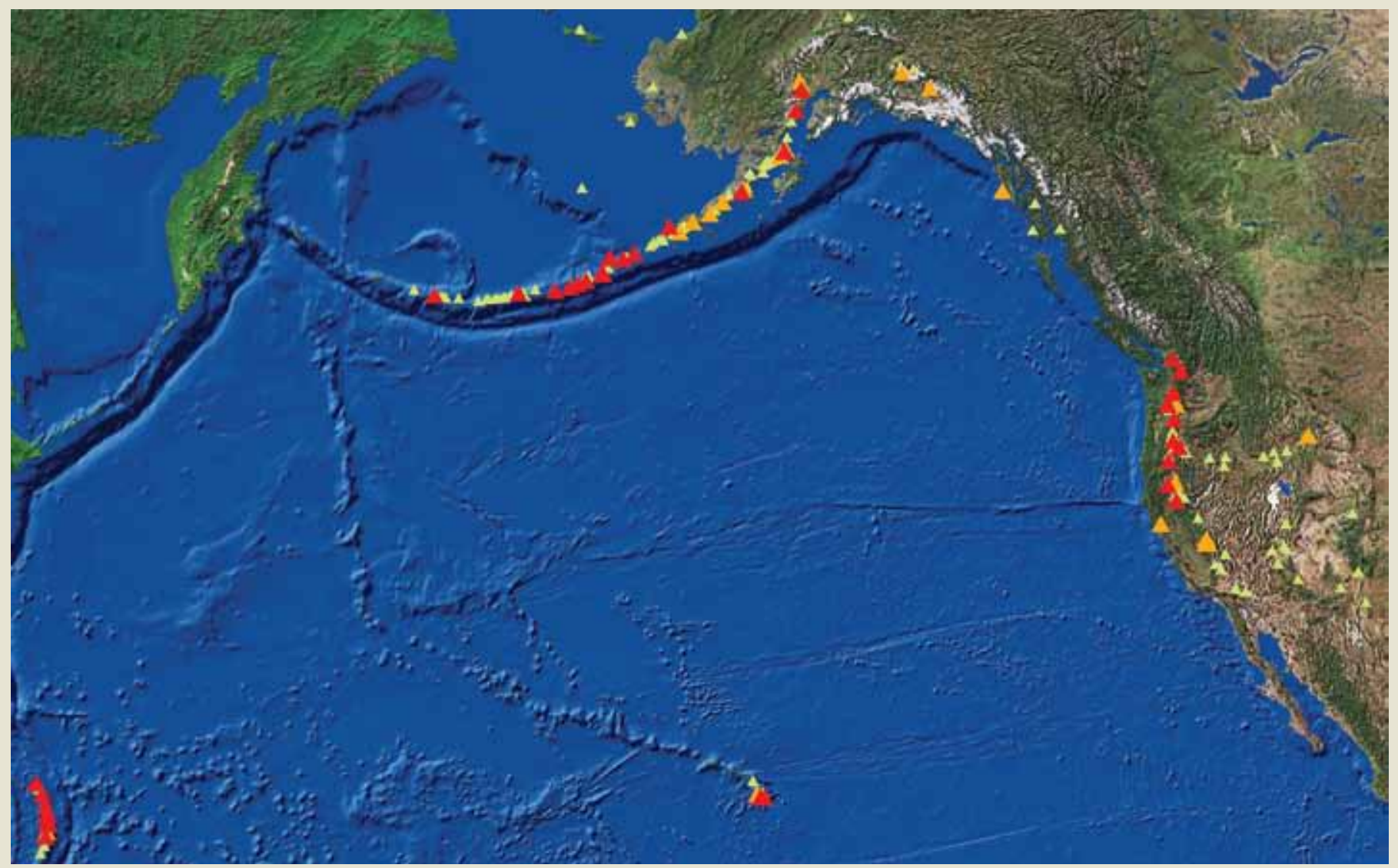

Locations of active and potentially active U.S. volcanoes. Colors indicate priority for monitoring: highest, red; high, orange; other, green. From USGS (2010b). 


\section{Strategic Actions}

\section{Conduct targeted hazards research that will lead to next-generation monitoring and assessment capabilities}

Understanding the processes controlling hazards is essential to our ability to assess those hazards, provide hazard and disaster information when and where needed, understand risk, and forecast events. The USGS faces increasing public demand and expectations for its monitoring systems, hazards assessment, and communication products. For the USGS to meet this demand in the future, it must maintain its traditional strength in supporting both internal and external research on a wide range of geologic hazards, research that has underpinned the successes to date and is critical to continuous improvement of our monitoring networks and assessment methodologies. Research investigations will target geographic areas of greatest vulnerability and outstanding opportunities for scientific discovery focused on the following topics: developing hazard early warning technology; understanding the natural processes and human actions that can produce hazards and increase or reduce risk; improving hazard models, simulations, prediction, and forecasting; quantifying uncertainty; and understanding past and future rates of hazard occurrence.

\section{Improve and expand capability in hazard monitoring, warnings, and prediction}

Monitoring is vital to understanding the fundamental processes that cause hazards and increasing our ability to issue timely and adequate warnings. The USGS will make new investments in expansion and modernization of our monitoring networks, including the Advanced National Seismic System, the Global Seismographic Network, the National Volcano Early Warning System (highlight 13), and the USGS geomagnetic observatories. Other emphases include expansion of our geodetic capabilities and use of radar- and laser-based remote sensing. These investments will take advantage of improvements in sensor and telecommunications technology to provide real-time and early warning systems. The goal of an early warning seismic system, for example, is to reduce the time needed for detection and notification such that warning messages arrive before damaging shaking. Goals of volcano monitoring systems are to provide the earliest possible (weeks to months) detection of volcano deformation and unrest, giving communities and aviation authorities time to prepare for likely eruption scenarios; to provide short-term warning (hours before to minutes after onset) of an eruption; and to acquire and share data from real-time tracking of the progress of the eruption. The USGS will also support the development and use of state-of-the-art technology for measuring, analyzing, and monitoring the Earth through continued investment, training, and collaboration with partners. Our focus will also be on improving instrument sensitivity, portability, automation, and longevity. We will coordinate with, and take advantage of, unique research opportunities with the NSF-funded Earthscope facilities and integrate our diverse monitoring networks where advantageous. New partnerships will be developed to expand the USGS-NOAA debris flow warning system to other vulnerable parts of the country, such as the Pacific Northwest, and to continue work with NOAA on understanding tsunamis and improving the tsunami warning system. Increasing our understanding of and providing effective warnings for the potential magnitude and location of aftershocks from large earthquakes will also be a future emphasis.

\section{Incorporate multiple hazards, vulnerability, risk, and resilience into USGS hazard assessments}

The core USGS hazards mission will continue to be providing effective warnings through monitoring, assessment, and targeted research, with the goal of delivering the best possible hazards information when and where it is needed. In the case of hazard assessments, an important step toward making the hazard more real to decisionmakers and the public alike is the addition of information about risk and vulnerability. This information also makes it possible to prioritize mitigation measures and to aid decisionmakers in focusing their hazard response efforts. Translating hazard science into risk and vulnerability assessments will entail reaching out to partners inside and outside the USGS to engage economic and social science expertise. We will build partnerships to develop methodologies to incorporate new information, such as inventories of housing, societal demographics, transportation infrastructure, and economic considerations, into hazard assessments to better portray and understand vulnerability, risk, and potential community resilience. The USGS will continue to build capability into systems such as PAGER (Prompt Assessment of Global Earthquakes for Response) that include information on potential loss of life and property.

In order to improve their emergency response plans and, ultimately, their resilience, communities also need information on the entire range of geologic and environmental hazards to which they are vulnerable. The USGS is uniquely positioned to provide such multiple-hazard assessments and convey the associated risk and will build on the success of the Southern California Multi-Hazards Demonstration Project by extending its application to other areas of the country. Effective communication of the risk associated with hazards and community vulnerability will entail collaboration within and outside of the USGS to build shared communication products and strategies. An emphasis will be on building effective hazard scenarios to understand and improve mitigation and response. 
4. Develop a formal interdisciplinary science capability to rapidly respond to disasters

Geologic, environmental, and anthropogenic disasters affect the economy, infrastructure, and people of the Nation. Perishable evidence is left behind in the wake of these events that, if investigated promptly, can be used to understand the recent event and to help anticipate the effects of future disasters (see map of Manhattan on facing page). The USGS will establish a formal, bureauwide, rapid-response capability to comprehensively document a broad range of destructive events and help to characterize their environmental and human-health effects. The exact roles and responsibilities of the USGS will be determined through cooperation with appropriate Federal, State, and local agencies. This capability, which will draw upon expertise from across the USGS, should include plans and funding for the initial disaster response and complementary analyses; release of preliminary data and interpretations; longer term monitoring; eventual publication of results in the scientific literature; and followup research as appropriate.

Facing page. Spectral shape map of lower Manhattan, September 16, 2001. Two days after the September 11, 2001, attack on the World Trade Center (WTC), the USGS was asked by the U.S. Environmental Protection Agency and the U.S. Public Health Service to conduct a rapid remote sensing and mineralogical characterization study of lower Manhattan around the WTC to help emergency response teams. The study was conducted in cooperation with the National Aeronautics and Space Administration and the Jet Propulsion Laboratory. Preliminary results were released to emergency response teams on September 18 and September 27, 2001. The map of lower Manhattan shows spatial variations in the reflectance characteristics of concrete, gypsum, and iron-rich materials after the WTC collapse. The image indicates that the dust plume generated by the building collapse generally traveled to the south-southeast from the WTC (white numbers 1 and 2 indicate where the towers stood). It also shows that heavier, coarser materials with abundant concrete and steel (dark red and yellow pixels) tended to settle closer to the WTC than lighter, finer particles composed of powdered gypsum wallboard, concrete, glass fibers, and paper (blue, aqua, green, and orange pixels). For more information, see Clark and others (2001). 


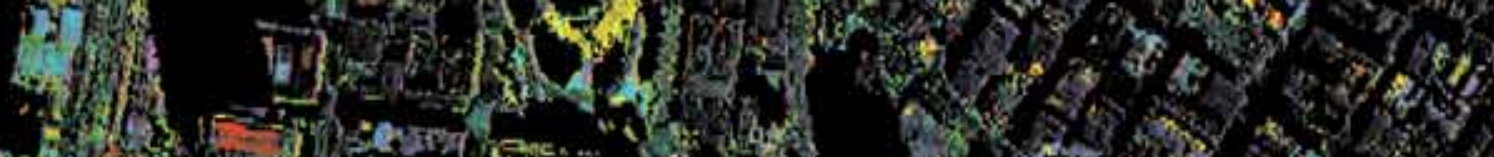
axs

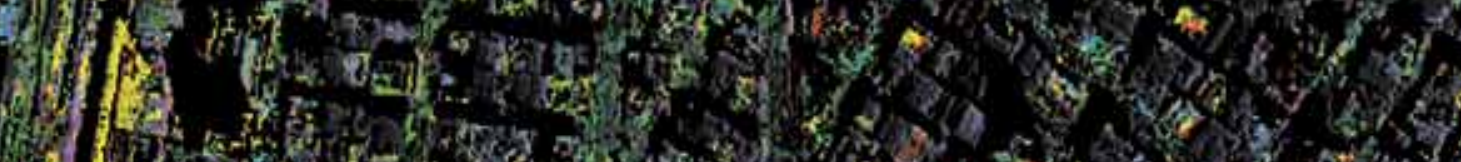

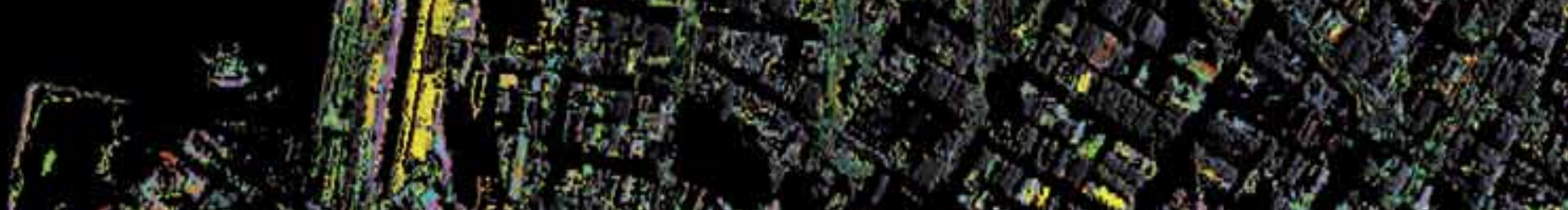

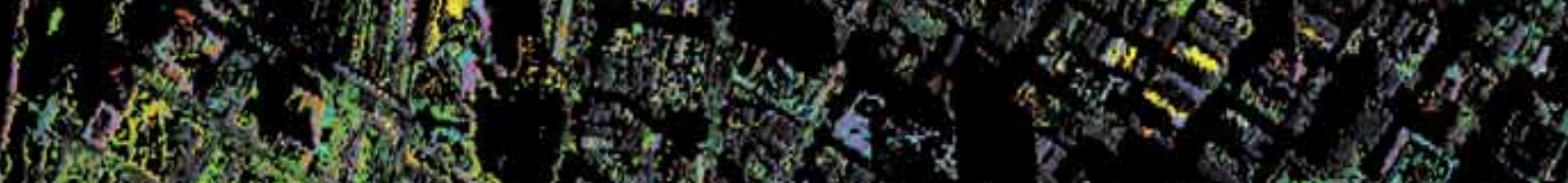

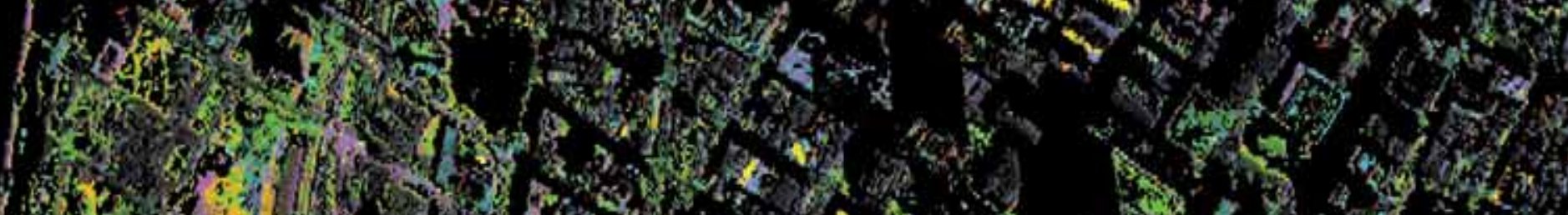

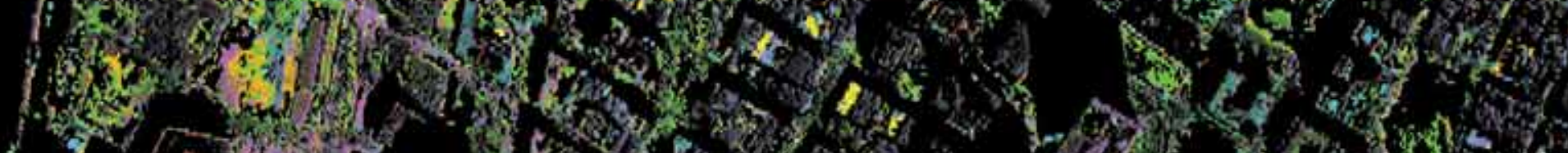

$\rightarrow$ on

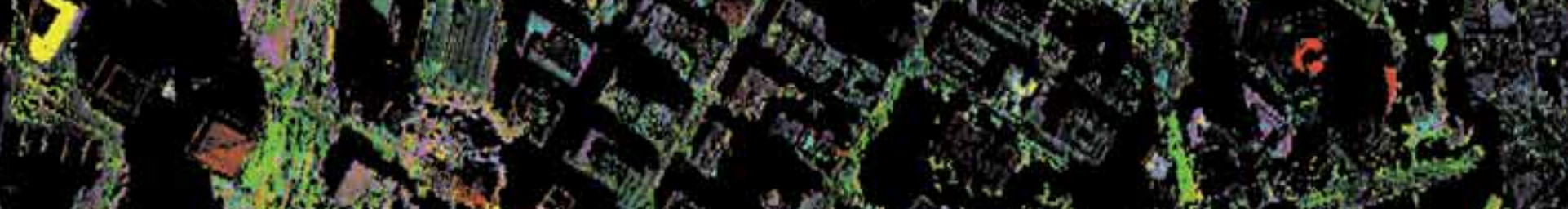

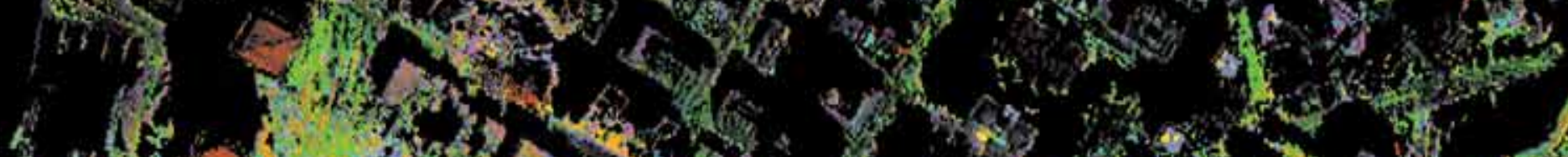

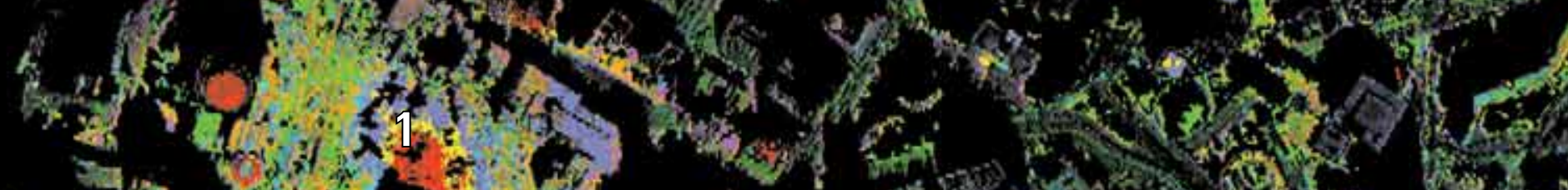

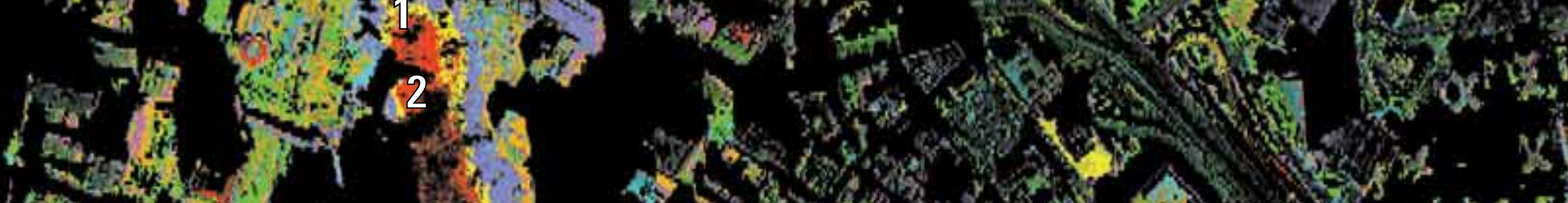

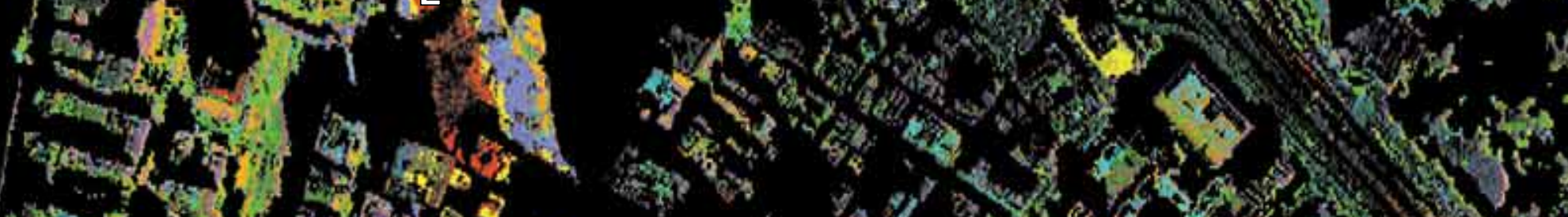

15. - 4015 ,

s. 争

(1)

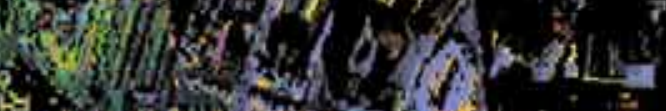

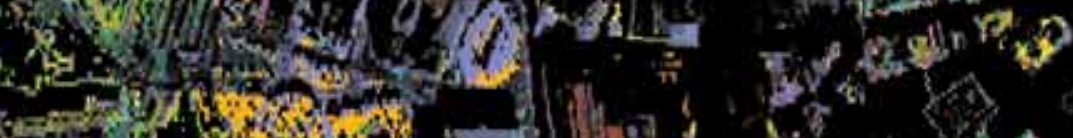
The

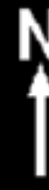




\section{\pm Understanding and Forecasting Coastal Change From Extreme Storms}

Beaches serve as a natural barrier between the ocean and inland communities, ecosystems, and resources. These dynamic environments move and change in response to winds, waves, and currents. During extreme storms, such as hurricanes and nor'easters, changes to the beach can be large, and the

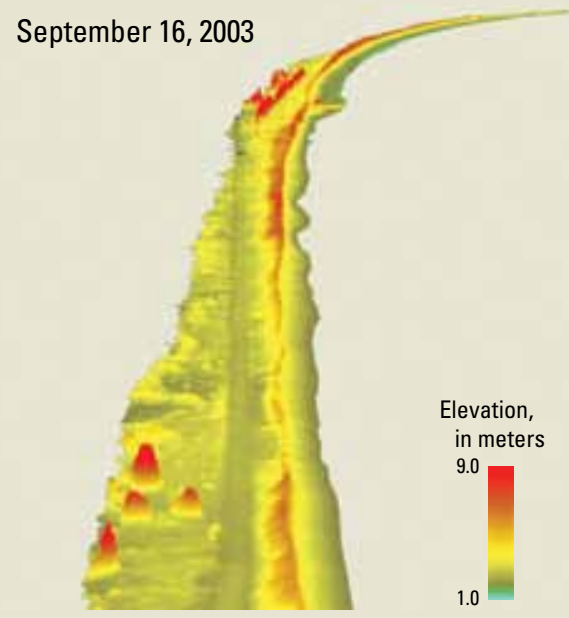

results are sometimes catastrophic. Lives are lost, communities are destroyed, and millions of dollars are spent on rebuilding. USGS coastal hazards research is identifying coastal areas that are likely to undergo dramatic coastal change during extreme storm events. This includes determining the risk level

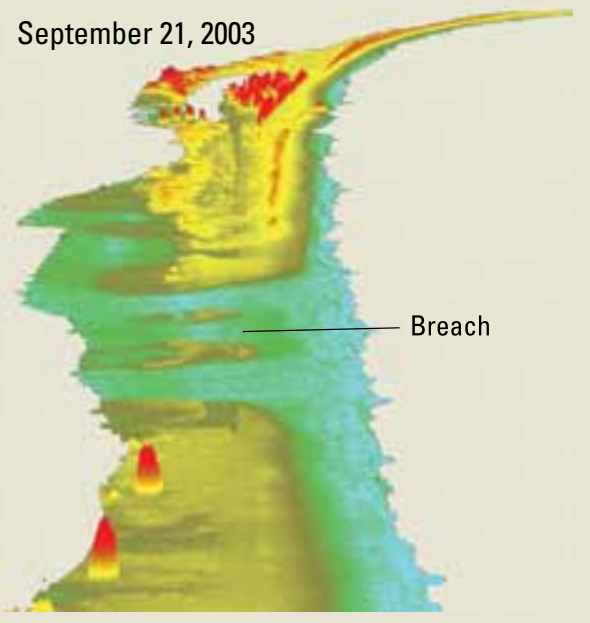

associated with human development and infrastructure. The USGS provides scientific support for both extremestorm planning and post-storm response. Using observations of beach changes and models of waves and storm surge, predictions of the coastal response and identification of vulnerable areas can be made.

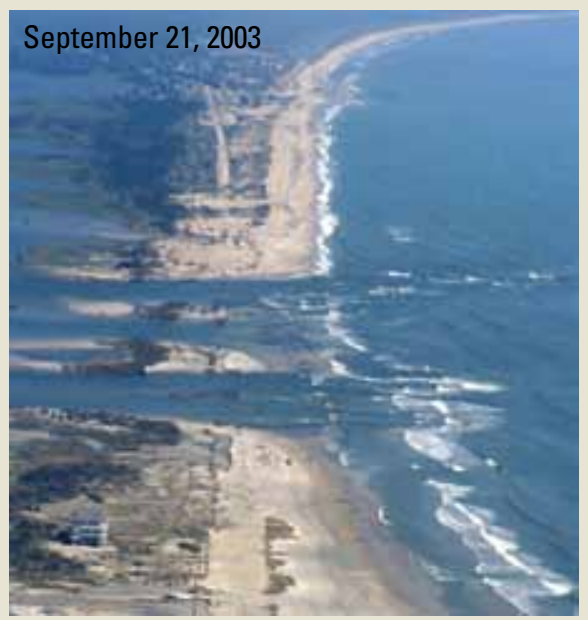

Observations of coastal change during storms has led to increased understanding of the characteristics and distribution of vulnerable areas. Waves and surge during Hurricane Isabel in 2003 battered an area of low, narrow dunes and created a 500-meter-wide breach that cut road transportation and utilities to and from the village of Hatteras, N.C. From Stockdon and Sallenger (2010).
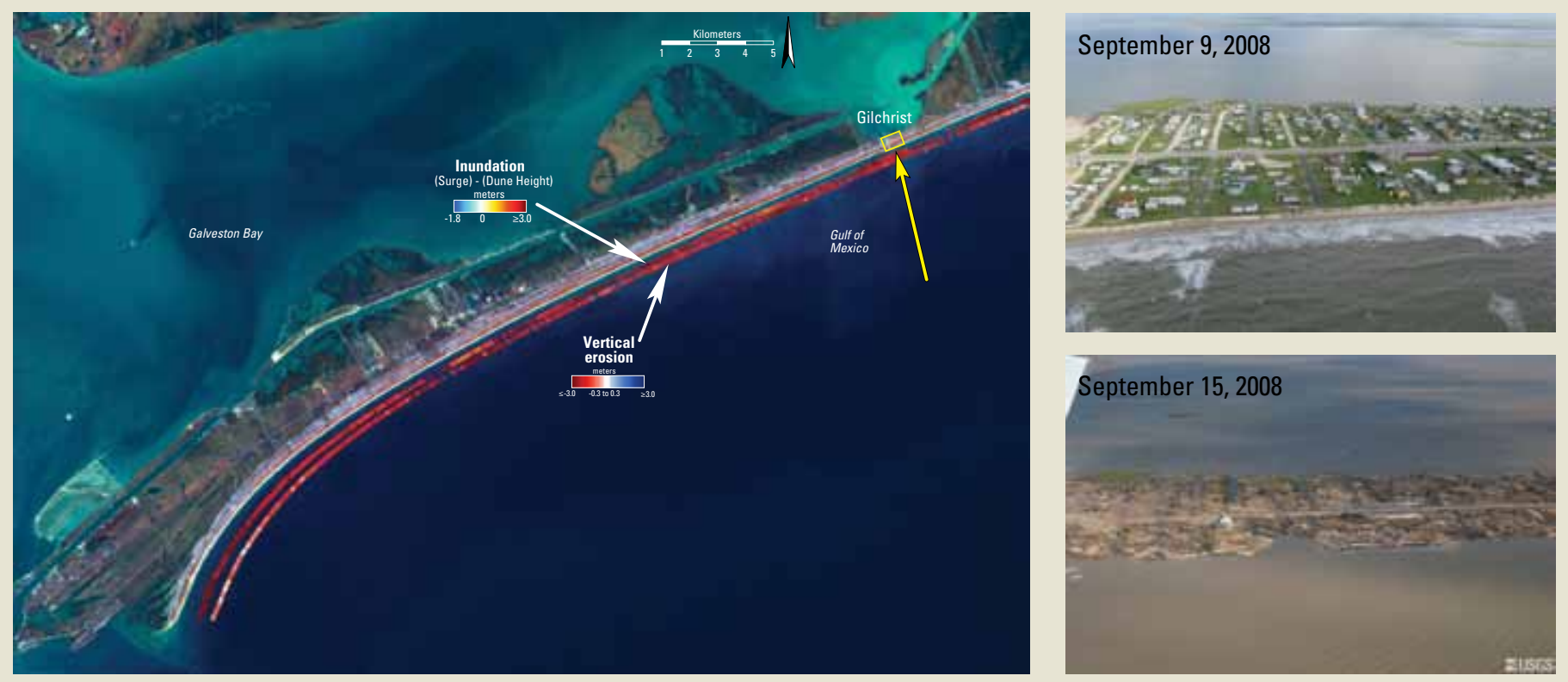

The USGS predicted that the beaches on the Bolivar Peninsula, Tex., would be inundated by storm surge during Hurricane Ike in 2008 and would undergo large magnitudes of erosion. The map above shows predictions of inundation exceeding 2 meters ( 6.5 feet) along much of the coast. Comparisons of photographs from before (top right) and after (bottom right) the storm reveal extensive structural damage, as well as signs of water flow over the island and subsequent erosion. Measurements of elevation changes due to the hurricane indicate widespread erosion and an almost complete destruction of the seaward dune, likely increasing vulnerability to future storms. Accurate forecasts of the coastal response to hurricanes play an essential role in successful mitigation and resiliency planning. From Stockdon and Sallenger (2010). 


\section{Products and Outcomes}

\section{Research on the processes that lead to hazards}

USGS geologic hazards research priorities should include building realistic and reliable physically based models of earthquake, volcano, landslide, tsunami, and inundation processes (highlight 14). Areas of priority include understanding and modeling coastal inundation and erosion processes, volcanic eruption processes, rates, and cycles, debris flow cycles and triggers, earthquake initiation and ground motion, toxicity characteristics of materials generated by disasters, and hazard prediction and uncertainty. Such research relies on increased investment in new computational and observational technologies, including partnering for capabilities in high-powered computing, hyperspectral imaging, interferometric synthetic aperture radar (InSAR) surveying, deploying Global Positioning System (GPS) receivers, seismic monitoring, and high-resolution lidar surveying.

\section{Improved alert and warning capabilities from} expanded and integrated monitoring networks

Monitoring networks are necessary to deliver alerts and warnings when and where needed. They also provide data that underpin hazard assessments. Effective monitoring entails investment in both in situ and remote-sensing instrumentation, network transmission paths, data processing, and data-distribution systems for rapid response. Substantial leveraging of current USGS capabilities will be achieved through full implementation of the Advanced National Seismic Network and the National Volcano Early Warning System and by facilitating citizen-scientist observation networks (for example, Did You Feel It? and other interactive Web tools). The USGS should continue to pursue effective partnerships with NSF in global seismic monitoring, with NOAA to support its national and global tsunami warning systems, with FAA and NOAA to provide ash cloud warnings to aircraft, and with multiple agencies to enhance geodetic monitoring capabilities; the USGS should also develop partnerships with NOAA and other Federal and State agencies to build a national landslide monitoring network. There will be an effort to maximize the amount of data and information that is cataloged, retained, and accessible online via an easy-to-use search mechanism. A continuous around-the-clock multiple-hazard watchoffice capability will be established at the earliest possible opportunity with an emphasis on partnerships and integration of monitoring network data streams where appropriate, such as for earthquake and volcano seismicity.

\section{Hazard and risk assessments tailored to user needs}

Hazards assessment will evolve toward an increasing emphasis on probabilistic assessments of individual and multiple hazards, multiple-hazard assessments, time-dependent hazard maps, and vulnerability and risk-assessment maps. Moving beyond traditional hazard assessments to address vulnerability, risk, and, ultimately, resilience will require the USGS to develop new capabilities or access them through partnerships. The USGS already has a unique range of expertise, and partnerships will allow us to conduct studies of sustainability and resilience using geospatial analysis of the relations among hazards, land use, and environmental systems. New hazard assessments will be prioritized relative to the associated risk to communities, albeit with recognition that exposure to hazards is not limited to proximal threats. For instance, remote volcanoes can threaten global air traffic, and earthquakes, landslides, and volcanoes far from urban areas can sever key transportation corridors. Riskbased interdisciplinary products that address multiple-scale scenarios will support communities in land-use planning and emergency-response coordination. To further support community resilience, the USGS will become a resource and clearinghouse for best practices learned during recovery from natural disasters. Environmental and health hazards assessments will become an integral component of USGS natural-hazards assessments, contributing to the understanding of mitigation and resiliency to anthropogenic hazards.

\section{Communication products that provide hazard} information when and where it is needed and that promote disaster resilience and risk-wise behavior

USGS hazards information represents an important public face for the USGS, as millions of people visit the hazard Web sites, and thousands receive alerts directly through various media. Going forward, the USGS will continue to find new pathways for effectively disseminating its hazard information, including a common Web portal for partners, stakeholders, and the general public. This portal will facilitate robust access to diverse information including hazard descriptions, hazard assessments and maps, and near-real-time data. Development of a common information technology (IT) infrastructure across the geographically and organizationally diverse workforce of the USGS will facilitate interoperability and access to data and information. Outreach on hazards issues, currently performed mainly at the program or observatory level as resources permit, will be supplemented by a more formal program of outreach in which the USGS partners with other Federal agencies active in the hazards arena (NOAA, FAA, Federal Emergency Management Agency (FEMA), U.S. Environmental Protection Agency (EPA), Smithsonian). There will be increased use of targeted, general-audience products such as "Putting Down Roots in Earthquake Country" (USGS, 2005, General Information Product 15) to guide hazard-avoidance and adaptation strategies and increase community resilience. An emphasis will also be placed on partnering to conduct scenario-based emergency exercises such as the Great Southern California ShakeOut (see highlight 2). 
Goal 5. Apply the Most Advanced Technologies and Best Practices To Effectively Acquire, Analyze, and Communicate Our Data and Knowledge

USGS scientists create a wide variety of important and unique data. Our ability to acquire, analyze, and share this information is critical to the achievement of USGS and DOI missions, the work of our collaborators, and the public welfare. The USGS will comprehensively manage scientific data and knowledge from collection through communication, adopt or develop advanced approaches to analyze and disseminate data, and provide facilities, training, and tools for users. 


\section{New Efforts in Data and Technology-The USGS Integrated Data Environment}

Geosciences information comes from many varied sources and disciplines and resides in widely distributed databases in government agencies at the local, State, and Federal level, as well as in universities, nongovernmental organizations, and the private sector. Modern informatics designers have developed the concept of service-oriented architecture (SOA) to connect disparate databases into a flexible information management system where interoperability, information exchange, and information and application technologies are intrinsically linked. For the USGS, the basic components of such a system could include a central catalog of USGS data sources that contains consistent metadata about each data collection; discovery and analysis tools; and access to databases with high-quality metadata that utilize common vocabularies and Web services that provide tools for interoperability such as the Web Feature Service (WFS), Web Mapping Service (WMS), and Web Coverage Service (WCS) implementation standards developed by the Open Geospatial Consortium, Inc. ${ }^{\circledR}$ (OGC; http://www.opengeospatial.org/).

USGS scientists are working with members of the informatics community (Brady and others, 2008) to tackle the many chal- lenges to such an infrastructure including the following: creating common standards and protocols across diverse information suppliers; discovering and linking to the vast number of distributed data resources; establishing practices for recognition of and respect for intellectual property; developing distributed integrated catalogs and sustaining a central catalog; building mechanisms to encourage development of Web service tools for analyses and exchange; and sustaining business models for continuing maintenance and evolution of information resources and analytical tools.
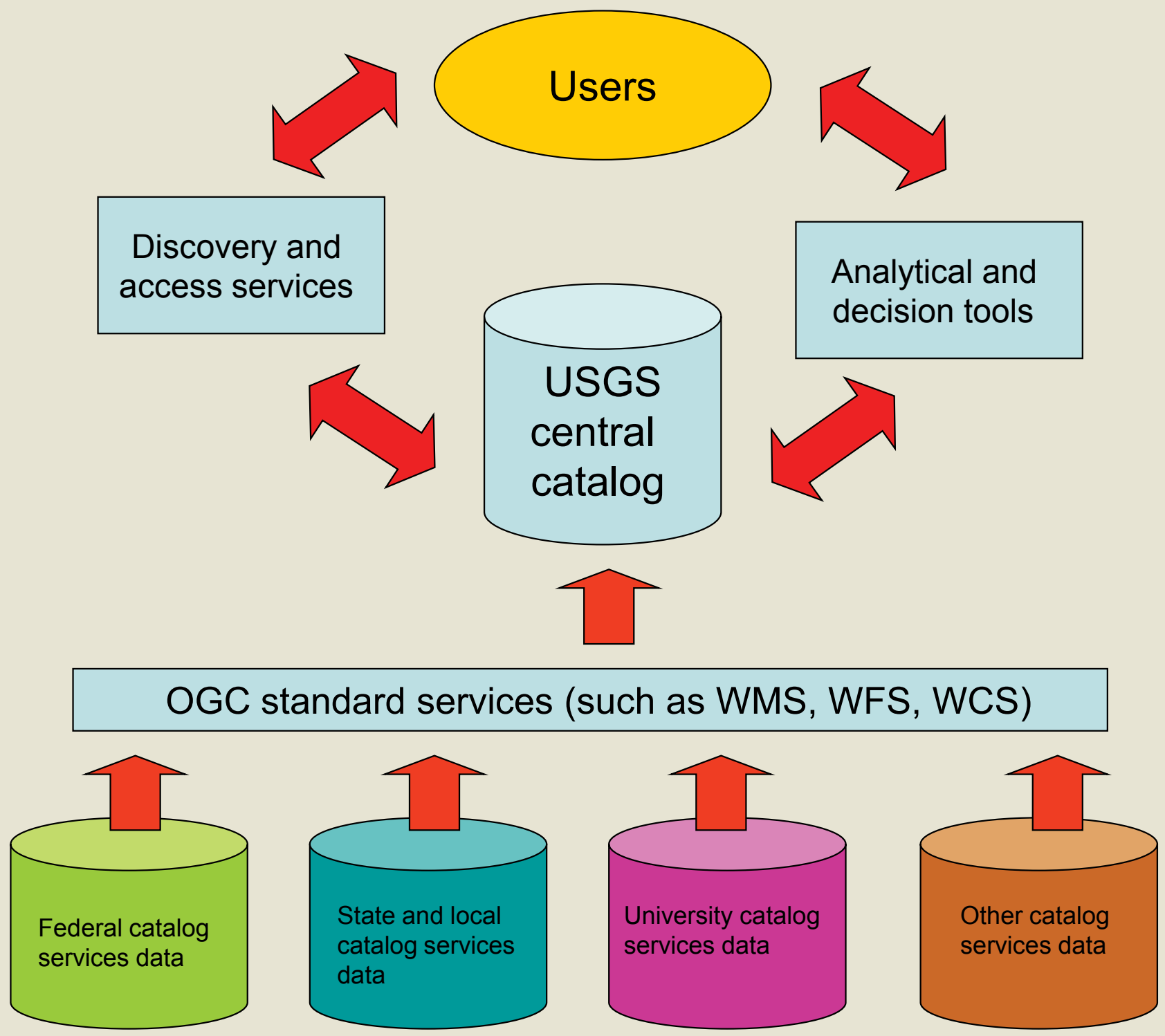

Diagram of a possible USGS integrated data environment. 


\section{Societal Needs and Benefits}

Data and materials collected by USGS scientists and our partners are fundamental building blocks of the scientific enterprise. The amount of complex data and materials produced by individual scientists and monitoring systems often exceeds our ability to use, preserve, and disseminate it beyond our projects and programs. USGS scientists convert data to knowledge through a sequence of steps including organization, integration, analysis, and interpretation, resulting in the ability to understand, model, and predict Earth processes. The success of these endeavors depends on our ability to communicate knowledge to our partners and the public in a way that they can understand and use. We must adopt and develop new information and communication technologies and work collaboratively to develop common standards and methods to find and integrate data. We must support and help create an integrated network for scientific exchange and data and material preservation (highlight 15). These tasks will involve working closely with users of USGS data and collections to provide services and science in more clear and usable forms. This step is an often neglected aspect of knowledge gathering, but it is critical to transferring our knowledge and providing services and science for decisionmaking.

The USGS currently disseminates many large and unique geological databases through the World Wide Web. We are also involved in national and international efforts to create global standards for data. For example, the USGS recently published standards for geologic map symbols to be used in State and Federal agencies nationwide (USGS, 2006) and participated in an international working group to create GeoSciML, a markup language that allows seamless integration of digital geologic maps. The USGS will continue to participate in community data repositories and networks such as the Incorporated Research Institutions for Seismology Data Management System for seismic data; EarthChem for geochemical data; and the Global Earth Observation System of Systems for satellite and other Earth-monitoring networks.

For our stewardship and dissemination efforts to be successful, they must begin with individual scientists entering metadata into an integrated information environment being developed for all of the USGS. This environment will increase collaboration among researchers and provide greater integration of the vast stores of USGS scientific data and materials. As stressed in the USGS science strategy, data integration across scientific disciplines and geographic, temporal, and political boundaries is vital to the future success of the USGS. Providing metadata and understanding the quality and uncertainty of data are essential in creating robust models. Further, increased participation of geologists in landscape and ecosystem modeling is needed to improve the representation of geologic parameters such as geomorphology and geochemistry as they affect ecosystem form and function.

The materials we collect and create in the course of our studies (including rocks, soils, fossils, cores, geophysical logs, and seismic profiles) must be preserved in systematic ways to be useful to future generations of scientists. Repositories across Federal and State governments, academia, and industry are struggling to manage the materials collected during many years of research and exploration. The USGS is partnering with States and industry to create a networked system of repositories and also to rescue data and materials in danger of being lost. We will need to invest in upgraded repositories and to partner with the Smithsonian, Federal and State agencies, academia, and industry to more effectively preserve these priceless data and materials.

Access to the best tools to collect and analyze data supports innovation and increases the quality of our science. Access to leading-edge technology will require strategic investment and management. New technologies in laser-based instrumentation allow analysis of very small amounts of material and produce very high resolution surveys of topography and rock properties. Laptop computers, hand-held data collectors and analyzers, and Global Positioning System (GPS) technologies provide real-time digital data collection, transmittal, organization, and analysis. New remote-sensing methods and sensors acquire data from inaccessible areas and provide global coverage. Faster computer processors and storage and memory technology are expanding the capability to analyze and model data. Much of this technology requires new expertise and training, as well as new investments and joint ventures with partners. 


\section{ShakeMap and PAGER}

Immediately following a large earthquake, information is needed on the extent and severity of strong shaking and the likely impacts on people and infrastructure. Improvements in seismic monitoring, coupled with advances in real-time data analysis and information technology, have enabled the USGS and its partners to develop a growing suite of earthquake information products. Produced and released online within minutes of any large earthquake, these products provide situational awareness well in advance of news accounts or onsite evaluations. ShakeMaps are near-real-time maps of ground motion and shaking intensity, providing an immediate synopsis of the region affected by shaking. PAGER (Prompt Assessment of Global Earthquakes for Response) provides near-real-time estimates of the human impacts resulting from significant earthquakes around the world and alerts emergency responders, government and aid agencies, and the media about the estimated ranges of fatalities and economic losses caused by an earthquake (Wald and others, 2010).

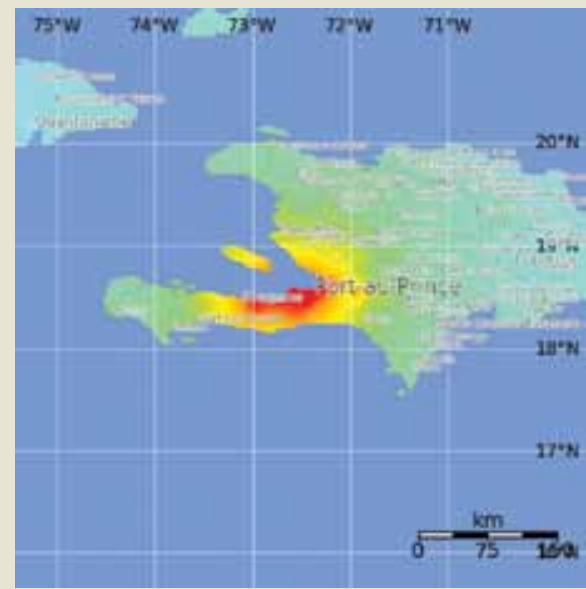

Shaking intensity map of the magnitude 7.0 earthquake in Haiti on January 12, 2010. From USGS (2010c).

Population exposure map of the magnitude $7.0 \rightarrow$ earthquake in Haiti on January 12, 2010. From USGS (2010c).

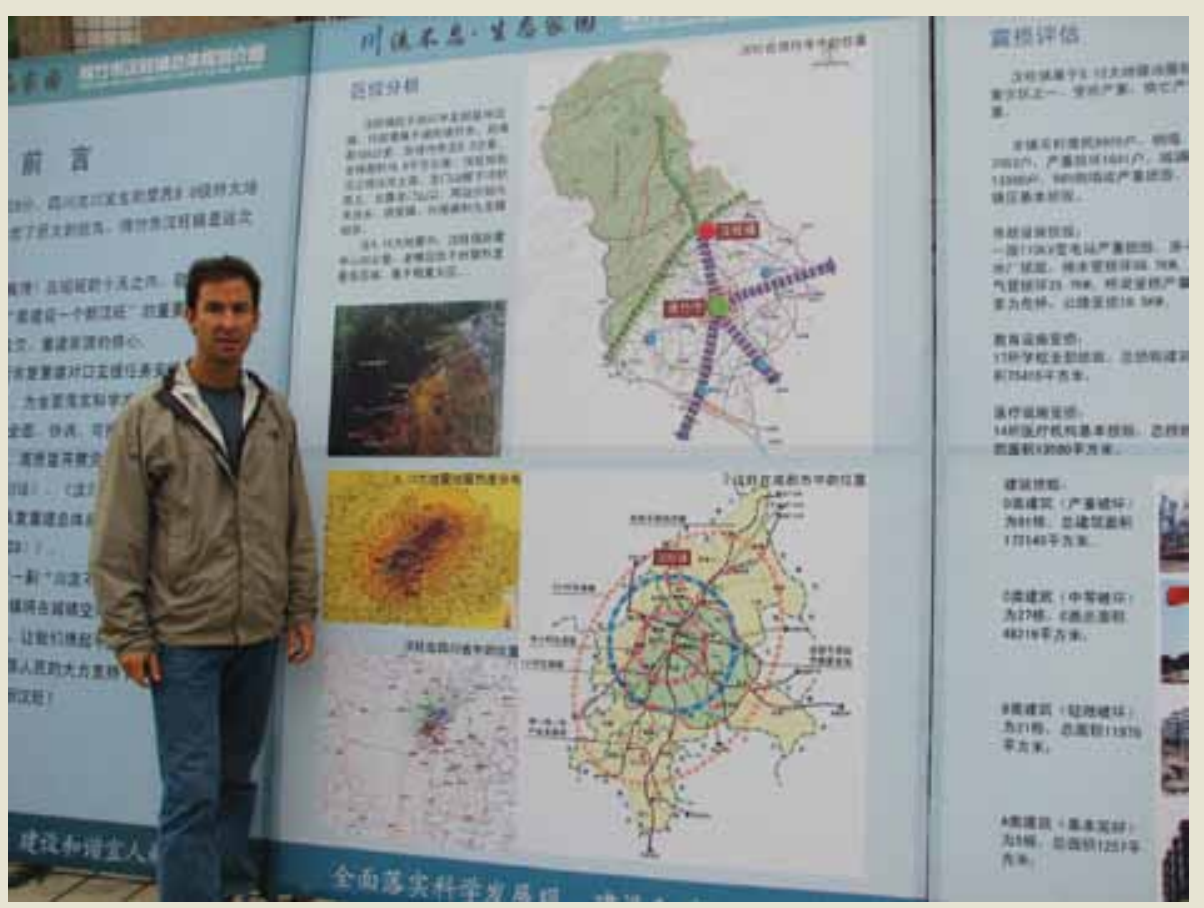

David Wald, USGS, beside an earthquake information display outside of Hanwang City, China, which was destroyed in the 2008 Wenchuan earthquake. The display describes the earthquake and rebuilding plans for Hanwang City. Inset in yellow/orange/red is the PAGER map of population and shaking intensity for the magnitude 7.9 earthquake. Photograph by Kishor Jaiswal, USGS.

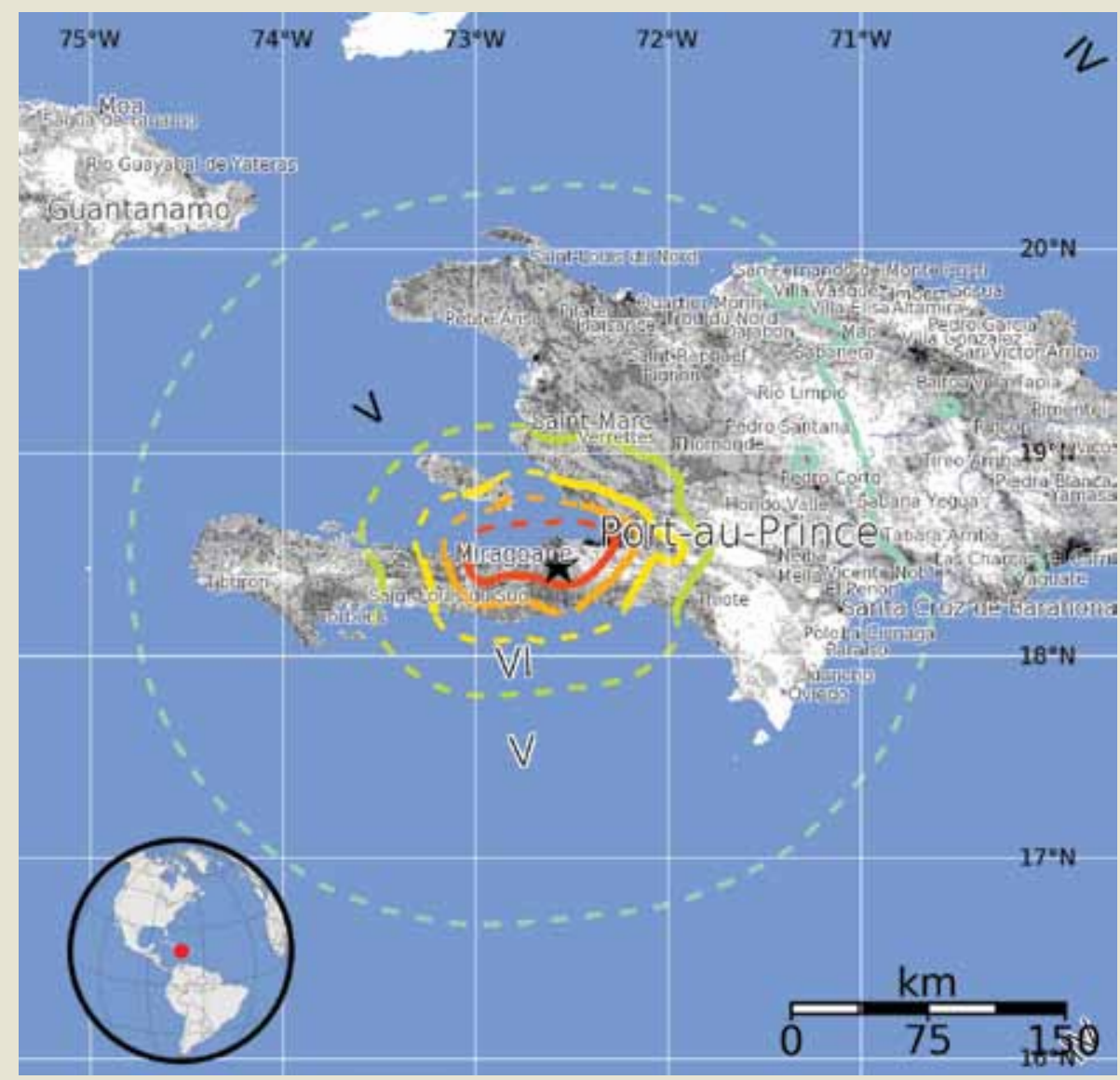




\section{Strategic Actions}

\section{Provide state-of-the-art scientific infrastructure for the} study of the Earth

The USGS will enhance the facilities, laboratories, and instruments needed for geochemical, geophysical, and geological analyses and mapping and will create long-term plans for the acquisition of new systems and technology. In collaboration with partners, we will improve our capability for sea-floor, coastal, and onshore mapping using lidar and other remote-sensing techniques. We will provide support for and upgrade our computer systems and partner with universities and the National Science Foundation for access to supercomputing facilities. The USGS will continue to collaborate with DOE, NASA, NOAA, universities, and NSF in the development of new sensors with application to understanding the underlying geologic processes related to resources, ecosystem health, hazards, and climate.

2. Assure that USGS data are preserved and available to the widest possible community of researchers

The USGS will invest in resources, tools, and facilities to ensure long-term data management and stewardship of scientific data and materials. Data and materials collected by the USGS must be widely available to other scientists both within and outside the USGS. We will collaborate with the broad earth science community, both within and outside the USGS, to develop standardized tools for documenting and publishing data. We will make existing, major USGS databases accessible and interoperable. This action will require new technologies, Web services, and applications to facilitate data sharing among scientists. Curation and preservation of materials (such as rocks, soils, cores, and fossils) are critical for future research and can reduce the need for future data collection. The USGS will help to establish new repositories with well-defined protocols for acquiring, curating, and preserving materials and making them accessible. Current facilities such as the USGS Core Research Center (established in 1974) will require new investments for maintenance and expansion.

\section{Turn our data into scientific knowledge}

Translating the data we collect into scientific understanding is the core of USGS research. It is critical that both individual researchers and the larger community be able to assess, analyze, and interpret collected data. To support this interpretive effort, we will foster the continued development and use of tools that facilitate the transition from data to understanding, such as geospatial, visualization, and modeling tools. Many of the datasets and tools may be outside of all users' individual skills and knowledge. We will therefore also need to provide opportunities for interaction among the various disciplines and education on the appropriate use of various tools and datasets.

\section{Communicate our data and scientific understanding to partners and customers}

Because our work is focused on societal needs, we need to communicate our data and understanding to decisionmakers and the public, as well as the scientific community. The USGS must continue to enhance communication of our scientific understanding to diverse audiences, involving user groups and stakeholders in the development of decision-support products (highlight 16).

\section{Develop and adopt state-of-the-art information technology}

All aspects of information technology are advancing at rapid rates. The USGS needs to participate in and stay abreast of these advances and incorporate them into our data collection, analysis, preservation, and knowledge dissemination efforts. In collaboration with the larger scientific community, we will contribute to the development of a USGSwide cyberinfrastructure. In addition, we will participate in the development of global interoperability and metadata standards, an international geoinformatics system, and Web services, data catalogs, and computer infrastructure to support national geologic databases (highlight 15). 


\section{Freserving our Nation's Geological and Geophysical Data and Materials}

Scattered across the Nation are collections of geological and geophysical materials and data (in a wide range of formats) that have long been recognized as valuable. Information that resides in these collections, as diverse as rock and ice cores, fossils, rock samples, geophysical tapes, and paper well logs, is invaluable to future scientific research and educational activities. The National Geological and Geophysical Data Preservation Program (NGGDPP) is working to identify, catalog, and preserve a wide range of materials and data that support a variety of activities, including the following:

- Identifying new oil and gas and mineral deposits

- Contributing to research on climate change

- Addressing issues related to water quality
- Enhancing the ability to identify geologic hazards

- Supporting research on development of unconventional energy sources

Since its beginning in 2007, NGGDPP has provided financial and technical assistance to State geological surveys and bureaus within the DOI in an effort to identify, catalog, and preserve geological and geophysical data and samples. The program is developing a National Digital Catalog that allows users to identify (via the Web) and access geoscience data and collections maintained by Federal or State agencies to improve the breadth of information available to inform science and decisionmaking.

The return of the Anvil Points oil shale cores to the USGS was one of the NGGDPP's 2009 highlights and exemplifies the value of geoscience data preservation. Approximately 170,000 feet
$(52,000$ meters) of oil shale core from 220 wells were transferred from the Anvil Points Mine near Rifle, Colo., where they had been stored for the last 13 years, and relocated at the USGS Core Research Center (CRC) in Denver, Colo. (Hicks and Adrian, 2009). These cores comprise a combination of USGS-drilled cores and cores donated by industry partners with the understanding that the USGS would curate them and provide access to those wishing to perform oil shale research. The collection is composed predominantly of cores from the world-class Green River oil shale deposit of the Western United States with a few cores from Devonian oil shales in Michigan and Kentucky, as well as from foreign deposits in Sweden and Morocco. The cost of redrilling the Green River cores alone would be in excess of $\$ 150$ million. The USGS CRC has curated the cores and crushed samples, and they are now available for viewing and sampling at the CRC.

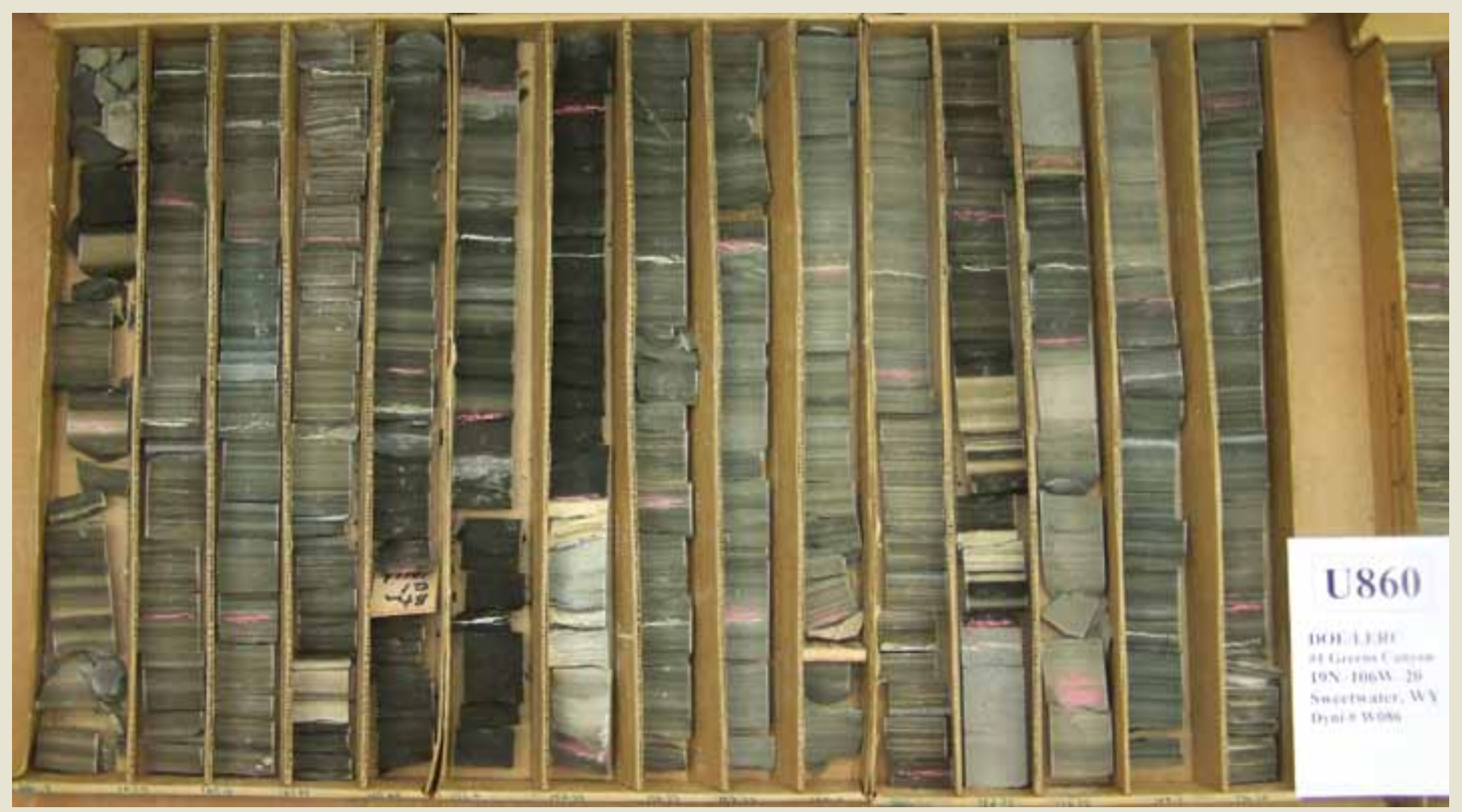

Boxes of oil shale cores from the Green River Formation in Wyoming that had been stored in the Anvil Points Mine near Rifle, Colo., and are now available for study at the Core Research Center in Denver, Colo. Photograph by Joshua Hicks, USGS. 


\section{Products and Outcomes}

1. Advanced facilities, laboratories, instruments, computers, and monitoring networks for conducting earth science

We will invest strategically and collaborate locally, nationally, and globally to ensure that USGS geological, geochemical, and geophysical investigations are supported with the needed infrastructure. Facilities and laboratories will have strategic plans and investment strategies for replacement and renewal of instruments and equipment. Joint ventures with partners will facilitate access to supercomputers, large-format instruments, research vessels, and remote-sensing platforms. Web sites and training will be created to enhance knowledge of and access to this infrastructure.

\section{Comprehensive regional, national, and global} earth science databases accessible through a shared catalog

We will support the creation and digital publication of community databases in the geosciences to serve nationally and globally integrated thematic, geographic, and topical data. We will adopt metadata standards, Open Geospatial Consortium, Inc. ${ }^{\circledR}$, standards, and international and community standards to facilitate interoperability. Geologic programs will contribute to the establishment of a USGS data catalog that will provide a systematic searchable window into USGS data and material collections. We will partner with other geological surveys and universities to extend the catalog, eventually providing a common earth sciences catalog that allows users to register data, collections, and attendant metadata.

\section{Long-term repositories for geologic materials and} scientific collections

We will expand and maintain our national repositories for geologic materials, scientific collections, and related data, establishing facilities internally and through partnerships (highlight 17). Where feasible, we will decrease paper and material holdings and increase accessibility by creating digital representations.

\section{Applications that facilitate interoperability and ease} of use

We will work with others internally and externally to develop Web services and data catalogs and to support metadata that facilitate data retrieval and discovery. We will continue to be involved in international efforts to develop markup languages (including XML, KML, and GeoSciML) and Web services that facilitate interoperability.

5. Innovative, real-time, and transparent communication of data, interpretations, and results

We will transfer the concepts and technology behind the Earthquake Notification System and the Prompt Assessment of Global Earthquakes for Response (PAGER) system (highlight 16) to implement similar communication and warning applications for coastal storm and inundation vulnerability, the National Volcano Early Warning System, the debris-flow warning system, and other areas as appropriate. We will develop decisionsupport and model applications to facilitate decisionmaking by a wide variety of users, especially resource managers, emergency responders, and government officials. We will increase Internet access to digital files of USGS publications and data. 


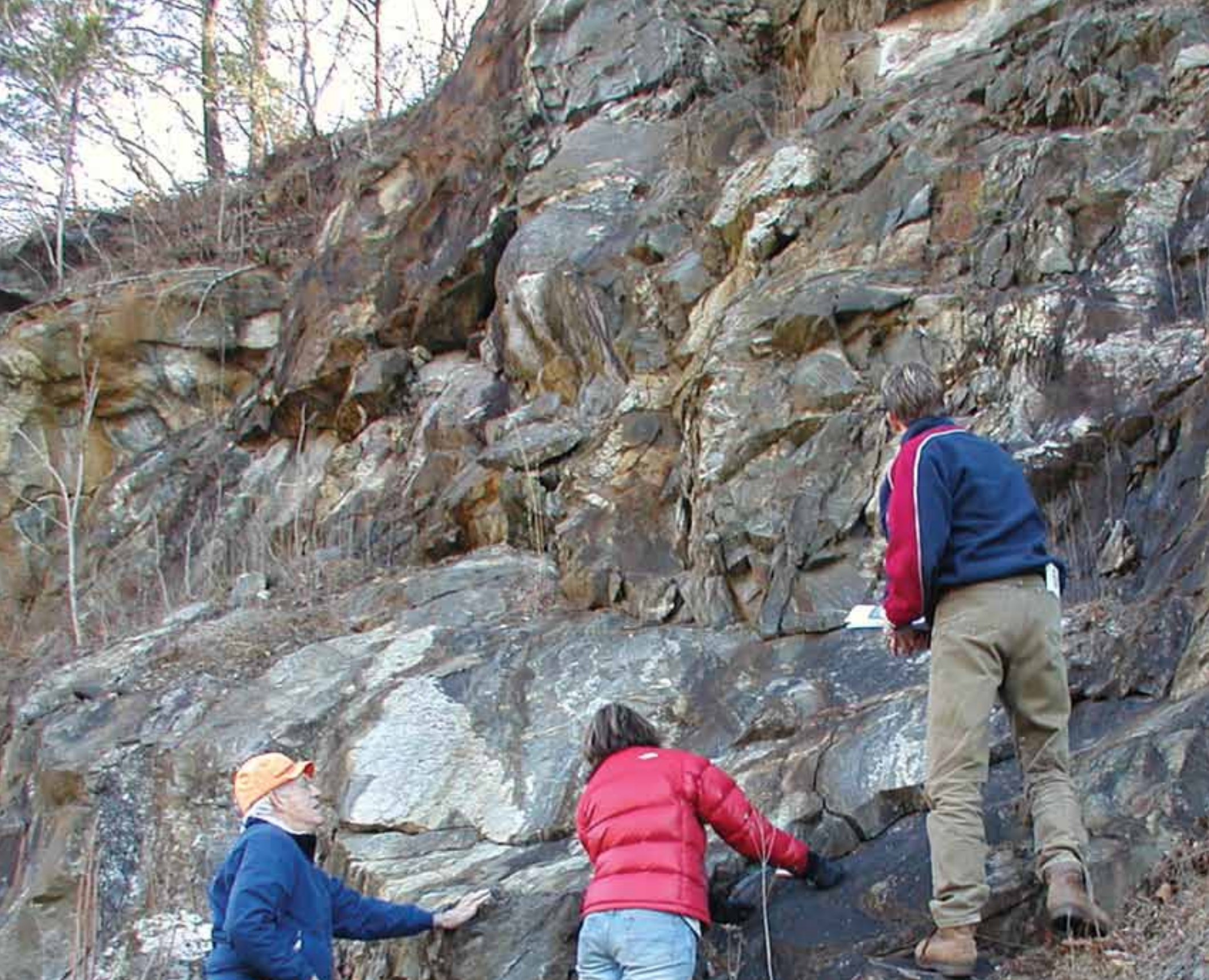




\section{Goal 6. Develop a Flexible and Diverse Workforce for the}

\section{Future}

Our great diversity of expertise enables the USGS to carry out large-scale multidisciplinary investigations that provide essential knowledge about the Earth. The capabilities of our workforce must evolve to meet the needs of society and accomplish the USGS science strategy. Hiring flexibility is needed to respond to long- and short-term changes in priorities and funding. Maintaining core competencies while acquiring new expertise will require a strategic workforce plan and innovative approaches to meet the demands associated with interdisciplinary science and advanced technology. The accelerating attrition of the workforce makes it imperative that we act now. 


\section{$\stackrel{\infty}{=}$ The Changing Demographics of Geologists Inside and Outside the USGS}

One of the biggest challenges facing the USGS is building and maintaining a strong scientific workforce. In 2009, 42 percent of USGS geologists and 37 percent of USGS geophysicists were eligible to retire (see lower graph). Earth scientists are in ever-increasing demand, but the number of students entering the earth sciences peaked in the early 1980s and leveled off in the 2000s (see upper graph). The number of students earning graduate degrees has been relatively level since the early 1990s. The USGS needs to be aggressive in earlystage educational initiatives to encourage more students to become interested in the earth sciences. We will work with partners to create recruitment efforts and internships to attract and retain future scientists (see highlight 19).

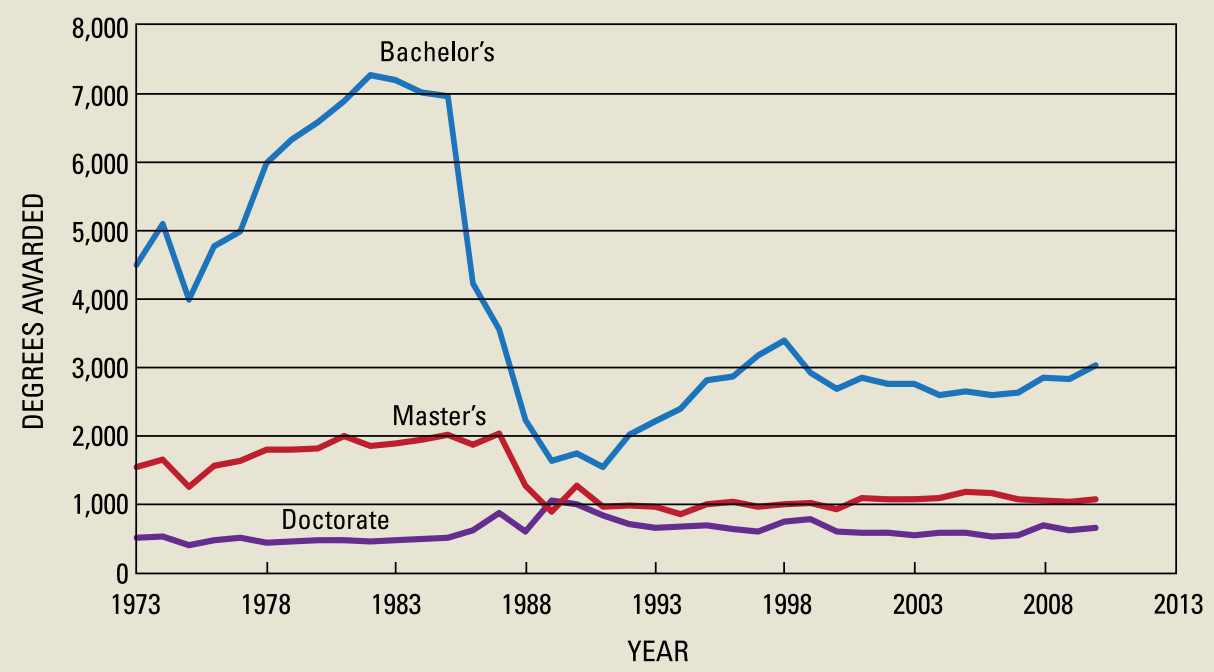

U.S. geoscience degrees granted, 1973-2010. Modified from Keane (2010); used with permission.

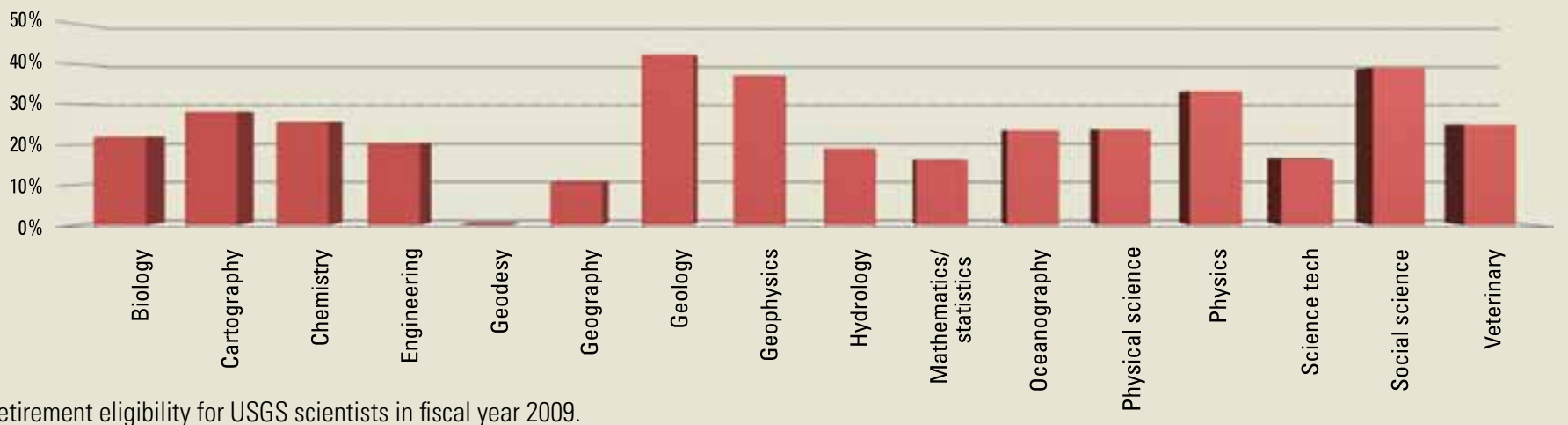

Retirement eligibility for USGS scientists in fiscal year 2009.

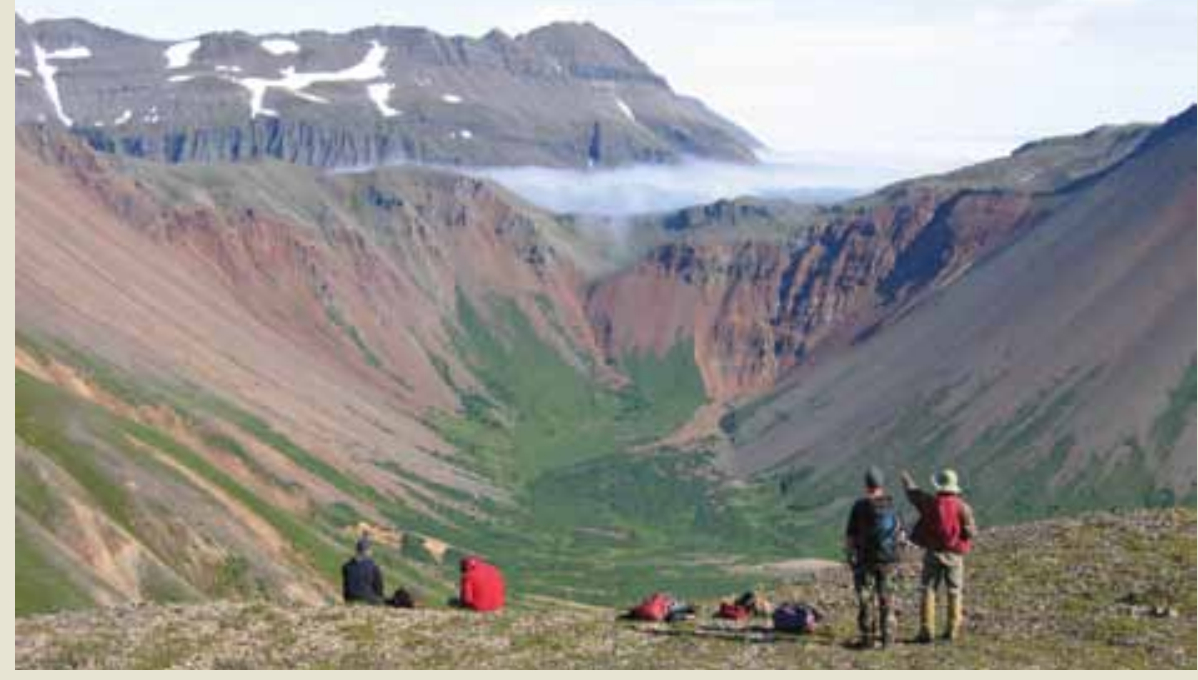

Professor and students from Illinois State University working under the EDMAP program at the Bee Creek porphyry copper prospect near Chignik, Alaska, in summer 2005. Photograph by David Malone, Illinois State University; used with permission.

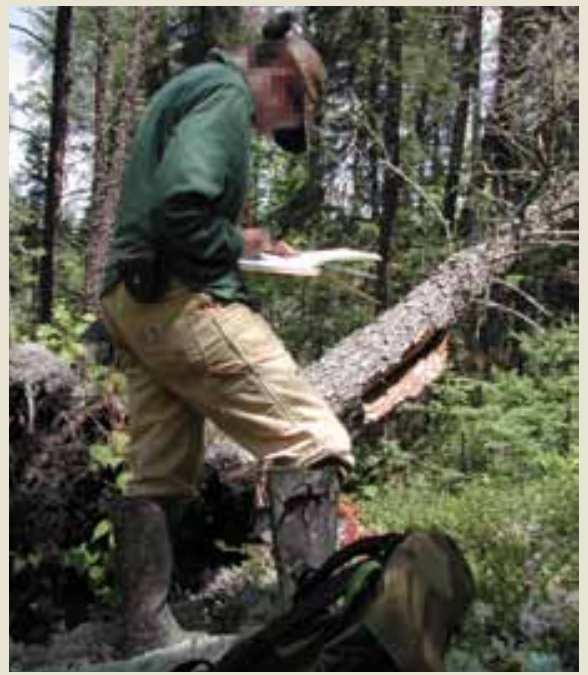

Student conducting fieldwork at Wilder Lake, Minn., as part of the EDMAP program. Photograph by James D. Miller, University of MinnesotaDuluth; used with permission. 


\section{Societal Needs and Benefits}

The USGS faces critical workforce challenges (highlight 18). Limitations on funding resources have dictated limited replacement of departing employees. As a result, core expertise in many areas has been diminished, and critical mentoring and training opportunities have been missed. We must hire new staff before the precipitous loss of our most experienced employees. Our talent base must be renewed both to maintain our core competencies and to gain new expertise to meet the science needs of the future.

The USGS is composed of a community of scientists who provide a breadth of expertise and innovation not found anywhere else in the Federal Government. Because of the nature of the USGS mission, USGS scientists often have the unique opportunity to focus large portions of their careers on a region, a specific hazard, a specific natural resource, or a particular physical process. As a result, they often become critical information resources to the larger science community, as well as the public. On the other hand, the complex challenges we face today in the earth sciences also demand that geologists be able to work across disciplines, be skilled with multiple technologies, and understand connections to global natural processes. This demand often requires developing expertise outside of traditional geological training and acquiring an ability to recognize and promote the role that geologic methods, such as mapping or geochemistry, can bring to biological and hydrological issues. The accelerating attrition of the workforce is undermining our capacity to fulfill our mission and to meet the new challenges posed by changing societal needs. With attrition, however, comes the opportunity to renew our workforce.

The USGS will need to develop strategic workforce plans and policies that seek to provide the proper mix of scientists and support staff to accomplish the USGS science strategy and provide for a diverse and flexible workforce. Science positions will need to be balanced among research, development, and operational staff to meet mission needs. Support staff positions need to be structured to provide attractive career options and development opportunities. Limited resources will require sharing of both support staff and research expertise across organizational units. Development and training programs with schools and other organizations need to be nurtured to provide the next generation of earth scientists (highlight 19). The USGS will need to partner with diverse organizations and disciplines to acquire nontraditional and new expertise. 


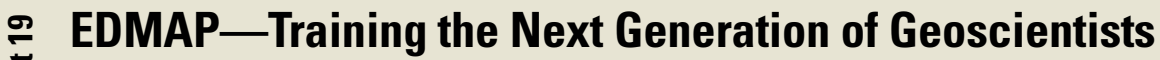

Development of observational skills and vision is enhanced through guided apprenticeship. Fieldwork is the formative experience central to geologic sciences, and the USGS is well suited to guide the upcoming workforce. The primary objective of EDMAP, the educational component of the National Cooperative Geologic Mapping Program (NCGMP), is to train the next generation of geologic mappers. To do this, NCGMP provides funds for graduate and selected undergraduate students in academic research projects that involve geologic mapping as a major component. Through these cooperative agreements, NCGMP expands the research and educational capacity of academic programs that teach earth science students the techniques of geologic mapping and field data analysis. Another important goal is to increase the level of communication between the Nation's geological surveys (both State geological surveys and the USGS) and geologic mappers in the academic community. This improved communication has two results: (1) the academic mapping community learns more about the societal needs that drive geologic mapping projects at the USGS and State geological surveys and (2) more geologic maps produced in academia are made available to the public.

EDMAP facts follow:

- Since 1996, EDMAP has funded 750 students from 140 universities. All Federal funds are matched 1:1 by the universities.

- Funding levels are $\$ 17,500$ for graduate students and $\$ 10,000$ for undergraduate students.

- Of students surveyed, 95 percent either received jobs in geoscience fields or pursued further degrees (this high percentage of EDMAP students remaining in the geosciences is well above the national average).

- Student work contributes to geologic mapping of the United States.
To encourage more students to major in the geosciences, NCGMP also has been working closely with the University of Texas GeoFORCE Program. GeoFORCE is a summer program that rewards outstanding 8th through 12th grade minority students from South Texas and Houston schools by providing the opportunity to travel the country, meet inspiring people, and learn about opportunities for careers in the geosciences. Of the original 80 students who started with GeoFORCE in 2005, 76 were admitted to college. Fifty percent of these students declared majors in earth science, engineering, or mathematics. NCGMP is tracking these students to encourage them to participate in EDMAP.

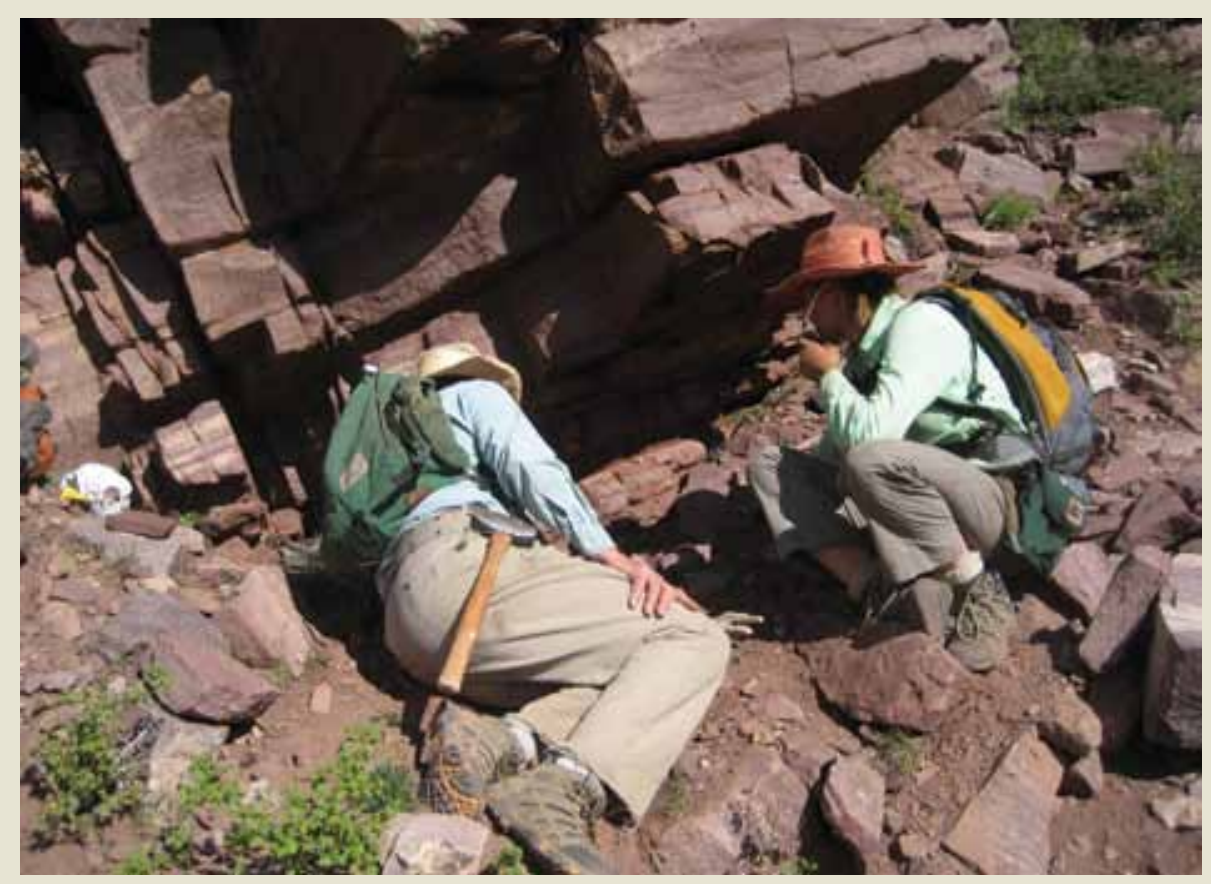

EDMAP students from Idaho State University working in the Kings Peak area of Idaho in summer 2008. Photograph by Paul Link, Idaho State University; used with permission.

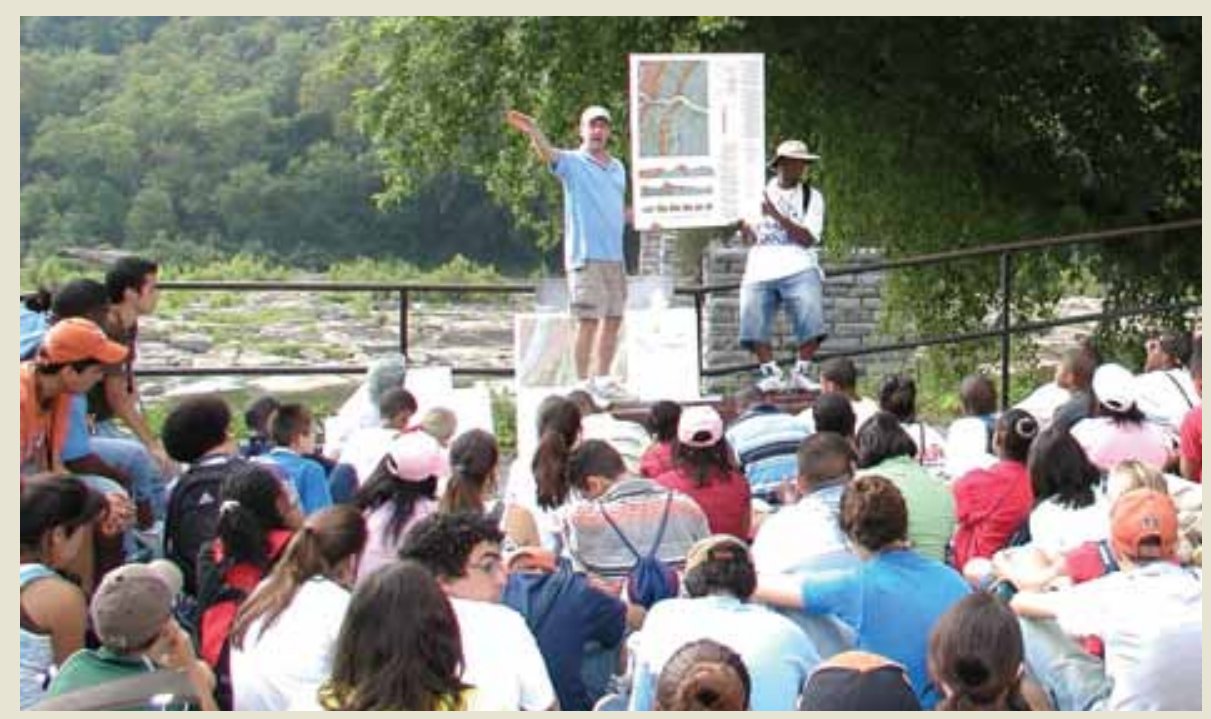

USGS geologist Randall Orndorff relating the geologic map of the Harpers Ferry area, West Virginia, to the topography during a trip with GeoFORCE students. Photograph by Lydia Quintana, USGS. 


\section{Strategic Actions}

1. Build on the existing workforce strategies and help develop a bureauwide approach to renew our workforce

USGS studies of its workforce have identified gaps in our capabilities on the basis of future research requirements, projected retirements, and current capabilities. These studies should be updated and enhanced collaboratively across the USGS and should be used to create a plan to proactively renew our workforce and achieve the goals outlined in the USGS science strategy. The new plan should include new tools and procedures to create and support interdisciplinary teams and rapidly respond to changing needs for expertise.

\section{Ensure the core discipline expertise and experience} needed to fulfill the USGS mission

We must maintain our core geologic expertise and transfer valuable experience across generations of USGS scientists. Our internal perception of this need has been reinforced by advice from stakeholders, including users of USGS data, information, and knowledge. Others depend on our geologic expertise, and our future depends on our continued scientific excellence.

\section{Use a wide variety of tools and hiring practices to meet special scientific and technical needs}

A mix of permanent, temporary, and volunteer expertise is needed to respond to the fast-changing nature of science and technology. We will expand interaction and collaboration with the academic community by using appointments such as the "when actually employed" (WAE) positions for faculty members; sabbaticals for visiting faculty members and USGS scientists; and temporary, career, and National Association of Geoscience Teachers (NAGT) appointments for students. We also will maintain robust volunteer, emeritus, and postdoctoral programs. The Mendenhall Research Fellowship Program for postdoctoral scientists will continue to be one of our most important programs for recruitment of people having new skills and capabilities, as well as conducting state-of-the-art research.

\section{Enhance employee development and re-energize our scientists}

Evaluation, promotion, and reward systems, rotational assignments, and training mechanisms will all be oriented to meet the goals outlined in the USGS science strategy, challenge our scientists, and enhance their experience. While continuing to reward outstanding scientific achievements, our performance evaluation and promotion systems will be adapted to more fully recognize the value of science leadership, crossdisciplinary work, and working in teams. Clear career ladders will be provided for the development of our scientists and managers, and managers across the USGS will work to develop common practices in the creation and evaluation of support and operational scientific positions. To encourage more integrated scientific study, we will develop cross-disciplinary classes to allow scientists to learn fundamental principles and issues of biology, geography, geology, and hydrology. Finally we will foster collaboration with the broader scientific community by facilitating USGS scientist participation in leadership positions for professional societies and as adjunct and affiliated faculty at academic institutions. 


\section{Products and Outcomes}

1. A diverse and flexible workforce with the capability and expertise needed to accomplish the USGS mission

The USGS will create a comprehensive bureauwide workforce plan that examines current and future workforce issues within the context of the USGS science strategy. The workforce plan will define a 10-year hiring strategy to renew the workforce that will include increasing diversity, enhancing both core and new expertise, and providing for succession planning. We will examine the possibility of expanding programs such as EDMAP, which is helping to train the next generation of geologic mappers, to other critical subdisciplines of the earth sciences.

2. Employee evaluation, support, and development programs that foster worker satisfaction, retention, and effectiveness for the long term

The USGS will review and update its implementation of the Research Grade Evaluation Guide to appropriately reward teamwork and integrated science. Updated training for members of review panels will be required to ensure equitable evaluation of scientific achievement. We will use Web and video-streaming technology more effectively to provide low-cost scientific training and seminars. We will work with other agencies and universities to create a USGS sabbatical program and be more proactive in the use of Interagency Personnel Agreements to provide midcareer development experiences. The USGS will also analyze internal workflow needs and use short-term details, internships, and longer term temporary assignments to provide development opportunities. A formal scientific mentoring program will be created to transfer knowledge and expertise from experienced scientists to new scientists, so that institutional knowledge is not only maintained but enhanced during a period of increased workforce turnover.

\section{Enhanced mechanisms to communicate the} attractiveness of a career with the USGS, recruit diverse, high-quality candidates, and retain expertise

The USGS will continue and expand the USGS Mendenhall Research Fellowship Program and the scientist emeritus program. We will provide centralized information regarding student and intern hiring mechanisms and better publicize available opportunities. Through partnerships with other DOI bureaus and scientific societies, we will expand our summer intern and student learning programs, providing early career opportunities for women and minorities. We will work with the NSF to expand the earth science curriculum in grades $\mathrm{K}-12$, and we will work with high schools and undergraduate programs to provide educational and employment opportunities. 


\section{Conclusion}

The ultimate goal of USGS science and of the strategy laid out in this document is to contribute to the sustainability of society and the ecosystems that support us. As we begin the second decade of the 21st century, our Nation faces growing challenges in resource availability, climate change, environmental degradation, and natural hazards. The growing human population places increasing stress on the resources and ecosystems of our planet. These problems are shared with other nations across the globe and have resulted in significant modifications to the global environment and its physical and biological processes. In fact, human actions may be altering some natural processes faster than scientists can recognize these changes and faster than society can adapt to them. As a consequence, it is more essential than ever that earth scientists apply their understanding of the natural world to benefit society. The USGS has responded to this urgent societal need by developing a bold plan laid out in Circular 1309, "Facing Tomorrow's Challenges," which will unite the capabilities of USGS biologists, hydrologists, geologists, and geographers to provide decisionmakers the comprehensive, unbiased natural science information they require. The success of this endeavor demands that each scientific discipline within the USGS remain at the forefront of its distinct sphere of research, as well as integrate its expertise across the full spectrum of the natural sciences. The six goals described in this document represent a mix of scientific focus areas and operational necessities that together provide a comprehensive roadmap for USGS geologic science to effectively contribute to the USGS mission to provide science for a changing world. 


\section{References Cited}

Aagaard, B.T., Graves, R.W., Rodgers, Arthur, Brocher, T.M., Simpson, R.W., Dreger, Douglas, Petersson, N.A., Larsen, S.C., Ma, Shuo, and Jachens, R.C., 2010, Ground-motion modeling of Hayward fault scenario earthquakes; Part II, Simulation of long-period and broadband ground motions: Bulletin of the Seismological Society of America, v. 100, no. 6, p. 2945-2977, doi:10.1785/0120090379, accessed January 24, 2011, at http://bssa.geoscienceworld.org/cgi/ content/full/100/6/2945.

Barnhardt, W.A., ed., 2009, Coastal change along the shore of northeastern South Carolina-The South Carolina coastal erosion study: U.S. Geological Survey Circular 1339, 77 p., accessed July 19, 2010, at http://pubs.usgs.gov/circ/circ1339/.

Billingsley, G.H., 2000, Geologic map of the Grand Canyon $30^{\prime} \times 60^{\prime}$ quadrangle, Coconino and Mohave Counties, northwestern Arizona: U.S. Geological Survey Geologic Investigations Series I-2688, scale 1:100,000, accessed September 21, 2010, at http://pubs.usgs.gov/imap/i-2688.

Bird, K.J., Charpentier, R.R., Gautier, D.L., Houseknecht, D.W., Klett, T.R., Pitman, J.K., Moore, T.E., Schenk, C.J., Tennyson, M.E., and Wandrey, C.J., 2008, Circum-Arctic resource appraisal; Estimates of undiscovered oil and gas north of the Arctic Circle: U.S. Geological Survey Fact Sheet 2008-3049, 4 p., accessed July 28, 2010, at http://pubs.usgs.gov/fs/2008/3049/.

Blome, C.D., Faith, J.R., and Ozuna, G.B., 2007, Geohydrologic framework of the Edwards and Trinity aquifers, south-central Texas: U.S. Geological Survey Fact Sheet 2006-3145, 4 p., accessed July 21, 2010, at http://pubs.usgs.gov/fs/2006/3145/.

Bohlen, S.R., Halley, R.B., Hickman, S.H., Johnson, S.Y., Lowenstern, J.B., Muhs, D.R., Plumlee, G.S., Thompson, G.A., Trauger, D.L., and Zoback, M.L., 1998, Geology for a changing world - A science strategy for the Geologic Division of the U.S. Geological Survey, 2000-2010: U.S. Geological Survey Circular 1172, 59 p. (Also available at http://pubs.usgs.gov/circ/c1172/.)

Brady, S.R., Sinha, A.K., and Gundersen, L.C., eds., 2008, Geoinformatics 2008-Data to knowledge, proceedings: U.S. Geological Survey Scientific Investigations Report 2008-5172, 76 p., also available at http://pubs.usgs.gov/ $\operatorname{sir} / 2008 / 5172$.

Cahoon, D.R., 2007, Factors affecting coastal wetland loss and restoration, chap. 12 of Phillips, S.W., ed., Synthesis of U.S. Geological Survey science for the Chesapeake Bay ecosystem and implications for environmental management: U.S. Geological Survey Circular 1316, p. 50-53, accessed July 21, 2010, at http://pubs.usgs.gov/circ/circ1316/.
Cannon, S.H., Gartner, J.E., Rupert, M.G., Michael, J.A., Staley, D.M., and Worstell, B.B., 2009, Emergency assessment of postfire debris-flow hazards for the 2009 Station fire, San Gabriel Mountains, southern California (revised April 2010): U.S. Geological Survey Open-File Report 2009-1227, 27 p., accessed July 26, 2010, at http://pubs.usgs.gov/of/2009/1227/.

Clark, R.N., Green, R.O., Swayze, G.A., Meeker, Greg, Sutley, Steve, Hoefen, T.M., Livo, K.E., Plumlee, Geoff, Pavri, Betina, Sarture, Chuck, Wilson, Steve, Hagemen, Phil, Lamothe, Paul, Vance, J.S., Boardman, Joe, Brownfield, Isabelle, Gent, Carol, Morath, L.C., Taggart, Joseph, Theodorakos, P.M., and Adams, Monique, 2001, Environmental studies of the World Trade Center area after the September 11, 2001, attack: U.S. Geological Survey Open-File Report 2001-0429, version 1.1, accessed July 27, 2010, at http://pubs.usgs.gov/of/2001/ofr-01-0429/.

Cronin, T.M., 2007, Sediment sources and deposition in the estuary, chap. 7 of Phillips, S.W., ed., Synthesis of U.S. Geological Survey science for the Chesapeake Bay ecosystem and implications for environmental management: U.S. Geological Survey Circular 1316, p. 32-35, accessed July 21, 2010, at http://pubs.usgs.gov/circ/circ1316/.

Crossett, K.M., Culliton, T.J., Wiley, P.C., and Goodspeed, T.R., 2004, Population trends along the coastal United States; 1980-2008: National Oceanic and Atmospheric Administration, National Ocean Service, 47 p., accessed July 19, 2010, at http://oceanservice.noaa.gov/programs/ mb/supp_cstl_population.html.

Cunningham, C.G., Zappettini, E.O., Vivallo S., Waldo, Celada, C.M., Quispe, Jorge, Singer, D.A., Briskey, J.A, Sutphin, D.M., Gajardo M., Mariano, Diaz, Alejandro, Portigliati, Carlos, Berger, V.I., Carrasco, Rodrigo, and Schulz, K.J., 2008, Quantitative mineral resource assessment of copper, molybdenum, gold, and silver in undiscovered porphyry copper deposits in the Andes Mountains of South America: U.S. Geological Survey Open-File Report 2008-1253, 282 p., available on CD-ROM and online at http://pubs.usgs.gov/of/2008/1253/.

Diamond, Jared, 2005, Collapse; How societies choose to fail or succeed: New York, Viking, 575 p., 24 p. of plates.

Ewert, J.W., Guffanti, Marianne, and Murray, T.L., 2005, An assessment of volcanic threat and monitoring capabilities in the United States - Framework for a National Volcano Early Warning System (NVEWS): U.S. Geological Survey OpenFile Report 2005-1164, version 1.1, 62 p., accessed July 26, 2010, at http://pubs.usgs.gov/of/2005/1164/.

Field, J.P., Belnap, Jayne, Breshears, D.D., Neff, J.C., Okin, G.S., Whicker, J.J., Painter, T.H., Ravi, Sujith, Reheis, M.C., and Reynolds, R.L., 2009, The ecology of dust: Frontiers in Ecology and the Environment, doi:10.1890/090050, 
accessed July 22, 2010, at http://www.esajournals.org/doi/ pdf/10.1890/090050.

Goldhaber, M.B., Morrison, J.M., Holloway, J.M., Wanty, R.B., Helsel, D.R., and Smith, D.B., 2009, A regional soil and sediment geochemical study in northern California: Applied Geochemistry, v. 24, no. 8, p. 1482-1499, doi:10.1016/j.apgeochem.2009.04.018.

Helmke, P.A., 2000, The chemical composition of soils, in Sumner, M.E., ed., Handbook of soil science: Boca Raton, Fla., CRC Press, p. B-3 to B-24.

Hicks, Joshua, and Adrian, Betty, 2009, Core Research Center: U.S. Geological Survey General Information Product 94, 2 p. (Also available at http://pubs.usgs.gov/gip/94/.)

Jones, L.M., Bernknopf, Richard, Cox, Dale, Goltz, James, Hudnut, Kenneth, Mileti, Dennis, Perry, Suzanne, Ponti, Daniel, Porter, Keith, Reichle, Michael, Seligson, Hope, Shoaf, Kimberley, Treiman, Jerry, and Wein, Anne, 2008, The ShakeOut Scenario: U.S. Geological Survey OpenFile Report 2008-1150 and California Geological Survey Preliminary Report 25, 308 p., accessed August 2, 2010, at http://pubs.usgs.gov/of/2008/1150/.

Keane, Christopher, 2010, Geoscience enrollments \& degrees continue their sharp rise in 2009-2010: American Geological Institute Geoscience Currents, no. 31 (27 April 2010), accessed August 3, 2010, at http://www.agiweb.org/ workforce/Currents/Currents-031-Enrollments2010.pdf.

Morrison, J.M., Goldhaber, M.B., Lee, Lopaka, Holloway J.M., Wanty, R.B., Wolf, R.E., and Ranville, J.F., 2009, A regional-scale study of chromium and nickel in soils of northern California, USA: Applied Geochemistry, v. 24, no. 8, p. 1500-1511, doi:10.1016/j.apgeochem.2009.04.027.

Neff, J.C., Ballantyne, A.P., Farmer, G.L., Mahowald, N.M., Conroy, J.L., Landry, C.C., Overpeck, J.T., Painter, T.H., Lawrence, C.R., and Reynolds, R.L., 2008, Increasing eolian dust deposition in the Western United States linked to human activity: Nature Geoscience, v. 1, p. 189-195, doi:10.1038/ngeo133.

Painter, T.H., Barrett, A.P., Landry, C.C., Neff, J.C., Cassidy, M.P., Lawrence, C.R., McBride, K.E., and Farmer, G.L., 2007, Impact of disturbed desert soils on duration of mountain snow cover: Geophysical Research Letters, v. 34, L12502, 6 p., doi:10.1029/2007GL030284.

Perry, Suzanne, Cox, Dale, Jones, Lucile, Bernknopf, Richard, Goltz, James, Hudnut, Kenneth, Mileti, Dennis, Ponti, Daniel, Porter, Keith, Reichle, Michael, Seligson, Hope, Shoaf, Kimberley, Treiman, Jerry, and Wein, Anne, 2008, The ShakeOut Earthquake Scenario; A story that southern Californians are writing: U.S. Geological Survey Circular 1324 and California Geological Survey Special Report 207,
16 p., accessed August 2, 2010, at http://pubs.usgs.gov/ circ/1324/.

Stockdon, Hilary, and Sallenger, Abby, 2010, Impacts and predictions of coastal change during hurricanes: U.S. Geological Survey Fact Sheet 2010-3012, 2 p., accessed July 27, 2010, at http://pubs.usgs.gov/fs/2010/3012/.

Tully, John, comp., 1996, Coal fields of the conterminous United States: U.S. Geological Survey Open-File Report 96-92, scale 1:5,000,000, accessed August 6, 2010, at http://pubs.usgs.gov/of/1996/of96-092/index.htm.

U.S. Geological Survey, 2005, Putting down roots in earthquake country; Your handbook for the San Francisco Bay region (revised May 2007): U.S. Geological Survey General Information Product 15, 32 p., accessed July 22, 2010, at http://pubs.usgs.gov/gip/2005/15/gip-15.pdf.

U.S. Geological Survey, 2006, FGDC [Federal Geographic Data Committee] digital cartographic standard for geologic map symbolization (PostScript implementation): U.S. Geological Survey Techniques and Methods 11-A2, variously paged, available at http://pubs.usgs.gov/tm/2006/11A02/.

U.S. Geological Survey, 2007, Facing tomorrow's challenges - U.S. Geological Survey science in the decade 2007-2017: U.S. Geological Survey Circular 1309, 70 p. (Also available at http://pubs.usgs.gov/circ/2007/1309/.)

U.S. Geological Survey, 2009, Total mean undiscovered gas resources [for the United States]: U.S. Geological Survey Web page accessed July 26, 2010, at http://certmapper.cr.usgs.gov/data/noga00/natl/ graphic/2009/total_gas_mean_09.pdf.

U.S. Geological Survey, 2010a, Materials flow: U.S. Geological Survey Web page at http://minerals.usgs.gov/minerals/ mflow/.

U.S. Geological Survey, 2010b, NVEWS; National Volcano Early Warning System: U.S. Geological Survey Web page accessed July 27, 2010, at http://volcanoes.usgs.gov/ publications/2009/nvews.php.

U.S. Geological Survey, 2010c, PAGER-M 7.0-Haiti region: U.S. Geological Survey Web page accessed July 29, 2010, at http://earthquake.usgs.gov/earthquakes/pager/ events/us/2010rja6/index.html.

U.S. Geological Survey, [2010d,] World petroleum assessment; Publications and data: U.S. Geological Survey Web page accessed July 26, 2010, at http://certmapper.cr.usgs.gov/rooms/we/index.jsp.

Van Gosen, B.S., 2006, Reported historic asbestos mines, historic asbestos prospects, and natural asbestos occurrences in the Eastern United States (version 2.0): U.S. Geological Survey Open-File Report 2005-1189, 1 pl., 1 
database, accessed July 21, 2010, at http://pubs.usgs.gov/ of/2005/1189/.

Wagner, L.A., 2002, Materials in the economy-Material flows, scarcity, and the environment: U.S. Geological Survey Circular 1221, 29 p., accessed August 6, 2010, at http://pubs.usgs.gov/circ/2002/c1221/.

Wald, D.J., Jaiswal, K.S., Marano, K.D., Bausch, D.B., and Hearne, M.G., 2010, PAGER-Rapid assessment of an earthquake's impact: U.S. Geological Survey Fact Sheet 2010-3036, 4 p., accessed November 8, 2010, at http://pubs.usgs.gov/fs/2010/3036.
Williams, C.F., Reed, M.J., Mariner, R.H., DeAngelo, Jacob, and Galanis, S.P., Jr., 2008, Assessment of moderate- and high-temperature geothermal resources of the United States: U.S. Geological Survey Fact Sheet 2008-3082, 4 p., accessed July 26, 2010, at http://pubs.usgs.gov/fs/2008/3082/.

Wood, Nathan, 2007, Variations in city exposure and sensitivity to tsunami hazards in Oregon: U.S. Geological Survey Scientific Investigations Report 2007-5283, 37 p. and database, accessed July 26, 2010, at http://pubs.usgs.gov/sir/2007/5283/. 


\section{Appendix A. Documents Reviewed by the Geology Science Strategy Team}

American Association for the Advancement of Science, 2006, Review and guidance to the United States Geological Survey National Cooperative Geologic Mapping Program: American Association for the Advancement of Science, 51 p., available at http://ngmdb.usgs.gov/Info/reports/ AAAS_2006FinalReport.pdf.

Bohlen, S.R., Halley, R.B., Hickman, S.H., Johnson, S.Y., Lowenstern, J.B., Muhs, D.R., Plumlee, G.S., Thompson, G.A., Trauger, D.L., and Zoback, M.L., 1998, Geology for a changing world-A science strategy for the Geologic Division of the U.S. Geological Survey, 2000-2010: U.S. Geological Survey Circular 1172, 59 p. (Also available at http://pubs.usgs.gov/circ/c1172/.)

Brantley, S.L., White, T.S., White, A.F., Sparks, D., Richter, D., Pregitzer, K., Derry, L., Chorover, J., Chadwick, O., April, R., Anderson, S., and Amundson, R., 2006, Frontiers in exploration of the Critical Zone-Report of a workshop sponsored by the National Science Foundation (NSF), October 24-26, 2005, Newark, Del.: Critical Zone Exploration Network, 30 p., available at http://www.czen.org/files/czen/CZEN_Booklet.pdf.

Clark, W.C., Crutzen, P.J., and Schellnhuber, H.J., 2005, Science for global sustainability-Toward a new paradigm: CID (Center for International Development at Harvard University) Working Paper No. 120, 28 p., available at http://www.cid.harvard.edu/cidwp/120.htm. (Originally published as chap. 1 of Schellnhuber, H.J., Crutzen, P.J., Clark, W.C., Claussen, Martin, and Held, Hermann, eds., 2004, Earth system analysis for sustainability: Cambridge, Mass., MIT Press.)

Climate Change Science Program and the Subcommittee on Global Change Research, 2006, Our changing planet-The U.S. Climate Change Science Program for fiscal year 2007; A supplement to the President's budget for fiscal year 2007: 262 p. (Also available at http://www.usgcrp.gov/usgcrp/ Library/ocp2007/default.htm.)

McMahon, Gerard, Benjamin, S.P., Clarke, Keith, Findley, J.E., Fisher, R.N., Graf, W.L., Gundersen, L.C., Jones, J.W., Loveland, T.R., Roth, K.S., Usery, E.L., and Wood, N.J., 2005, Geography for a changing world-A science strategy for the geographic research of the U.S. Geological Survey, 2005-2015: U.S. Geological Survey Circular 1281, 54 p. (Also available at http://geography.usgs.gov/ feature_scienceplan.php.)

National Research Council, 1996, Mineral resources and society-A review of the U.S. Geological Survey's Mineral Resource Surveys Program Plan [1995]: Washington, D.C., National Academies Press, 99 p. (Also available at http://books.nap.edu/openbook.php?isbn=NI000047.)

National Research Council, 1999, Meeting U.S. energy resource needs - The Energy Resources Program of the U.S. Geological Survey: Washington, D.C., National Academies Press, 80 p. (Also available at http://books.nap.edu/openbook.php?record $\mathrm{id}=6297$ \&page $=\mathrm{R} 1$.)

National Research Council, 1999, Our common journey-A transition toward sustainability: Washington, D.C., National Academies Press, 384 p. (Also available at http://www.nap.edu/catalog.php?record_id=9690.)

National Research Council, 1999, Science for decisionmaking - Coastal and marine geology at the U.S. Geological Survey: Washington, D.C., National Academies Press, 124 p. (Also available at http://www.nap.edu/ openbook.php?isbn=0309065844.)

National Research Council, 2000, Review of the U.S. Geological Survey's Volcano Hazards Program: Washington, D.C., National Academies Press, 152 p. (Also available at http://books.nap.edu/openbook.php?record $\mathrm{id}=9884$ \&page $=\mathrm{R} 1$.)

National Research Council, 2001, Basic research opportunities in earth science: Washington, D.C., National Academies Press, 168 p. (Also available at http:/www.nap.edu/ catalog.php?record_id=9981.)

National Research Council, 2001, Future roles and opportunities for the U.S. Geological Survey: Washington, D.C., National Academies Press, 192 p. (Also available at http://books.nap.edu/catalog.php?record_id=10069.)

National Research Council, 2001, Grand challenges in environmental sciences: Washington, D.C., National Academies Press, 106 p. (Also available at http://www.nap.edu/catalog.php?record_id=9975.)

National Research Council, 2002, Evolutionary and revolutionary technologies for mining: Washington, D.C., National Academies Press, 102 p. (Also available at http://books.nap.edu/catalog.php?record_id=10318.)

National Research Council, 2002, Research opportunities in geography at the U.S. Geological Survey: Washington, D.C., National Academies Press, 144 p. (Also available at http://www.nap.edu/catalog.php?record_id=10486.)

National Research Council, 2003, Living on an active Earth-Perspectives on earthquake science: Washington, D.C., National Academies Press, 432 p. (Also available at http://www.nap.edu/catalog.php?record_id=10493.)

National Research Council, 2003, Summary of a Workshop on U.S. Natural Gas Demand, Supply, and TechnologyLooking Toward the Future: Washington, D.C., National Academies Press, 112 p. (Also available at http://books.nap.edu/openbook.php?record_id=10806.)

National Research Council, 2004, A geospatial framework for the coastal zone-National needs for coastal mapping and charting: Washington, D.C., National Academies 
Press, 168 p. (Also available at http://www.nap.edu/ openbook.php?isbn=0309091764.)

National Research Council, 2004, Future challenges for the U.S. Geological Survey's Mineral Resources Program: Washington, D.C., National Academies Press, 154 p. (Also available at http://books.nap.edu/openbook.php?record_id=10817.)

National Research Council, 2004, Materials count-The case for material flows analysis: Washington, D.C., National Academies Press, 144 p. (Also available at http://books.nap.edu/openbook.php?record_id=10705.)

National Research Council, 2004, Partnerships for reducing landslide risk - Assessment of the national landslide hazards mitigation strategy: Washington, D.C., National Academies Press, 144 p. (Also available at http://books.nap.edu/openbook.php?record_ id $=10946$ \&page $=$ R1.)

National Research Council, 2006, Improved seismic monitoring-Improved decision-making; Assessing the value of reduced uncertainty: Washington, D.C., National Academies Press, 196 p. (Also available at http://www.nap.edu/catalog.php?record_id=11327.)

National Research Council, 2007, Coal-Research and development to support national energy policy: Washington,
D.C., National Academies Press, 184 p. (Also available at http://www.nap.edu/catalog.php?record_id=11977.)

National Research Council, 2007, Earth materials and health-Research priorities for earth science and public health: Washington, D.C., National Academies Press, 188 p. (Also available at http://www.nap.edu/ catalog.php?record_id=11809.)

National Research Council, 2008, Managing materials for a twenty-first century military: Washington, D.C., National Academies Press, 208 p. (Also available at http://books.nap.edu/catalog.php?record_id=12028.)

National Research Council, 2008, Minerals, critical minerals, and the U.S. economy: Washington, D.C., National Academies Press, 264 p. (Also available at http://books.nap.edu/catalog.php?record_id=12034.)

Sarewitz, Daniel, Pielke, R.A., Jr., and Byerly, Radford, Jr., eds., 2000, Prediction-Science, decision making, and the future of nature: Washington, D.C., Island Press, 405 p.

U.S. Geological Survey, 2007, Facing tomorrow's challenges-U.S. Geological Survey science in the decade 2007-2017: U.S. Geological Survey Circular 1309, 70 p. (Also available at http://pubs.usgs.gov/ circ/2007/1309/.) 


\section{Appendix B. Selected Accomplishments of the Geology Science Strategy for 2000-2010}

This report builds on the strong foundation provided by the geology science strategy described in U.S. Geological Survey Circular 1172, "Geology for a Changing World: A Science Strategy for the Geologic Division of the U.S. Geological Survey, 2000-2010" (Bohlen and others, 1998). As noted in the introduction of this report, implementing the strategy defined in Circular 1172 led to scientific integration with other disciplines becoming a hallmark of the geologic mapping, coastal and marine geology, and Earth surface dynamics programs.

Highlight B1 gives examples of successful results achieved by working toward the seven goals of Circular 1172:

- Goal 1. Conduct Geologic Hazard Assessments for Mitigation Planning

- Goal 2. Provide Short-Term Prediction of Geologic Disasters and Rapidly Characterize Their Effects

- Goal 3. Advance the Understanding of the Nation's Energy and Mineral Resources in a Global Geologic, Economic, and Environmental Context

- Goal 4. Anticipate the Environmental Impacts of Climate Variability

- Goal 5. Establish the Geologic Framework for Ecosystem Structure and Function

- Goal 6. Interpret the Links Between Human Health and Geologic Processes

- Goal 7. Determine the Geologic Controls on GroundWater Resources and Hazardous Waste Isolation

\section{References Cited}

2007 Working Group on California Earthquake Probabilities, 2008, The Uniform California Earthquake Rupture Forecast, version 2 (UCERF 2): U.S. Geological Survey Open-File Report 2007-1437 and California Geological Survey Special Report 203, accessed August 4, 2010, at http://pubs.usgs.gov/of/2007/1437/.

Bohlen, S.R., Halley, R.B., Hickman, S.H., Johnson, S.Y., Lowenstern, J.B., Muhs, D.R., Plumlee, G.S., Thompson,
G.A., Trauger, D.L., and Zoback, M.L., 1998, Geology for a changing world-A science strategy for the Geologic Division of the U.S. Geological Survey, 2000-2010: U.S. Geological Survey Circular 1172, 59 p. (Also available at http://pubs.usgs.gov/circ/c1172/.)

Field, E.H., Milner, K.R., and the 2007 Working Group on California Earthquake Probabilities, 2008, Forecasting California's earthquakes; What can we expect in the next 30 years?: U.S. Geological Survey Fact Sheet 2008-3027, 4 p., accessed August 4, 2010, at http://pubs.usgs.gov/ fs $/ 2008 / 3027 /$.

Grauch, V.J.S., Phillips, J.D., Koning, D.J., Johnson, P.S., and Bankey, Viki, 2009, Geophysical interpretations of the southern Española Basin, New Mexico, that contribute to understanding its hydrogeologic framework: U.S. Geological Survey Professional Paper 1761, 88 p., accessed August 4, 2010, at http://pubs.usgs.gov/pp/1761/.

Robinson, Marci, and Dowsett, Harry, 2010, Why study paleoclimate?: U.S. Geological Survey Fact Sheet 2010 3021, 2 p., available only online at http://pubs.usgs.gov/ fs $/ 2010 / 3021 /$.

Rodriguez, B.D., Deszcz-Pan, Maria, and Sawyer, D.A., 2007, Electromagnetic studies and subsurface mapping of electrical resistivity in the La Bajada constriction area, New Mexico, chap. F of Minor, S.A., ed., The Cerillos uplift, the La Bajada constriction, and hydrogeologic framework of the Santo Domingo basin, Rio Grande rift, New Mexico: U.S. Geological Survey Professional Paper 1720, p. 121-162, accessed August 4, 2010, at http://pubs.usgs.gov/pp/1720/.

U.S. Geological Survey, 2009, 2008 Bay Area earthquake probabilities: U.S. Geological Survey Web site accessed August 4, 2010, at http://earthquake.usgs.gov/regional/nca/ ucerf/.

Williams, C.F., Reed, M.J., Mariner, R.H., DeAngelo, Jacob, and Galanis, S.P., Jr., 2008, Assessment of moderate- and high-temperature geothermal resources of the United States: U.S. Geological Survey Fact Sheet 2008-3082, 4 p., accessed July 26, 2010, at http://pubs.usgs.gov/ fs $/ 2008 / 3082 /$. 


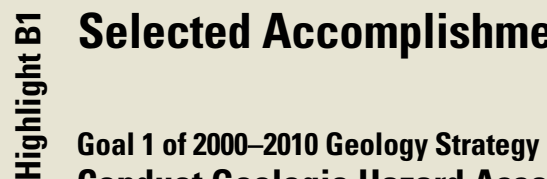 Conduct Geologic Hazard Assessments for Mitigation Planning}

"Regional- and national-scale probabilistic hazard maps and interactive data bases ... will be prepared for hazards such as earthquakes, volcanoes, landslides, coastal erosion, and floods ..." (Circular 1172, p. 15)
In 2008, the USGS released the Uniform

California Earthquake Rupture Forecast, version

2 (2007 Working Group on California Earthquake

Probabilities, 2008). The forecast was a collaborative effort with the California Geological Survey, the Southern California Earthquake Center, and the California Earthquake Authority. Results indicate that the probability of California having one or more magnitude 6.7 earthquakes between 2007 and 2036 is more than 99 percent.

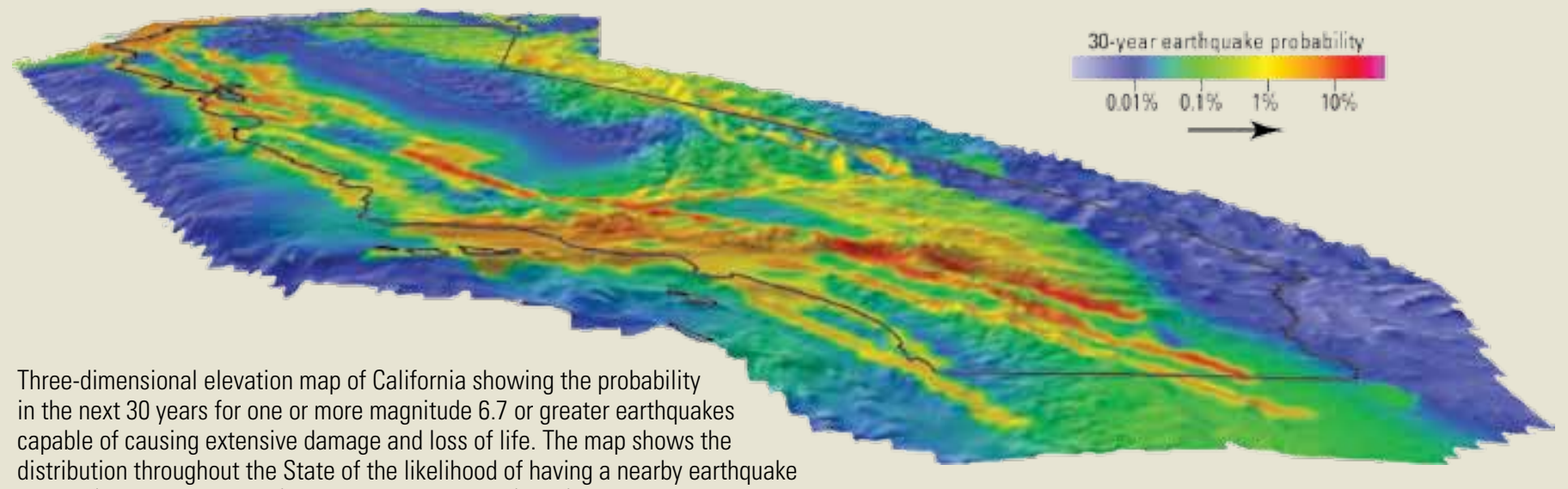

rupture (within 3 or 4 miles). From Field and others (2008).

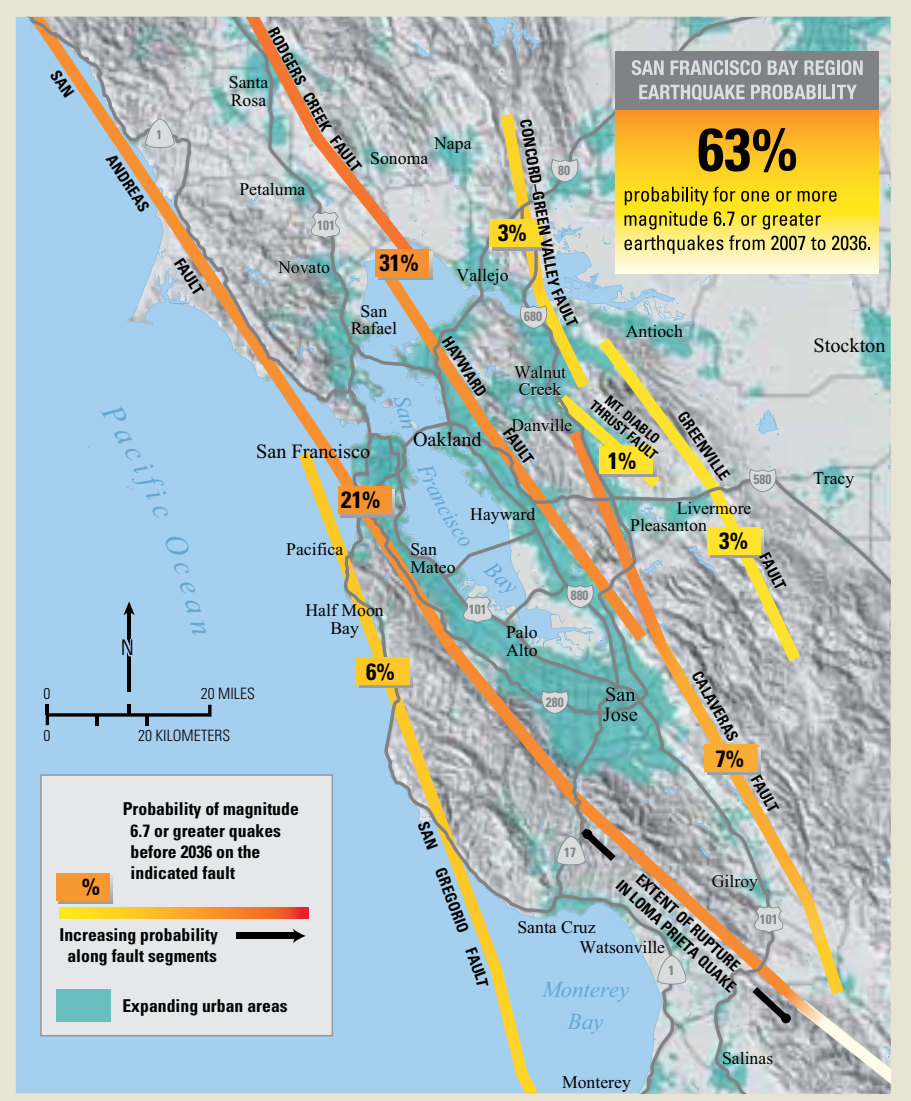

The overall probability of a magnitude 6.7 or greater earthquake in the San Francisco Bay region by 2036 is 63 percent. From USGS (2009).

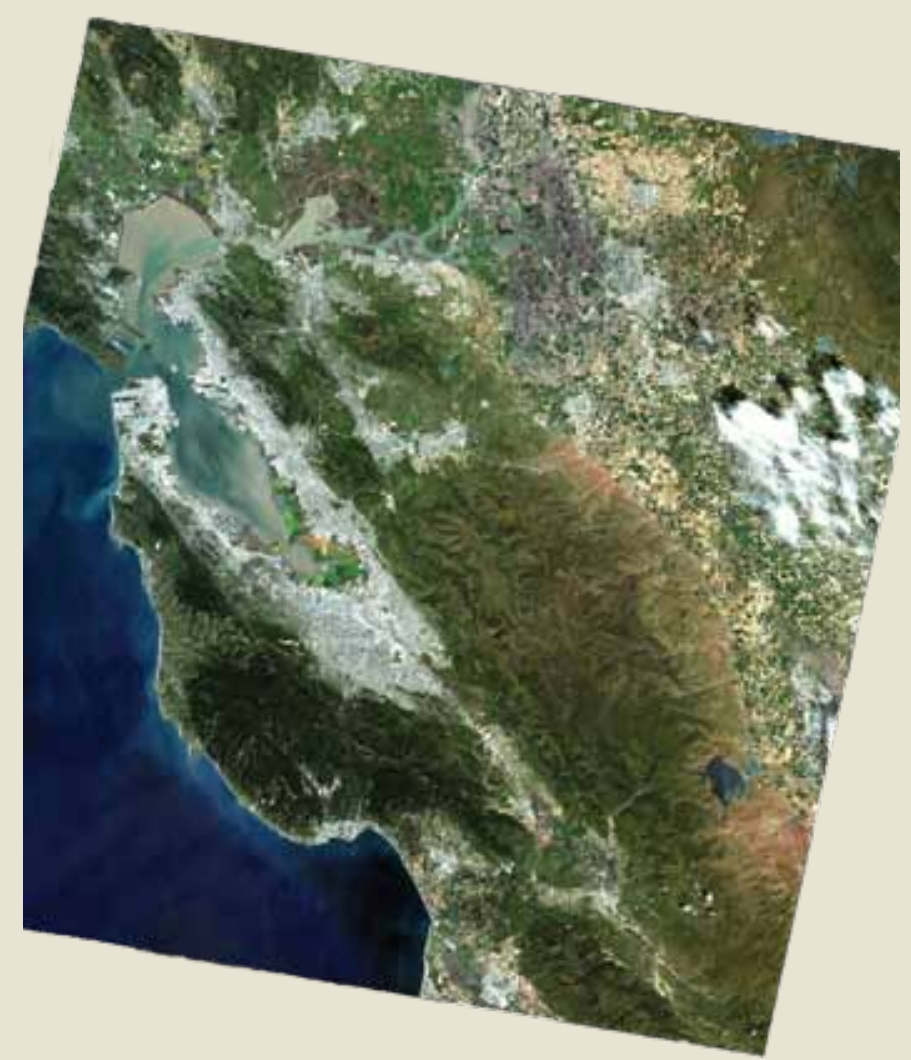

Landsat 7 image of the San Francisco Bay region showing fault traces. From http://sfbay.wr.usgs.gov/highlight_archives/images/SanFran.jpg. 


\section{Selected Accomplishments of the Geology Science Strategy for 2000-2010 - Continued}

\section{Goal 2 of 2000-2010 Geology Strategy \\ Provide Short-Term Prediction of Geologic Disasters and Rapidly Characterize Their Effects}

"In collaboration with USGS divisions and other agencies, the [Geologic Division] will ... establish alert levels, and provide appropriate warnings for volcanic eruptions ..." (Circular 1172, p. 19)

During the decade 2000-2010, the USGS Volcano Hazards Program advanced rapidly in its ability to deliver short-term forecasts and warnings of eruption impacts to partner agencies and the public. Digital imagery of seismic records (known as webicorders) and other geophysical datasets enabled scientists to make real-time assessments of seismicity associated with precursory activity and eruptions. Periodic updates on eruptions and images from Web cameras were put on public Web sites. Specialized warnings in standardized format were introduced for the aviation industry. Particle dispersion models were used in predicting the path and evolution of ash clouds from eruptions. Responses are based on hazard assessments from field investigations and on plans developed carefully with partner agencies. The result is that people and property are kept out of harm's way to the maximum extent possible, and disruptions to travel, commerce, and daily life are minimized.

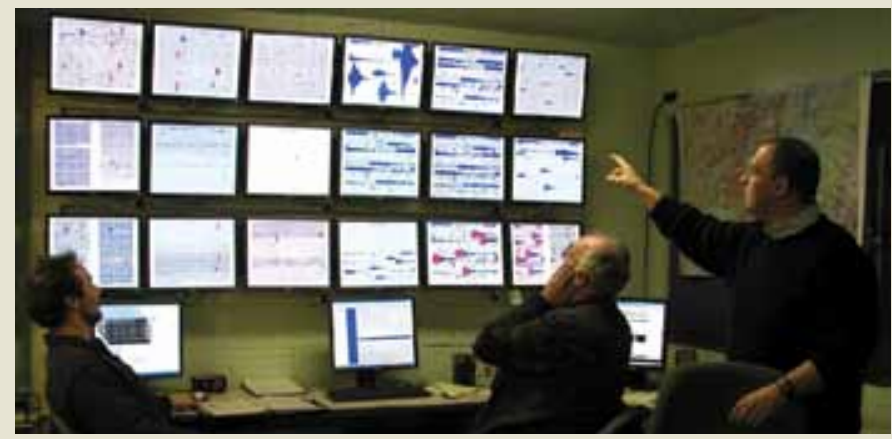

The operations room at the Alaska Volcano Observatory where multiple webicorder displays, satellite images, and other geophysical data can be viewed simultaneously. USGS photograph.
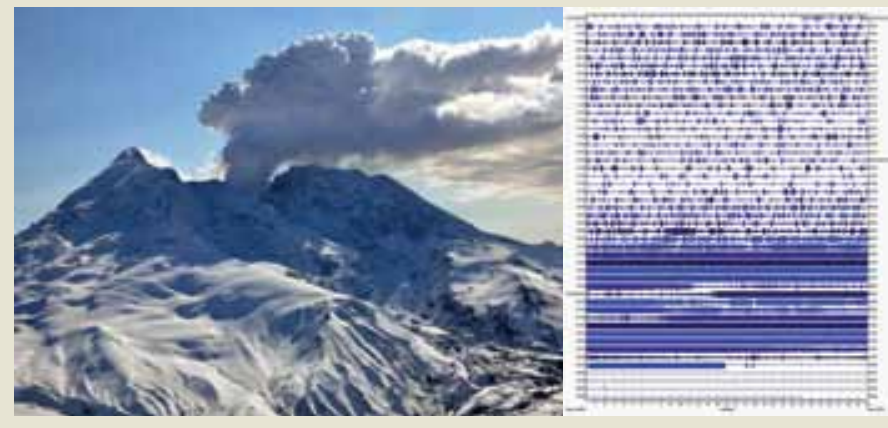

The eruption at Mount Redoubt (left) on April 16, 2009, was monitored at the Alaska Volcano Observatory, where the webicorder (right) of the seismic activity was recorded. Photograph by Cyrus Read, USGS.

\section{Goal 3 of 2000-2010 Geology Strategy \\ Advance the Understanding of the Nation's \\ Energy and Mineral Resources in a Global Geologic, Economic, and Environmental Context}

"Focus interdisciplinary research on the key geologic processes that control the origin and distribution of energy resources with present or anticipated high demand." (Circular 1172, p. 25).

USGS scientists recently completed a national assessment of geothermal resources capable of producing electricity. Scientists estimated the electric power generation potential of identified and undiscovered conventional geothermal systems, as well as the potential from unconventional Enhanced Geothermal Systems (EGS) resources. The results indicate that full development of identified conventional geothermal systems alone could increase current geothermal power production by about 260 percent. If unconventional EGS resources are successfully developed, they could provide an installed geothermal electric power generation capacity equivalent to about 50 percent of the total 2008 U.S. electric power generating capacity.

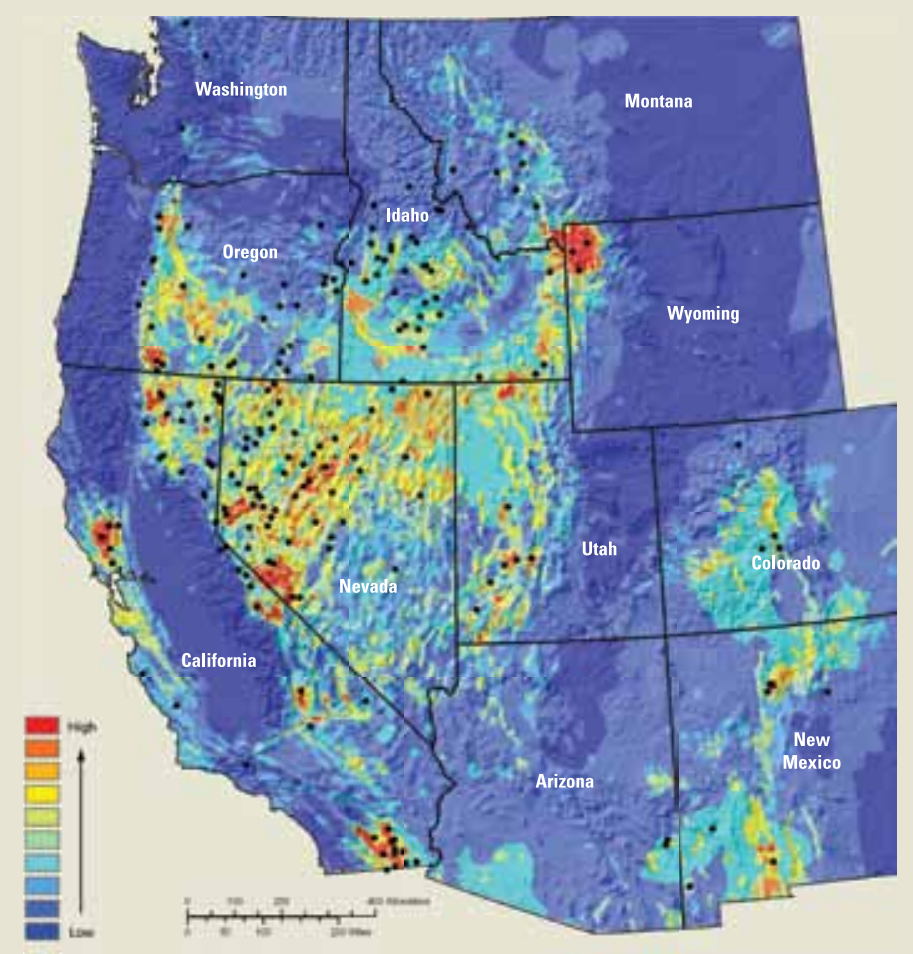

Map showing the relative favorability of occurrence for geothermal resources in the western contiguous United States. Warmer colors equate with higher favorability. Identified geothermal systems are represented by black dots. From Williams and others (2008, fig. 3) 


\section{흘 \\ Goal 4 of 2000-2010 Geology Strategy \\ Anticipate the Environmental Impacts of Climate Variability}

\begin{abstract}
"Reconstruct key past climates under a range of conditions and compare these to atmospheric general-circulation model results. These reconstructions will emphasize warm climates of the past but will also include some studies of cold climates and the transitions between past climate states. Highly interdisciplinary paleoclimate studies of both terrestrial and marine records and frequent interaction with the climate-modeling community will be required." (Circular 1172, p. 30)
\end{abstract}

Under the PRISM (Pliocene Research, Interpretation and Synoptic Mapping) Project, USGS scientists are reconstructing and systematically documenting the magnitude and variability of Pliocene surface and deep ocean temperatures and circulation, ice volume, and sea level on a global scale for a focused interval (approximately 3.3-3.0 million years ago). The main purpose of efforts to reconstruct
Pliocene paleoenvironmental parameters is to provide a conceptual model and synoptic view of the Earth during an interval considerably warmer than present to be used in model experiments designed to explore the impacts of climate variability and resultant feedbacks. PRISM findings are aiding our understanding of the climate system and possible future climate conditions.

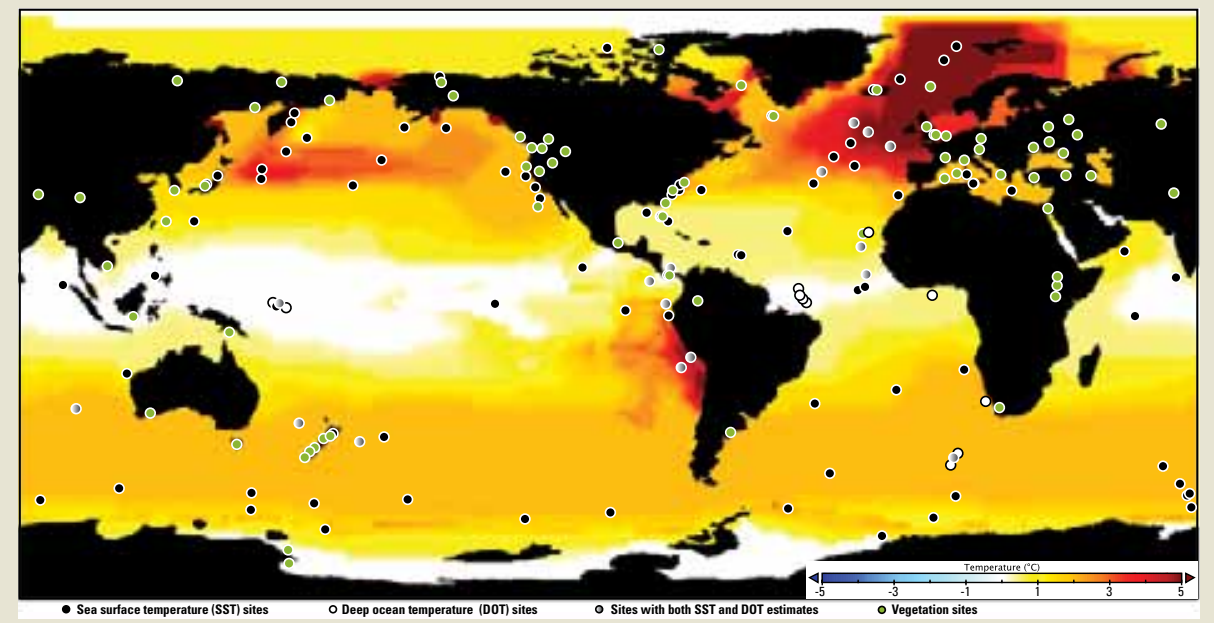

Mean annual sea-surface-temperature anomaly; the colors show the mean annual temperature differences in degrees Celsius when modern temperatures are subtracted from those estimated for the Pliocene Warm Period of approximately 3.3-3.0 million years ago. From Robinson and Dowsett (2010).
Goal 5 of 2000-2010 Geology Strategy

\section{Establish the Geologic Framework} for Ecosystem Structure and Function

\author{
"Determine rates of floral, faunal, \\ and other environmental changes ... \\ by using stratigraphy, paleontology, \\ sedimentology, soil science, \\ geochemistry, and high-resolution \\ geochronology" (Circular 1172, p. 37)
}

USGS scientists have been studying tree islands in the Everglades to determine the development and timing of treeisland formation throughout the greater Everglades ecosystem and to document the response of tree islands to climatic and human-induced changes. Tree islands are small forested islands in the Everglades wetlands that are known for their biodiversity. Findings indicate that tree island development was triggered by four climatic events ranging from about 2,600 years to 200 years ago. Twentieth-century water management practices reduced the size of the islands and affected the plant communities. Knowing the history of tree island development and the rate of response to water management practices will help managers predict ecosystem responses to Everglades restoration plans.

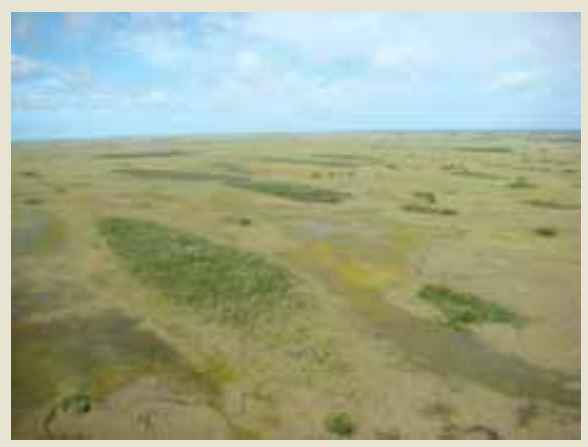

Aerial photograph of tree islands in Shark River Slough, Everglades National Park. Photograph by Thomas P. Sheehan, USGS. 


\section{Selected Accomplishments of the Geology Science Strategy for 2000-2010 - Continued}

\author{
Goal 6 of 2000-2010 Geology Strategy \\ Interpret the Links Between Human Health and Geologic \\ Processes
}

\begin{abstract}
"Continue research on the geologic occurrence, geoavailability, environmental mobility and degradation, and health effects of potential toxins." (Circular 1172, p. 41)
\end{abstract}

Since the publication of Circular 1172, USGS earth scientists have forged many exciting new research collaborations with health scientists to examine potential links between geologic processes and the health of humans and ecosystems (http://health.usgs.gov/). For example, USGS research is helping health scientists better understand potential health effects resulting from exposure to dusts of asbestos or other fibrous silicate minerals that are natural components of some rocks and mineral deposits such as vermiculite at Libby, Mont. Detailed mineralogical characterization of asbestiform or fibrous mineral particles in dust samples and source materials documents the complexities of the particles to which various populations have been exposed. The USGS has also taken a leadership role in the development of well-characterized dosing materials for asbestos-related toxicity testing, in compiling information on the range of geologic environments in which asbestiform minerals occur nationwide and globally, and in understanding how these mineral particles may interact chemically with the body to cause toxicity.

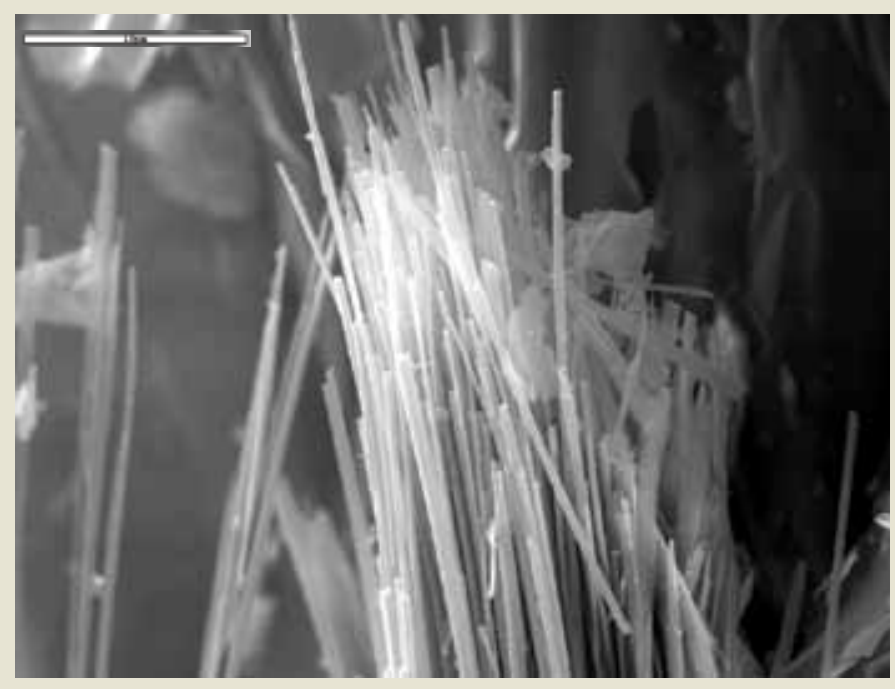

Scanning electron photomicrograph showing asbestiform (fibrous) amphiboles in vermiculite insulation produced at Libby, Mont.; the scale bar is 10 micrometers long. Photograph by G. Meeker, USGS.

\section{Goal 7 of 2000-2010 Geology Strategy Determine the Geologic Controls on Ground- Water Resources and Hazardous Waste Isolation \\ "Conduct multidisciplinary research on the origin, development, and hydrologic properties of fracture and fault systems." (Circular 1172, p. 46)}

The Española basin in New Mexico is the primary groundwater resource for the cities and surrounding urbanizing areas of Santa Fe, Española, Los Alamos, and eight Pueblo Nations. Sound management of the groundwater in the basin requires understanding the subsurface geology that affects groundwater flow, quality, and storage. USGS scientists conducted a multidisciplinary study, collecting and synthesizing high-resolution aeromagnetic data, deeplooking electrical geophysical soundings, and gravity data compilations with geology and other geophysical information to develop a three-dimensional geologic framework that will improve regional groundwater flow models for sound groundwater management (Rodriguez and others, 2007; Grauch and others, 2009).

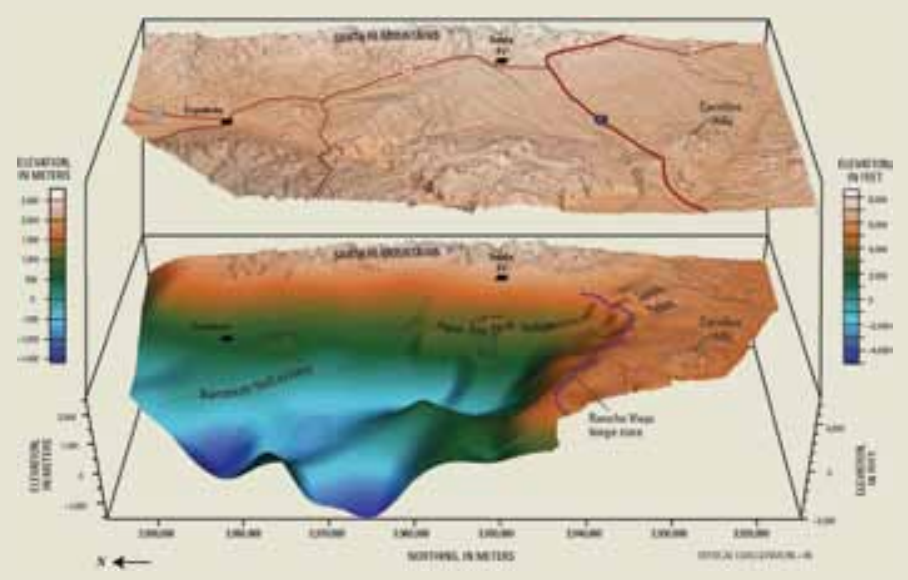

Perspective view (looking east) of the modeled elevation of the base of the Santa Fe Group in relation to topography of the southern Española basin. Topographic surface is raised above the base. From Grauch and others (2009, fig. 32). 


\section{Appendix C. Divisions of Geologic Time}

Effective communication in the geosciences requires the consistent use of divisions of geologic time. The chart shows major chronostratigraphic and geochronologic units and boundary ages approved by the U.S. Geological Survey Geologic Names Committee in 2010.

\section{Reference Cited}

U.S. Geological Survey Geologic Names Committee, 2010, Divisions of geologic time-Major chronostratigraphic and geochronologic units: U.S. Geological Survey Fact Sheet 2010-3059, 2 p., accessed July 27, 2010, at http://pubs.usgs.gov/fs/2010/3059/. (Supersedes USGS Fact Sheet 2007-3015.)

Divisions of geologic time approved by the U.S. Geological Survey Geologic Names Committee in 2010. Map symbols are in parentheses. From U.S. Geological Survey Geologic Names Committee (2010).

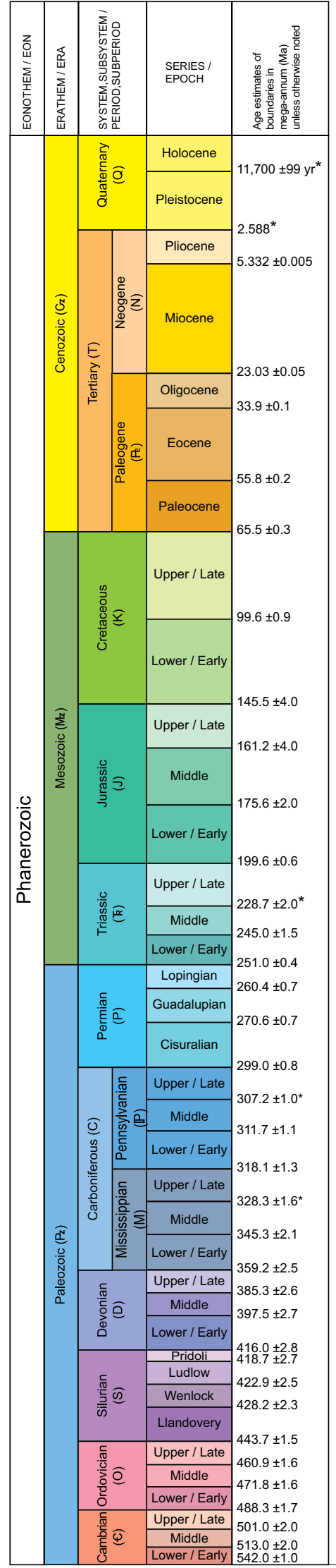

${ }^{*}$ Changes to the time scale since March 2007.

${ }^{* * *}$ The Ediacaran is the only formal system in the Proterozoic with a global boundary stratotype section and point (GSSP). All other units are periods. 

